University of Louisville ThinkIR: The University of Louisville's Institutional Repository

Electronic Theses and Dissertations

$5-2016$

\title{
Green logistic network design : intermodal transportation planning and vehicle routing problems.
}

Xiaoren Duan

University of Louisville

Follow this and additional works at: https://ir.library.louisville.edu/etd

Part of the Operational Research Commons

\section{Recommended Citation}

Duan, Xiaoren, "Green logistic network design : intermodal transportation planning and vehicle routing problems." (2016). Electronic Theses and Dissertations. Paper 2473.

https://doi.org/10.18297/etd/2473

This Doctoral Dissertation is brought to you for free and open access by ThinkIR: The University of Louisville's Institutional Repository. It has been accepted for inclusion in Electronic Theses and Dissertations by an authorized administrator of ThinkIR: The University of Louisville's Institutional Repository. This title appears here courtesy of the author, who has retained all other copyrights. For more information, please contact thinkir@louisville.edu. 


\title{
GREEN LOGISTIC NETWORK DESIGN: INTERMODAL TRANSPORTATION PLANNING AND VEHICLE ROUTING PROBLEMS
}

\author{
By \\ Xiaoren Duan \\ A Dissertation \\ Submitted to the Faculty of the \\ J. B. Speed School of Engineering of the University of Louisville \\ in Partial Fulfillment of the Requirements \\ for the Degree of \\ Doctor of Philosophy \\ In Industrial Engineering \\ Department of Industrial Engineering \\ University of Louisville \\ Louisville, Kentucky
}

May 2016 
Copyright 2016 by Xiaoren Duan

All rights reserved 

GREEN LOGISTIC NETWORK DESIGN: INTERMODAL TRANSPORTATION

PLANNING AND VEHICLE ROUTING PROBLEMS

By
Xiaoren Duan
B.E., Soochow University, 2007
M.S., Soochow University, 2010

A Dissertation Approved on

January 19, 2016

by the following Dissertation Committee:

Dr. Sunderesh S. Heragu

Dr. John S. Usher

Dr. Gerald W. Evans

Dr. Mahesh C. Gupta 


\section{ACKNOWLEDGMENTS}

This dissertation could not have been able to complete without the great support from so many people over these years. I wish to offer my most heartfelt thanks to the following people.

First of all, I would like to express my sincere gratitude to my advisor, Dr. Sunderesh S. Heragu, who has been a constant source of encouragement, inspiration and guidance throughout this endeavor. His considerable support is the most precious fortune during my studying period abroad.

My sincere appreciation is due to my co-advisor Dr. John S. Usher, my committee member Dr. Gerald W. Evans and Dr. Mahesh C. Gupta. They generously given their time and valuable suggestions towards my qualifying proposal and the ensuing research work. I am indebted to Dr. Gerald W. Evans and Dr. Lihui Bai, who provided me a great opportunity to involve in the project.

Many thanks are given to the faculty in the IE department of University of Louisville, who provided me the opportunity of studying here, increased my basic knowledge to make this work possible. I also would like to thank my friends who always support me and make my life colorful during these years.

Any gains, academic or otherwise, achieved by me today would not have been possible without the love from my parents, my husband and my daughter. They have been always the source of power allowing me to make any progress. 


\title{
ABSTRACT
}

\section{GREEN LOGISTIC NETWORK DESIGN: INTERMODAL TRANSPORTATION PLANNING AND VEHICLE ROUTING PROBLEMS}

\author{
Xiaoren Duan
}

January 19, 2016

Due to earth's climate change and global warming, environmental consideration in the design of logistic systems is accelerating in recent years. In this research we aim to design an efficient and environmentally friendly logistical system to satisfy both government and carriers. In particular, we considered three problems in this dissertation: intermodal network design, deterministic green vehicle routing problem and stochastic green vehicle routing problem.

The first problem aims to design an economic and efficient intermodal network including three transportation modes: railway, highway and inland waterway. The intent of this problem is to increase the utilization percentage of waterway system in the intermodal transportation network without increasing the cost to the consumer. In particular, we develop a real world coal transportation intermodal network across 15 states in the United States including highway, railway and inland waterway. The demand data were obtained from the Bureau of Transportation Statistics (BTS) under the US Department of Transportation (DOT). Four boundary models are built to evaluate the potential improvement of the network. The first boundary model is a typical minimum cost problem, where the total transportation cost is minimized while the flow balance and 
capacity restrictions are satisfied. An additional constraint that help obtain an upper bound on carbon emission is added in the second boundary model. Boundary model 3 minimizes the total emission with flow balance and capacity restrictions the same as boundary model 1. Boundary model 4 minimizes the total emission with an additional current cost restriction to achieve a less-aggressive lower bound for carbon emission. With a motivation to minimize the transportation and environmental costs simultaneously, we propose multiobjective optimization models to analyze intermodal transportation with economic, time performance and environmental considerations. Using data from fifteen selected states, the model determines the tonnage of coal to be transported on roadways, railways and waterways across these states. A time penalty parameter is introduced so that a penalty is incurred for not using the fastest transportation mode. Our analysis provides authorities with a potential carbon emission tax policy while minimizing the total transportation cost. In addition, sensitivity analysis allows authorities to vary waterway, railway and highway capacities, respectively, and study their impact on the total transportation cost. Furthermore, the sensitivity analysis demonstrates that an intermodal transportation policy that uses all the three modes can reduce the total transportation cost when compared to one that uses just two modes.

In contrast with traditional vehicle routing problems, the second problem intends to find the most energy efficient vehicle route with minimum pollution by optimization of travel speed. A mixed integer nonlinear programming model is introduced and a heuristic algorithm based on a savings heuristic and Tabu Search is developed to solve the large case for this problem. Numerical experiments are conducted through comparison with a solution obtained by BONMIN in GAMS on randomly generated small problem instances to 
evaluate the performance of the proposed heuristic algorithm. To illustrate the impact of a time window constraint, travel speed and travel speed limit on total carbon emission, sensitivity analysis is conducted based on several scenarios. In the end, real world instances are examined to further investigate the impact of these parameters.

Based on the analysis from the second problem, travel speed is an important decision factor in green vehicle routing problems to minimize the fuel cost. However, the actual speed limit on a road may have variance due to congestion. To further investigate the impact of congestion on carbon emission in the real world, we proposed a stochastic green vehicle routing problem as our third problem. We consider a green vehicle problem with stochastic speed limits, which aims to find the robust route with the minimum expected fuel cost. A two-stage heuristic with sample average approximation is developed to obtain the solution of the stochastic model. Computational study compares the solutions of robust and traditional mean-value green vehicle routing problems with various settings. 
TABLE OF CONTENTS

PAGE

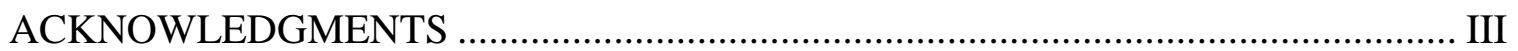

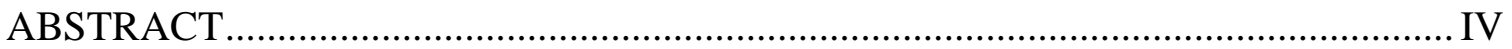

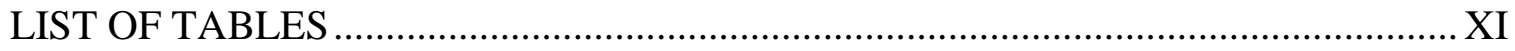

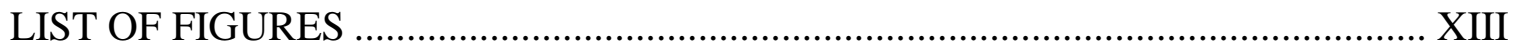

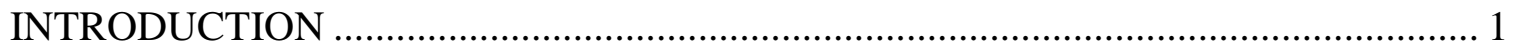

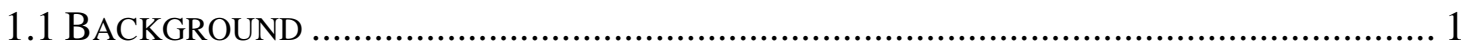

1.1.1 Green Logistics ....................................................................................... 1

1.1.2 Intermodal Transportation ....................................................................... 3

1.1.3 Green Vehicle Routing ............................................................................. 4

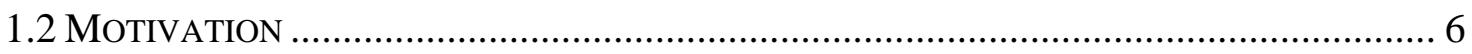

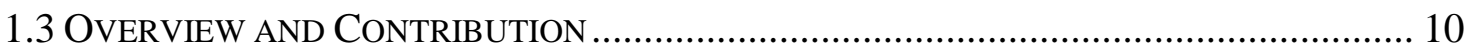

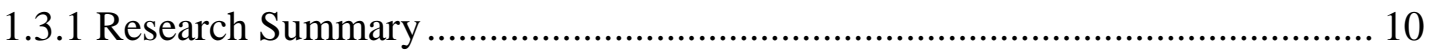

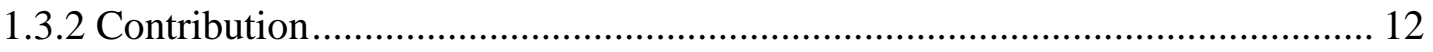

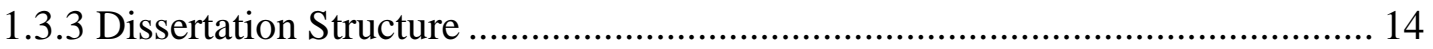

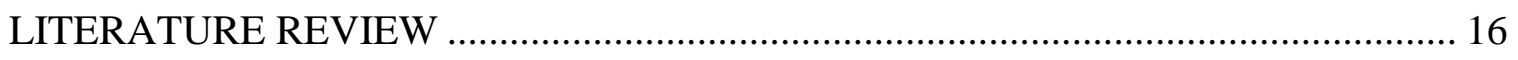

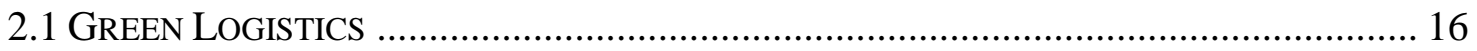

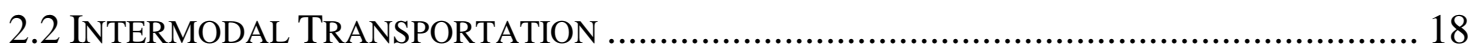

2.2.1 Intermodal Transportation .......................................................................... 18

2.2.2 Intermodal Transportation with Environmental Concerns ............................... 22

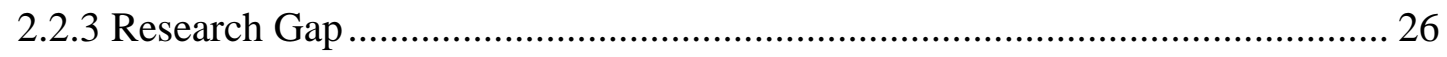




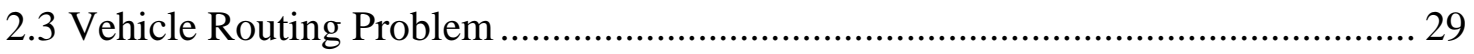

2.3.1 Vehicle Routing Problem .......................................................................... 29

2.3.2 Green Vehicle Routing Problem.................................................................. 33

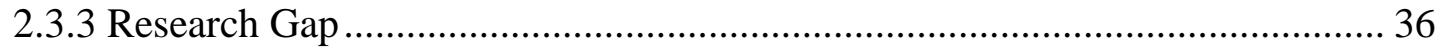

MULTI-OBJECTIVE INTERMODAL NETWORK DESIGN ……………………....... 39

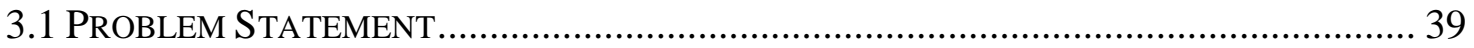

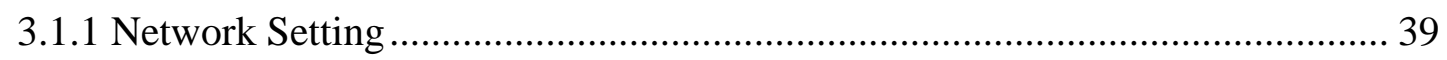

3.1.2 Carbon Emission Functions ......................................................................... 42

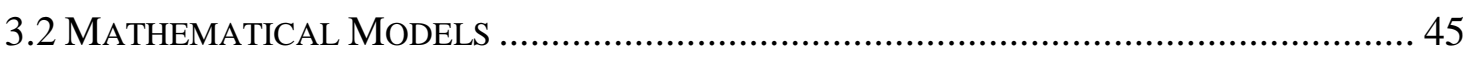

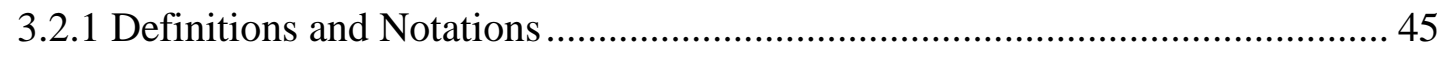

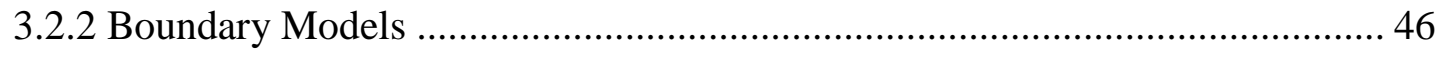

3.2.3 Multi-objective Intermodal Transportation Model............................................ 50

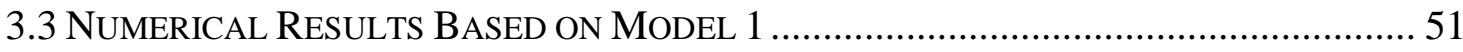

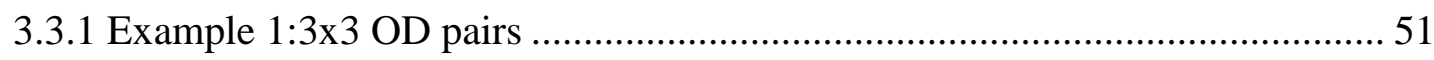

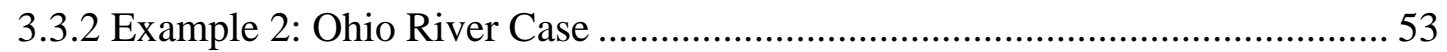

3.3.3 Sensitivity Analysis Based on Ohio River Case .............................................. 53

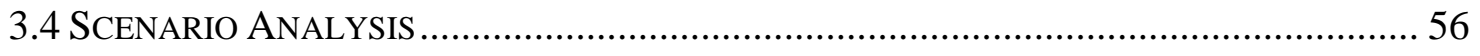

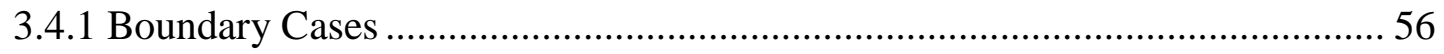

3.4.2 Carbon Emission Tax Policy …………………………………................... 58

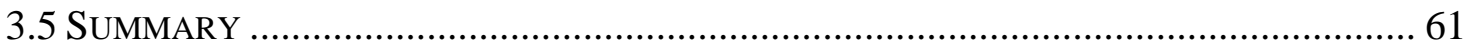

DETERMINISTIC GREEN VEHICLE ROUTING ..................................................... 62

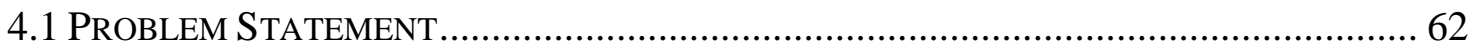

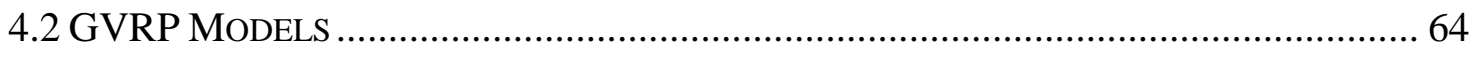




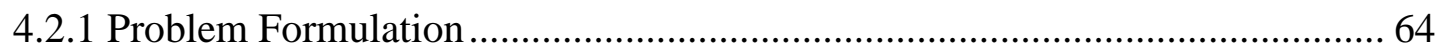

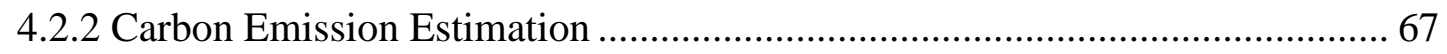

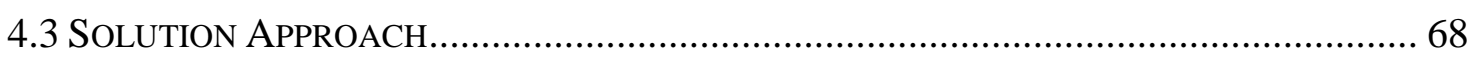

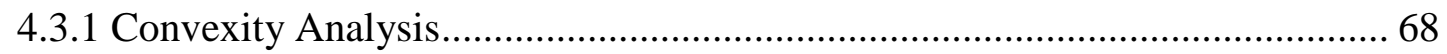

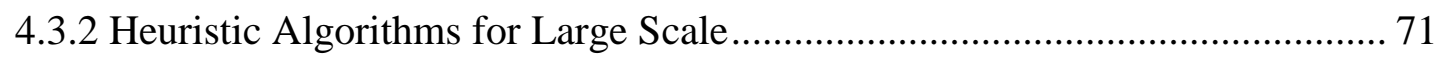

4.4 Computational StUdy AND SENSITIVITY ANALYSIS .......................................... 76

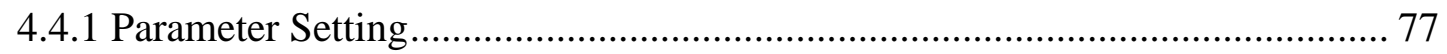

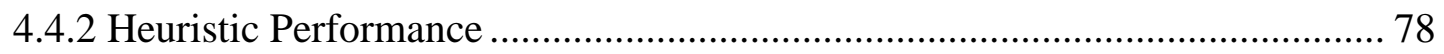

4.4.3 Results for instances without time window constraints.................................... 83

4.4.4 Results for instances with time window constraints....................................... 89

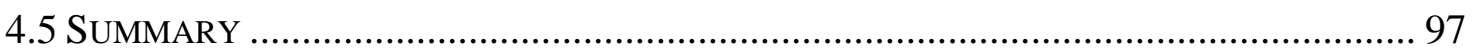

STOCHASTIC GREEN VEHICLE ROUTING PROBLEM............................................. 99

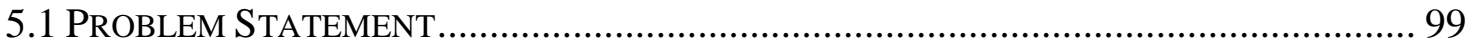

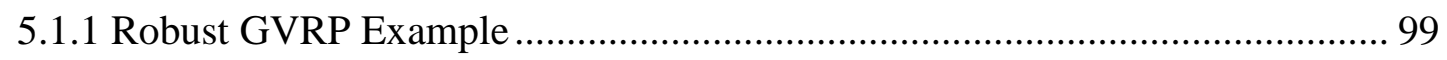

5.1.2 Carbon Emission Functions ....................................................................... 102

5.2 GVRP ModeLS WITH STOCHASTIC SPEed LiMIT ................................................. 103

5.2.1 Definitions and Notations .............................................................................. 103

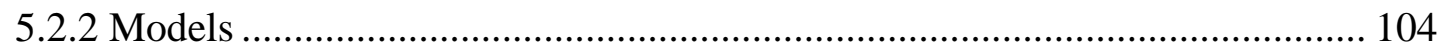

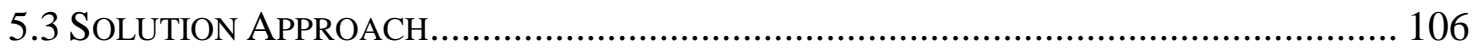

5.3.1 Two Stage Heuristic Algorithm....................................................................... 106

5.3.2 Sample Average Approximation ................................................................ 111

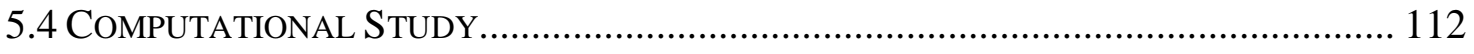

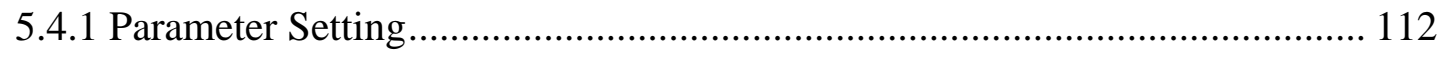




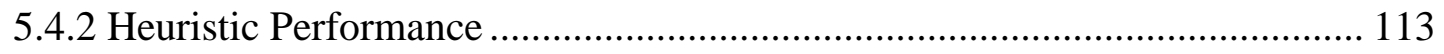

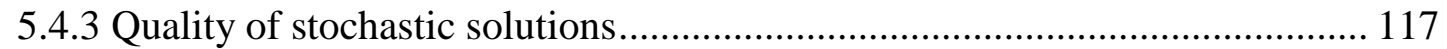

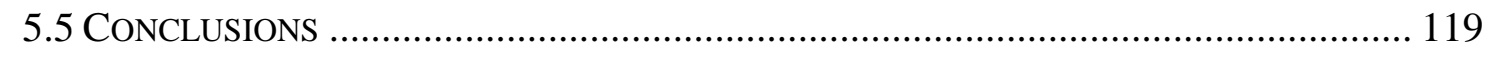

CONCLUSIONS AND FUTURE RESEARCH …........................................... 121

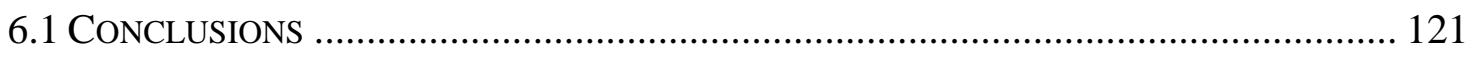

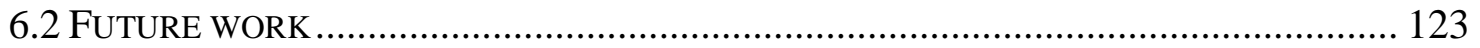

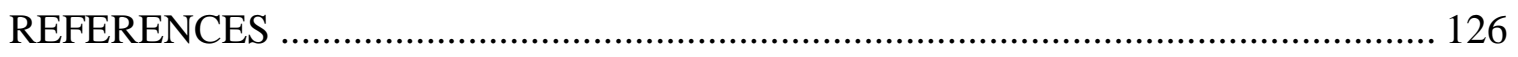

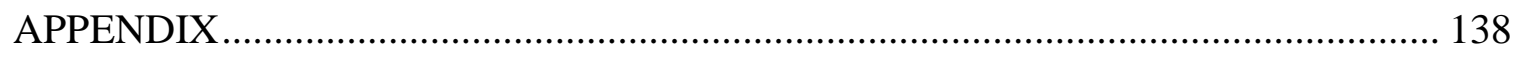

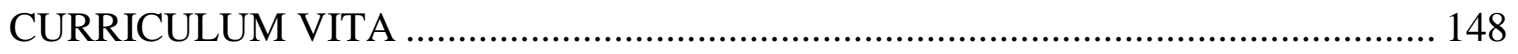




\section{LIST OF TABLES}

TABLE

PAGE

1. Comparison of intermodal transportation papers..................................................... 27

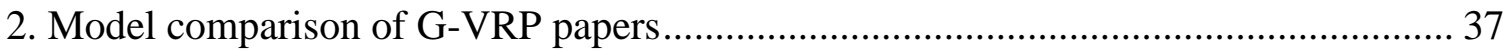

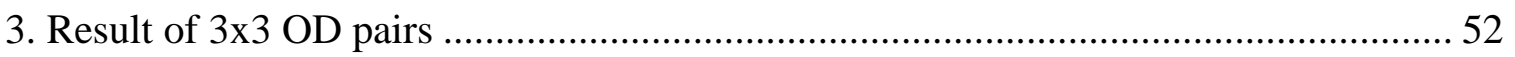

4. Outcomes for increasing waterway capacity ......................................................... 54

5. Outcomes for increasing highway capacity .......................................................... 54

6. Outcomes for increasing railway capacity ............................................................. 55

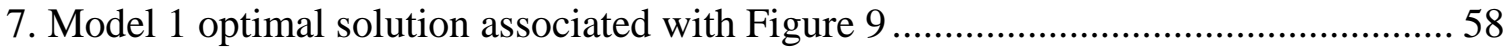

8. Estimation of carbon emission tax policy …………................................................. 59

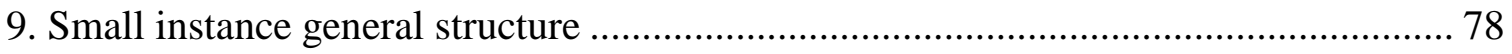

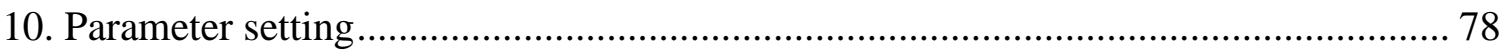

11. Heuristic performance for a tight time window with maximum speed limit.............. 79

12. Heuristic performance for a loose time window with maximum speed limit............. 79

13. Heuristic performance for no time window with maximum speed limit.................... 80

14. Heuristic performance for loose time window with random speed limit..................... 81

15. Heuristic performance for no time window with random speed limit ........................ 81

16. Average run time for large cases ....................................................................... 82

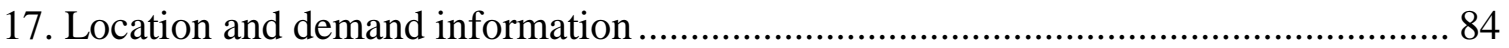

18. Result of our proposed model without time window constraint ................................ 85

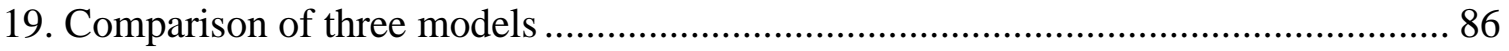




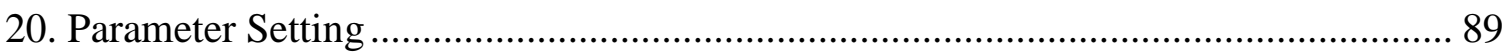

21. Result of proposed model with time window constraints .......................................... 90

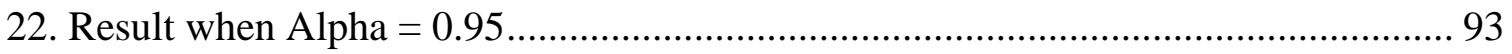

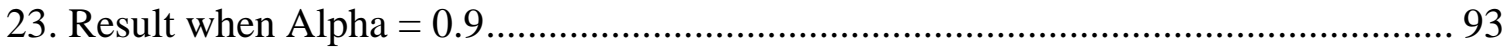

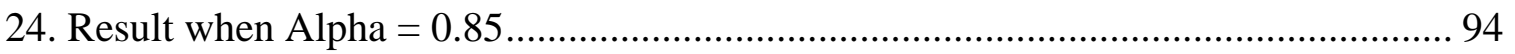

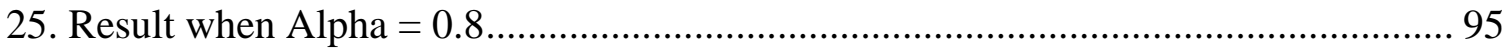

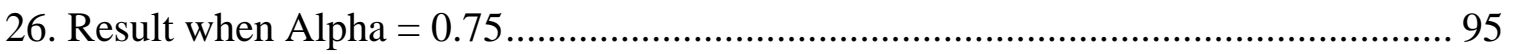

27. Results of different average speeds with time window constraint............................. 96

28. The average optimal costs with different distribution assumptions.......................... 100

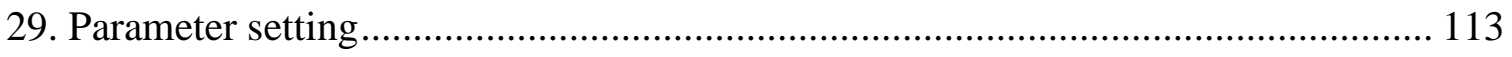

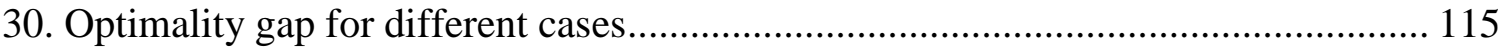

31. Average processing time in seconds over 100 iterations ....................................... 115

32. The sensitivity of VSS to variance....................................................................... 118

33. Estimated optimality gap and confidence intervals .............................................. 119 


\section{LIST OF FIGURES}

FIGURE

PAGE

1. Classification of green logistics based on literature reviews ....................................... 2

2. A typical example of rail-truck-barge intermodal freight transportation chain .............. 3

3. Relationships among the two problems and implementation ...................................... 11

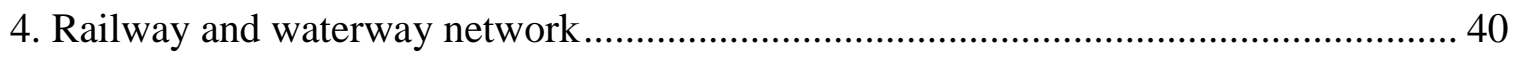

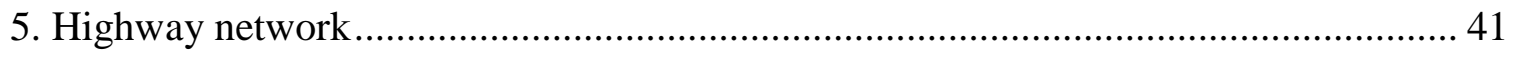

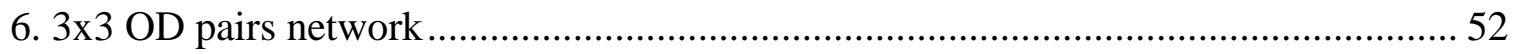

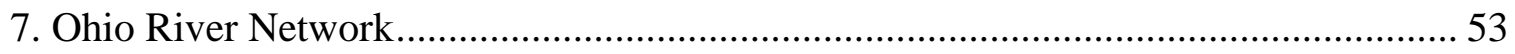

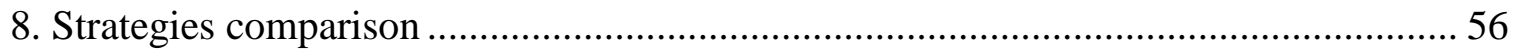

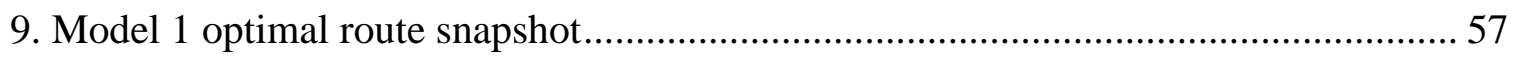

10. Unit Time Penalty Cost Estimation ....................................................................... 59

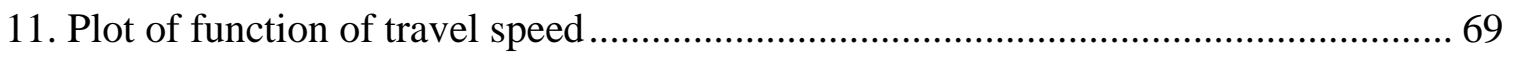

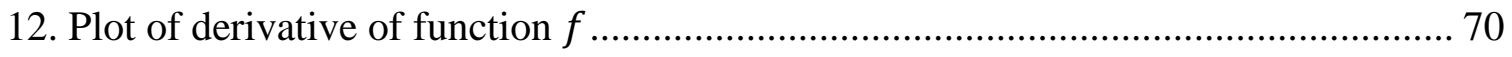

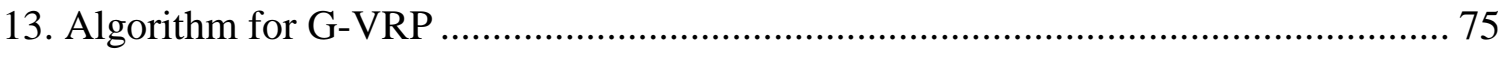

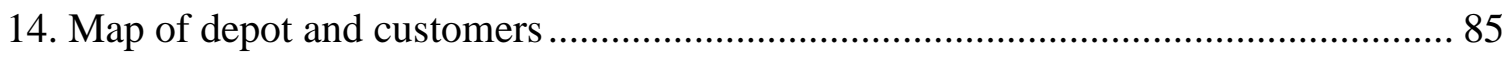

15. Near-optimal route for basic model 1 and our proposed model ............................... 87

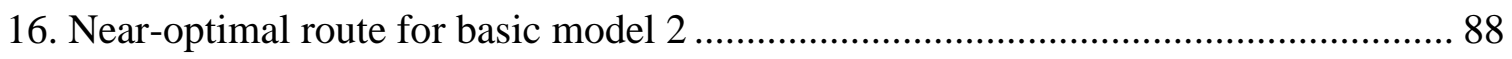

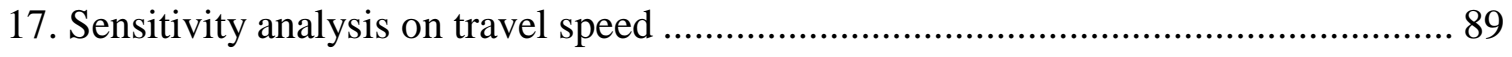

18. Optimal route for our proposed model with time window limitation......................... 91

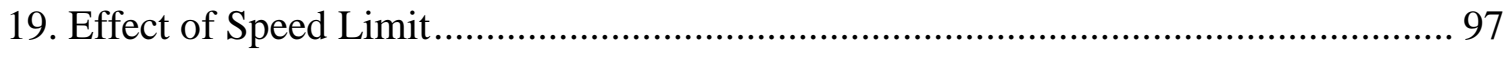


20. Four-node instance.

21. Algorithm for stochastic G-VRP

110

22. The convergence of the algorithm against iterations for 7 nodes ......................... 116

23. The convergence of the algorithm against iterations for 15 nodes ......................... 116 


\section{CHAPTER I}

\section{INTRODUCTION}

\subsection{Background}

\subsubsection{Green Logistics}

A consensus in addressing environmental concerns in the design of logistic systems has been reached recently due to the severe emission issues of greenhouse gases, especially carbon dioxide. Green supply chain management is defined by Srivastava (2007) as:

"Integrating environmental thinking into supply chain management including product design, material sourcing and selection, manufacturing processes, delivery of the final product to the consumers as well as end-of-life management of the product after its useful life".

The combination of operational decisions in a supply chain and their environment impact has been studied and presented in different areas of the logistics literature: inventory control, facility location and layout, transportation design and planning (Dekker et al., 2012). For example, some firms focus on reducing emissions caused by physical processes, and recommend redesigning or replacing inefficient parts of equipment, using lowemission or renewable energy and shipping through efficient routes 
(Benjaafar et al., 2010). Figure 1 shows a categorization of green logistic problems according to classifications in different literatures, including Beltran et al. (2009), Janic (2011), Macharis and Bontekoning (2004), Quariguasi et al. (2009), Sasikumar et al. (2010) and Iakovou et al. (2010). Green logistics, with consideration of social, economic and environmental factors, basically focuses on reducing greenhouse gas emissions during the production and distribution process in a sustainable way (Dekker et al. 2012). Green logistics solutions may include designing distribution networks with consideration of environmental impact, reducing energy usage and carbon emission, and managing waste treatment. Compared with those ideal scenarios, a significant drawback of current supply chain systems is that they are not sustainable (Sbihi and Eglese, 2007). In this research, we focus on the distribution network design and transportation planning in green supply chains.

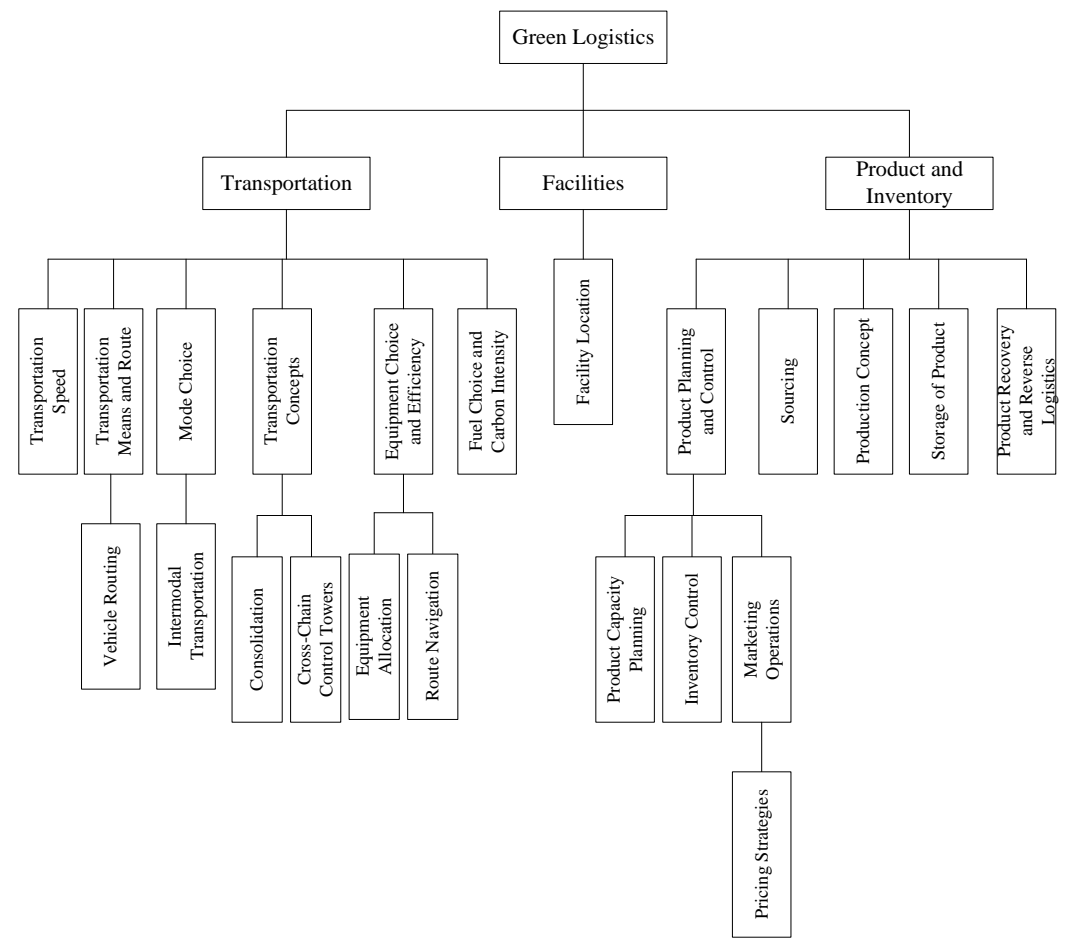

Figure 1. Classification of green logistics based on literature reviews 


\subsubsection{Intermodal Transportation}

Unlike traditional transportation models which consider alternate transportation modes separately, the definition of intermodal freight transport (European Conference of Ministers of Transport, 1993) is: "movement of goods in one and the same loading unit or vehicle, which uses successive, alternate modes of transportation (road, rail, water) without any handling of the goods themselves during transfers between modes". There are three important parts in the intermodal transportation network: suppliers, carriers and intermodal terminals. Suppliers generate demand for freight transportation while carriers take care of freight distribution according to the corresponding demand. Intermodal terminal or facilities which include almost all types of freight terminals are used as the transfer node to transfer cargo from one mode to another. The responsibility of the operators of these intermodal facilities is providing services and strategies to decision makers by operating one or multiple hub locations. Figure 2 illustrates an example for a rail-truck-barge intermodal freight transportation chain (Bektas and Crainic, 2007).

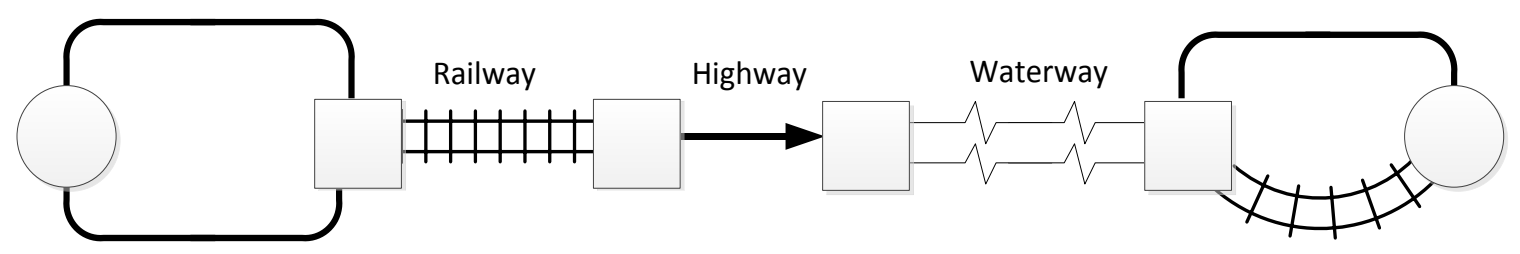

Figure 2. A typical example of a rail-truck-barge intermodal freight transportation chain

In this example, a shipment that leaves the suppliers' facilities is first shipped by truck using highway to a rail station. Then, the containers are consolidated there and shipped to another rail terminal by train. Trucks are again used to transport cargo from the rail terminal to a port. The trucking part of the intermodal network is called drayage 
(Macharis and Bontekoning, 2004). After that, containers are shipped from one port to another, and then via road or rail to the destination.

The fundamental advantage of intermodal transportation is consolidation of multiple transportation modes and services together. Thus, this transfer method reduces damage of cargo that usually occurs in the process of freight handling. Another key benefit of this method is that transportation costs and greenhouse gas emissions over road networks are reduced. In the past three decades, intermodal freight transport, which provides an economic and efficient means to transport goods in supply chains, has grown to be a significant sector in the transport industry. Over the next few decades, environmental factors will still have a significant influence on operational decisions and require attention. Intermodal transportation provides an efficient way to change the consumption pattern, and thus reduce the emissions of air pollutants.

Although researchers in the operations research field have worked on intermodal freight transportation for years, there are still many problems that need to be addressed (Macharis and Bontekoning, 2004). In this dissertation, we will focus on the transportation flow and logistic planning of intermodal transportation networks, and investigate the potential environmental benefit from a national planning perspective.

\subsubsection{Green Vehicle Routing}

The traditional vehicle routing problem (VRP) focuses on minimizing the economic costs for carriers. In recent years, the impact of environmental factors has received significant attention. Under the legislation and policies that limit the specific amount of emissions, individual companies and carriers are seeking new routing and scheduling methods to satisfy such restrictions. A variant of the traditional VRP, the green vehicle 
routing problem (GVRP), is studied in this dissertation. Environmental and social costs are considered along with time window constraints.

Touati-Moungla and Jost (2012) summarizes the related routing and scheduling problems in sustainable logistics into the following eight categories.

1. Routing of Hazardous Materials (RHM):

The goal of this problem is to select the optimal route with minimum risk of population exposure when transporting hazardous materials.

2. Routing and Scheduling in a Time-Dependent Environment (RS TDE):

The goal of this problem is not to minimize the carbon emissions or fuel consumption directly. It is to reduce the travel time by considering and avoiding congestion on the route, thus, reducing air pollution.

3. Waste Collection Vehicle Routing Problem (WCVRP):

This problem belongs to the Multi-Depot Vehicle Routing Problem with InterDepot Routes (MDVRPI). The main purpose of this type of problem is to minimize travel cost in terms of number of vehicles, travel distance and the total travel time, like the traditional VRP. But for the waste collection vehicle routing problem, each vehicle must empty their disposal container before they visit customer nodes.

4. Multi-Modal Vehicle Routing Problem (MMVRP):

This problem involves determining the optimal route for vehicles that operate in a multimodal transportation network. Because alternate transportation modes have different emission rates, this model provides choices for the environmental friendly transportation modes without violating other delivery constraints.

5. Dial-a-Ride Problem (DARP): 
The goal of this problem is to minimize the vehicle route cost to accommodate more users between the origins and destinations (Cordeau and Laporte, 2003). This problem decreases gas emissions indirectly by minimizing the fleet size and congestion of the transportation route.

6. Pick-up and Delivery Vehicle Routing Problem (PDVRP):

This problem, which requires simultaneous pick-up and delivery service is an extension of the Capacitated Vehicle Routing Problem (CVRP). It belongs to one of the problems of reverse logistics which aims to provide an efficient method to recycle the waste in the supply chain.

7. Energy Routing Problems (ERP):

This problem aims to reduce the fuel consumption and pollution emissions generated during a tour by vehicles. This topic is relatively new.

8. Air Traffic Control (ATC):

Air traffic control can reduce the emission of aircraft by controlling the air traffic flow efficiently. The objective of this problem is selecting the optimal path with minimum fuel consumption and travelling time.

\subsection{Motivation}

The research in this dissertation is conducted partially within the Logistics and Distribution Institute (LoDI) at the University of Louisville. Because logistics and distribution is identified as an important part of the US economy, especially for metropolitan areas, LoDI was formed to assist the government and companies in industry to solve logistics and distribution problems. With the growth in economic activity worldwide, the environmental impact has been recognized as an important global issue 
today. Under the threat of government legislation, firms worldwide are seeking a more effective way to reduce their carbon emissions while their major cost (transportation cost) will not be increased significantly. As part of the project of a US Department of Transportation (DOT) project, this research focuses on intermodal transportation network design and green vehicle routing problems in a green supply chain system.

Transportation, which is an importation element of supply chains, is also the most visible source of carbon emissions. According to the US Environmental Protection Agency (EPA), around $28 \%$ of all carbon dioxide emissions were due to transportation which is the second largest contributor in the US (EPA, 2011). Because transportation cost and time performance are always the main concern in most logistical systems, freight shipped only using highways account for about $34.6 \%$ in US (Winston and Langer, 2006). However, at the same time, carbon dioxide emission on the freight road transportation has increased rapidly resulting from the long travel distance. With respect to the environment, over twothirds of the transportation carbon emissions come from road freight transportation.

Consequently, there is a need to design an efficient and environmentally friendly logistical system to satisfy both the government and carriers. To improve the environmental condition, governments are under pressure to introduce restrictions or legislation to control the amount of carbon emissions. For example, government agencies may seek policies to increase market share of other less polluting transportation modes, such as railway and waterways. Meanwhile, such legislation also stimulates firms worldwide, or their carrier companies, to reduce carbon emissions. Without legislation, companies are usually driven by profit or business practices while ignoring activities that can be a potential significant source of emissions. Intermodal transportation provides an economic and efficient way to 
address these issues. However, companies and governments have different perspectives regarding environmental issues. Naturally, government authorities tend to reduce the environmental emissions without threatening the benefit of carrier companies, whereas companies aim at pursue minimum strategies while satisfying the safety limitation set by the regulator.

For example, from the perspective of a company, determining the mode of transportation could have an important impact on mitigating carbon emissions. How to choose a transportation mode is the main topic in logistical systems. Each mode has different transportation costs, transit times, carbon emission rates, capacity and accessibility. For instance, highway and air transport provides better time performance, but it is more expensive compared to railway and waterway. Thus, it is mainly used for time sensitive commodities. Waterways are the most economic and environmental friendly mode. However, it has many restrictions since it has lower speed compared to other modes. It is typically used for transporting large volumes of commodities that are time insensitive, e.g., coal. In the real world, the type of products and travel distance are also two key points that determine the choice of transportation modes. In the case of international supply chains, the most frequently used modes are: sea and air. For domestic supply chains, the main choices are truck, train, airplane or ship.

Meanwhile, from the perspective of government, how to set legislation to stimulate companies to choose economical routes and low-emission modes is also important for the environment. Research and Innovative Technology Administration (RITA), a unit within the U.S. Department of Transportation (DOT), estimated that the total volume of intermodal truck and rail combination grew 47 percent from 118 million tons to 173 million 
tons and the average ton-miles grew 50 percent from 160 billion to 240 billion in the past nine years (U.S. Department of Transportation, 1993-2002). Some predict that this trend will continue in 2015 .

Because the growth in intermodal transportation impacts the current traffic from economic and environmental aspects, it is important to study the design and operational aspects of the current intermodal transport network to attract freight from trucks to rail or water aiming at reducing traveling distance using highway and, thus, using environmental friendly mode.

Similarly, determining the frequency of supply delivery and type of vehicle to use for delivery is also important because those decisions could also have great impact on the environment. According to US DOT, vehicles on the roadways accounted for $79 \%$ of emissions. Among these, medium and heavy duty trucks contributed almost $19 \%$ of transportation emissions (US DOT, 2010). Due to the new environmental legislations, government agencies and individual companies are seeking methods to convert their fleets from traditional fuel vehicles to alternative fuel vehicles. In this dissertation, based on the environmental strategy, a green vehicle routing problem is studied from a company's perspective.

In addition, intermodal transportation provides potential opportunities for collaboration of individual companies of the same transportation modes to reduce logistic costs. Specifically, because intermodal transport moves goods in the same loading unit, orders of product from different customers can be delivered at the same route by the same transportation mode. The collaborative distribution and planning can help companies 
reduce operational costs considerably. Hence, in this dissertation, we present a new collaboration scheme for intermodal transportation based on a given route.

\subsection{Overview and Contribution}

\subsubsection{Research Summary}

In this research, we consider environmental costs in the intermodal network and address this problem from the perspectives of two levels: the government, which sets policies to drive the entire transport system in a more environment-friendly manner, while maintaining efficiency; and the companies which make routing decisions to minimize their logistics cost while satisfying all practical constraints as well as the new environment related transportation policy.

The first part is intermodal transportation planning considering environmental issues. First, we develop an intermodal transportation network system consisting of major US intermodal facilities (as nodes) and three modes: inland waterway, railway and highway (as links) using ArcGIS. Based on publications from the Bureau of Transportation Statistics (BTS) under US DOT, we analyze the fixed demand of each origin and destination and assign preliminary capacities and demands to the network. Based on the data collection and analysis, we address the following tasks from the entire system's perspective.

(1) Minimizing transportation cost without considering environmental issues. Based on the model solutions, we evaluate the load feasibility and establish a lower bound of the transportation cost in the network, and thus help to evaluate the efficiency of current logistics performance.

(2) Transportation modeling with environmental cost. By assigning a weight to environmental factors, we perform sensitivity analysis on the environmental cost, 
e.g. relationship between mode selection and environmental cost policy. We seek to determine the type of environmental cost policy that can optimize the total cost and how to reach the balance between on economics and environment.

The second part looks at the green vehicle routing problem which takes into account micro behaviors of a single company, and thus is closer to the real world case. This problem will consider transportation cost and environmental cost, e.g. $\mathrm{CO}_{2}$ emissions. For example, a company delivers products to multiple customers (destinations), considering delivery cost, and demand time requirements. The given data for this problem are: distance, capacity, travel time between nodes in a network; demand volume and delivery time requirement of node; economic and environmental legislation that are provided from the first problem. This part includes two problems (time window constrained deterministic green vehicle routing problem and stochastic green vehicle routing problem) with the aim to obtain an optimal vehicle route with minimum carbon emission, in other words, minimum fuel consumption. The impacts of travel speeds, time window and travel speed limit on carbon emission will be studied. The solution of this problem will show companies new routing and cost under the new policy environment.

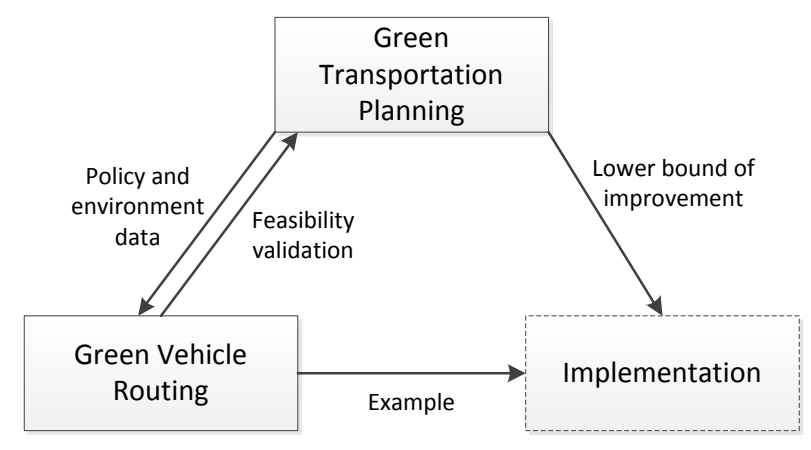

Figure 3. Relationships among the two problems and implementation

Figure 3 describes the relationship among the two problems in this dissertation and future implementation. The green transportation planning problem focuses on the analysis 
of the entire logistics network of multiple states. We will spend much effort in collecting data and mining it to reveal the needs and potential benefit of green transportation planning. The resulting network optimization analysis also leads to a tax policy to encourage improvement. This study provides necessary environment and policy data for the green vehicle routing problems in the execution level. Because analysis is conducted for the entire system, the optimal solution of such a problem provides a lower bound on practical implementation of environment improvement. Study in the green vehicle routing problem simulates a scenario in detailed level, and thus can be treated as an example in the future implementation. Also, the analysis at this level and a successful routing decision according to the new policies also demonstrate the feasibility of the application of environmental policy.

\subsubsection{Contribution}

This research has practical contributions with various models, analyses and suggestions that can be implemented in the real world. The intermodal network modeling considering environmental aspects can provide government agencies legislation suggestions without increasing the logistical costs of individual companies. The green vehicle routing problem and the corresponding solution method can be implemented under general industrial settings. The specific contributions of this research are summarized as follows.

1. Intermodal network modeling:

A real world coal transportation intermodal network across 15 states in the US including highway, railway and inland waterway is conducted using ArcGIS. Four boundary models are built to evaluate the potential improvement of the network. The first 
boundary model is a typical minimum cost problem, where the total transportation cost is minimized while the flow balance and capacity restrictions are satisfied. An additional constraint that help obtain an upper bound on carbon emission is added in the second boundary model. Boundary model 3 minimizes the total emission with flow balance and capacity restrictions the same as boundary model 1 . Boundary model 4 minimizes the total emission with an additional current cost restriction to achieve a less-aggressive lower bound for carbon emission. With the goal to minimize the economic and environment costs simultaneously, we propose multi-objective optimization models to analyze intermodal transportation with economic, time performance and environmental concerns. A time penalty parameter is introduced to simulate the real coal transportation behavior through the mathematical model. Scenario analysis provides authorities the resulting carbon emission tax policy and the change of the system-wide transportation cost. The breakeven point for tax is suggested to provide minimum carbon emission without increasing transportation cost. In other words, this research provides a practical strategy for governmental agencies from a high level planning perspective.

2. Green vehicle routing:

Two green routing problems that consider environmental aspects are investigated. There are only a few papers in the literature that have addressed the green vehicle routing problem, including Kara et al. (2007), Kuo (2010), Xiao et al. (2012), Schneider et al. (2012), and Bektas \& Laporte (2011). Bektas and Laporte (2011) include time windows in their PRP model. But the trade-off between environmental cost and economic cost under soft time window restriction has not been investigated until now. More importantly, travel speed is usually considered as a constant in much of the literature. However, none of these 
papers considers environmental issues associating with stochastic speed of vehicles based on our knowledge.

Given a planning horizon, green vehicle routing problems aim to determine the optimal route for a set of commodities with minimum carbon emission. By investigating the environmental impact of travel speed and time window limitation, the deterministic green vehicle routing models can provide routing and travel speed suggestions within a given range of time. The stochastic green vehicle routing model can simulate real world congestion and provide a robust vehicle route with minimum expected total carbon emission. In conclusion, the green vehicle routing models consider environmental impact and can be used at an operational level from individual carrier companies' perspective. This model can also be used to verify the practical implementation of strategy and planning analysis of the first problem.

\subsubsection{Dissertation Structure}

The remainder of the dissertation is organized as follows. The comprehensive literature review is provided in Chapter 2, including the literature related to green logistics, intermodal transportation, intermodal transportation considering environmental issues and green vehicle routing problem. In Chapter 3, the underlying assumptions of network model and carbon emission calculations are presented based on a real coal transportation network. Several boundary models and the multi-objective intermodal transportation network model with economic, time performance and environmental concerns are described. Scenario analyses are presented to demonstrate how the model can help government agencies determine appropriate legislation to improve the environment without increasing systemwide transportation cost. In Chapter 4, a deterministic green vehicle routing problem is 
formulated as a nonlinear mixed integer program with the aim to minimize total carbon emission by optimization of travel speed. Sensitivity analysis based on a real world case is conducted to investigate the impact of travel speed, time window constraint, and travel speed limit. In Chapter 5, a stochastic green vehicle problem which aims to find the robust route with the minimum expected fuel cost is proposed. A two-stage heuristic with sample average approximation is developed to solve the proposed mathematical model. Computational study compares the solutions of robust and traditional green vehicle routing problems with various settings. We end with the conclusion and discussions in Chapter 6 . 


\section{CHAPTER II}

\section{LITERATURE REVIEW}

\subsection{Green Logistics}

Operations research models have been applied to supply chain logistics with consideration of environmental factors in the following areas: inventory control, facility location and layout, transportation design and planning (Dekker et al., 2012). There is extensive literature on the topic of inventory and facility design. Papers in this area typically consider environmental impacts which include influence of carbon emission and other waste from production and manufacturing operations.

For example, Benjaafar et al. (2013) combined operational decisions in a supply chain and environment issues by integrating carbon emission parameters into traditional operations models. They evaluated how regulatory emission control policies affect cost and emissions. The impact of collaboration in supply chain on economic and environmental performance was also investigated in this paper. The authors presented several model formulations: production planning model for a single firm with strict carbon caps, a single firm with carbon tax and multiple firms with or without collaboration. In the first model, the author introduced three parameters to calculate carbon emission: fixed carbon emission, variable carbon emissions and emissions involved in the storage. They modified the first model by adding a parameter associated with tax paid on each unit emitted. The third model used the same parameters as the two 
previous models, but assumed that each firm acted like a supplier firm for another firm in the supply chain. Thus, the third model had limited application in the real world. They found that operational adjustments could lead to significant emission reduction without significant cost increase. More importantly, their result highlighted the importance of collaboration across the supply chain.

Elhedhli and Merrick (2012) proposed a supply chain network design model that included $\mathrm{CO}_{2}$ emissions to investigate the economic and environment effects. Emission costs associated with fixed cost, variable location and production costs were considered in this distribution network model. The relationship between $\mathrm{CO}_{2}$ emissions and the weight of vehicle was formulated as a nonlinear function according to the published data. The author used Lagrangian relaxation to solve the mixed integer programming model. Their results showed that the rigidity of the problem had a large impact on location of distribution centers. The distribution of costs was fairly stable when capacity levels of the distribution centers varied. The authors also varied the cost structure by making one of the costs dominant: dominant fixed costs, dominant variable costs, and dominant emissions costs. As expected, dominant emissions costs resulted in lower overall emission compared to the other components.

Tang et al. (2013) integrated environmental considerations in the classical incapacitated facility location problem which aims to minimize the economic cost and $\mathrm{CO}_{2}$ emissions while providing strategic facility locations within a logistics network. The model was developed as a mixture of mathematical formulations with three objectives: minimize $\mathrm{CO}_{2}$ emissions, minimize economic cost and maximize customer service reliability. The hybrid algorithm was provided to solve the multi-objective problem. First, the $\varepsilon$-constraint 
method was used to transform the multiple objectives into one. Then, the authors used a greedy heuristic to provide a feasible solution by deleting facilities from the solution greedily until further improvement cannot be achieved. Computational experiments and sensitivity analysis showed that $\mathrm{CO}_{2}$ emissions fall and reliability increases with more facilities. This result indicated that, to reduce $\mathrm{CO}_{2}$ emissions while maximizing service reliability, it may be more appropriate to open more logistics facilities than improving economic effectiveness.

A majority of the green supply chain literature takes a carrier company's perspective by focusing on problems with a single transportation mode and a single origin destination pair. In this review, we will not cover all aspects of logistics. Only one specific aspect of the green logistic problem, transportation with environment issues, is highlighted. Specifically, we mainly focus on the transportation mode selection and green vehicle routing as a method to reduce carbon emissions. This review summarized the current research of these aspects we mentioned above and will provide a sketch of possible developments in the future.

\subsection{Intermodal Transportation}

\subsubsection{Intermodal Transportation}

One of the main problems in transportation is mode selection. Macharis and Bontekoning (2004) reviewed the application of operations research to intermodal transportation systems. According to this literature, operators are classified based on their main responsibilities in intermodal and supply chain network. Generally, network operators are concerned more about infrastructure planning and scheduling of transportation among different modes. To determine which services should be used, first, 
how to choose the consolidation network is an important problem for the decision makers. Typically, there are four networks: point-to-point, hub-and-spoke, line and collectiondistribution. In most cases, a point-to-point network is the easiest method for operators. Then, the production model should be decided by the operator. Service frequency assignment, train length determination, equipment allocation and capacity planning of equipment are main issues for the production model.

According to different levels of operators and planning horizons, there are three typical network and transportation problems: strategic, tactical and operational problems. In this dissertation, we only focuses on the application of OR problems on network operators and intermodal operators. For strategic problems in transportation, a majority of the studies, e.g., Short and Kopp (2005), Crainic et al. (1990), Jourquin et al. (1999) and Southworth and Peterson (2000), are related to long term network planning and location of terminals determination. The impact of capacity and cost are two important areas of research in infrastructure networks. However, most models only developed one mode without considering intermodal flows. Some papers, e.g., Loureiro (1994) and Van Duin and Van Ham (1998), extended unimodal network models to multi-mode model by adding connecting links via multiple transportation modes. For instance, Duin and Ham (1998) developed a methodological transportation framework which combines multiple qualitative factors and uncertainties from different strategy levels. The author developed an actor modeling language (dynamic actor network analysis) which described multi-actor situations. Three specific arenas were identified by combining aspects from different levels. Corresponding to these three arenas, three different models were developed to seek for solutions that optimize the main performance indicators of each arena. First, because price 
is the most important evaluation factor at both international and national levels, a linear programming model was introduced to determine whether intermodal transportation was more efficient than road transportation based on regional transportation demand. Three kinds of costs were considered: shuttle cost between terminals, costs for pickup, delivery and transshipment at each terminal, and cost for direct road transportation between regions. A second detailed cost model which considered three more cost factors was developed to look for the exact location in this area. In the end, the author developed a simulation model to analyze the logistic factors for both the terminal and its customers, such as the suitability, timeliness and deliverance reliability of goods.

GIS technology also provides a new way to model large multi-modal networks. For instance, Southworth and Peterson (2000) used GIS to develop a digital multimodal transportation network and apply it to in a large network of transportation system. First, to load a version of the intermodal network into a commercial GIS, the authors modified the original GIS network by converting zero length links to points. In order to make the traffic routable, the authors generated a formulation to search the appropriate network access and connections. The authors also analyzed two methods for modeling intermodal terminal transfers. One method made each intermodal transfer as a connection node and modeled it as a single network combining multiple transportation modes. The other method identified a specific geographic location as a transfer facility. The authors used single truck freight modeling to compute the shipment distances. Costs for different route activities were assigned into each specific link. The relative cost of changing transport mode from one to another was also considered in this paper. A shortest path model was used to ensure that the lowest cost mode was used among network routes. 
Some articles address the issues of selecting the best investment options for a multimodal network when there is a budget. For searching optimal location problems, the possible lowest cost route will be determined with a fixed transportation flow. The objective functions for these problems could be: minimize transportation cost, maximize terminal profit, maximize modal shift and minimize drayage distance. Another location analysis is about selecting optimal site using the multi-criteria analysis method.

For tactical problems, consolidation networks are evaluated with multiple criteria. Some papers focus on determining service schedules and cargo shipment plans to minimize total cost while satisfying the capacity restrictions, such as Bostel and Dejax (1998), Taylor et al. (2002) and Kemper and Fischer (2000). Some papers focus on cost-related pricing strategies, such as Spasovic and Morlok (1993), Tsai et al. (1994) and Yan et al. (1995). Furthermore, most models for these problems are computationally difficult to solve. Decomposition, branch and bound algorithm, Lagrangian relaxation and heuristic algorithms were proposed to solve the minimum cost flow and shortest path problems.

From an operational aspect, these problems can be treated as classical assignment problems. Feo and Gonzalez-Velarde (1995) focused on how to assign highway trailers to railcar hitches with a minimum cost. Powell and Carvalho (1998) extended this by considering full utilization of equipment. Some assignment problems can be formulated as logistic queuing models with the aim to provide useful decision guidance for terminal operators. Another problem involves planning and allocations for the empty containers of the train. This problem can be treated as a classic dynamic fleet management problem with the objective of maximizing returns. 
Konings (2007) presented a conceptual model for barge network design considering the relationship between barge transport performance in the intermodal network and the entire supply chain. The author mentioned that, it was better to use smaller vessels if available transport volume was small. For large scale vessels, the method of bundling and cooperation would be more useful. Increasing the number of sailings would also result in a growth in transport volumes. Also, the number of annual roundtrips could be increased if the circulation time decreases. To demonstrate possible improvement using the general framework generated before, a case study on the Rhine River transport was presented in the paper.

\subsubsection{Intermodal Transportation with Environmental Concerns}

There are a large number of papers in the supply chain literature that focus on multiple transportation modes from a carrier company's perspective. However, relatively few papers address intermodal transportation while considering environmental issues.

Dekker et al. (2012) compared the characteristics of alternate transportation modes with respect to time performance, cost and environmental quality, especially emissions of different equipment types in his paper. They observed that water transport was carbon efficient because water could easily carry heavy loads, rail transport was more efficient than road, and air transport was not environmental friendly in terms of $\mathrm{CO}_{2}$ emission comparing with other transportation modes. It was also observed that there was no clearly difference in $\mathrm{SO}_{2}$ emissions except in air transport which emit much more than others modes. From an environmental point of view, it was very helpful to use OR to evaluate the potential benefit between alternate modes. They also determined that more research was 
needed to consider the environmental impact on collaboration supply chain system, for example, transport facility sharing in green supply chain.

Leal and D'Agosto (2011) considered the aspect of financial and socioenvironmental cost to optimizing routes for bio-ethanol transportation in Brazil. They conducted a field study to identify indicators to compare different transportation methods. It was found that the best choice was to use multimodal transportation including long distance pipelines. Moreover, multimodal transportation using more pipelines performed best relative to cost and environmental impacts if using equal weights for financial and socio-environmental indicators in the process of evaluation. The second best option was the combination of pipeline, roadway and waterway. Transporting bio-ethanol which only used roadway was considered the worst of the alternatives due to environmental impact.

Bloemhof et al. (2011) investigated energy consumption and pollution emissions of different transportation methods and pointed out that an inland waterway system will provide more environmental benefits than railway and highway system. From their case study, it appeared that road transport was the main source of emissions. However, due to the innovations in recent years, the gap between road transport and rail transport, inland waterway system was also a major source of emission. It was estimated that emissions coming from waterways will exceed the total emission by all other sources by 2020 . As a result, only sustainable and profitable resources will be widely used to reduce emissions and improve the environment.

Vanek and Morlok (2000) focused on improving the energy efficiency of frequently used trucks, taking into account shifting cargo to rail transportation. In order to use energy efficiently at the commodity level, they proposed a "commodity-based" approach which 
disaggregated freight energy and assigned it to the major commodity groups. Through analysis of energy usage and freight patterns for US commodity flow survey data, it was suggested that the ratio of energy used for manufacture to energy consumption in transportation varied widely for different commodity types. In addition, improvement in the efficiency of transportation modes may redistribute flow patterns, thus providing potential opportunities for saving energy. Another important aspect to improve the energy efficiency is enhancing the collaboration of shippers and carriers because it could improve the efficiency and address underlying new issues at the same time.

Mallidis et al. (2012) introduced a multi-objective supply chain design model to evaluate the impact of transportation cost, environmental factors, such as carbon emissions, on the transport geography of a region. Waterway transportation was introduced in this supply chain model because it is an energy-efficient method. Because minimizing supply chain carbon emissions may increase transportation costs, the share of warehouses and transportation services were introduced to minimize supply chains costs as well as minimize carbon emissions. Therefore, this model also assisted managers to make decisions on how to choose shared warehouses and transportation in the supply chain network. Through an application in the South-Eastern Europe region, this model indicated that both cost and environmental performance would be improved using shared warehouses and transportation services. At the same time, the amount of $\mathrm{CO}_{2}$ and particulate matter (PM) emissions were also reduced through shared transportation operations.

Blauwens et al. (2006) and Hoen et al. (2010) included an inventory perspective in a mode selection model while considering carbon emission limit as constraint. Based on the basic inventory model, Blauwens et al. (2006) calculated the freight flow of different 
transport modes and studied modal choice for a hypothetical freight transport market. In order to verify which modal shifting policy is the most efficient, the impact of different strategies that involve different transport modes on the intermodal market, such as highway, combination of railroad and highway and combination of waterway and highway were measured. It was noticed that significantly different transportation flow, shifting from highway to intermodal, occurred when different policies were applied. An example was the speed and the reliability of alternate transport modes. Hoen et al. (2010) investigated the impact of regulation and limitation of carbon emission on the transportation mode selection. Specifically, they investigated how emission related costs affect the decision maker's selection of available transportation modes. Four modes of transport were considered in this paper: air, rail, road and water. Their results showed that the impact of emission related cost need to be extremely high to stimulate the decision maker to select an alternate transportation mode.

Bauer et al. (2009) considered environmental costs (greenhouse gas emissions) in a multimodal freight transportation network. The authors provided transportation planning decisions while minimizing the amount of carbon emissions. The greenhouse gas emission $\left(\mathrm{CO}_{2}\right.$ emission) was calculated according to Ross's analytical approximation for energy consumption (Ross, 1997). The expression of fuel consumption and $\mathrm{CO}_{2}$ emissions were modeled as linear functions of the vehicle load. A real world rail network was studied as an application of the proposed model. Computational experiments had been conducted to evaluate the solutions that were obtained under different time and carbon emission conditions. Computational results showed that transportation time could be reduced by $45 \%$ while $\mathrm{CO}_{2}$ emissions only increasing by $0.5 \%$. Further extensions were mentioned in this 
paper, such as: more effective solution methodologies, and consideration of various vehicle velocities.

Goel (2010) combined route choice and shipment in the transportation network model. The value of visibility over assets was quantified and used to adjust the transportation flow in the multi-modal transportation network. The result showed that their model could improve the on-time performance by increasing the level of visibility.

Janic (2011) examined the potential social and environmental effects by developing an airport into a multimodal facility, by connecting it with the railway transport network. The capacity of the high speed railway, airport airside congestion and the social cost for corresponding delays, noise, and emissions of greenhouse gases were evaluated in this paper. Scenario analysis indicated that the capacity of the high speed railway did not have

much social impact for transforming the airport to multimodal transport node. The cost of airline and passenger delays was much higher than the environmental cost (gas emissions and noise). Within the environmental concerns, gas emissions had more impact than noise. Thus, it was suggested to increase the number of air passenger transport flights to save the cost.

\subsubsection{Research Gap}

Intermodal transportation has been an important method to reduce traffic congestion and expenses, but the incorporation of multi-commodity intermodal transportation and carbon emissions tax policy in supply network optimization is almost absent in the literature. Due to the critical environmental issue today, it has become more critical to integrate environmental protection problem and intermodal transportation optimization, especially based on real world data. The existing literature in the field of 
intermodal transportation either considers several dummy transportation modes or focuses on highway and railway only. Waterway, an environment friendly transportation mode, also plays an important role in distribution networks in human society, but is generally omitted in literature. Especially, there is no existing paper applying carbon emission tax strategy to stimulate people use inland waterway. The comparison of intermodal transportation papers is shown in Table 1.

\section{Table 1}

\section{Comparison of intermodal transportation papers}

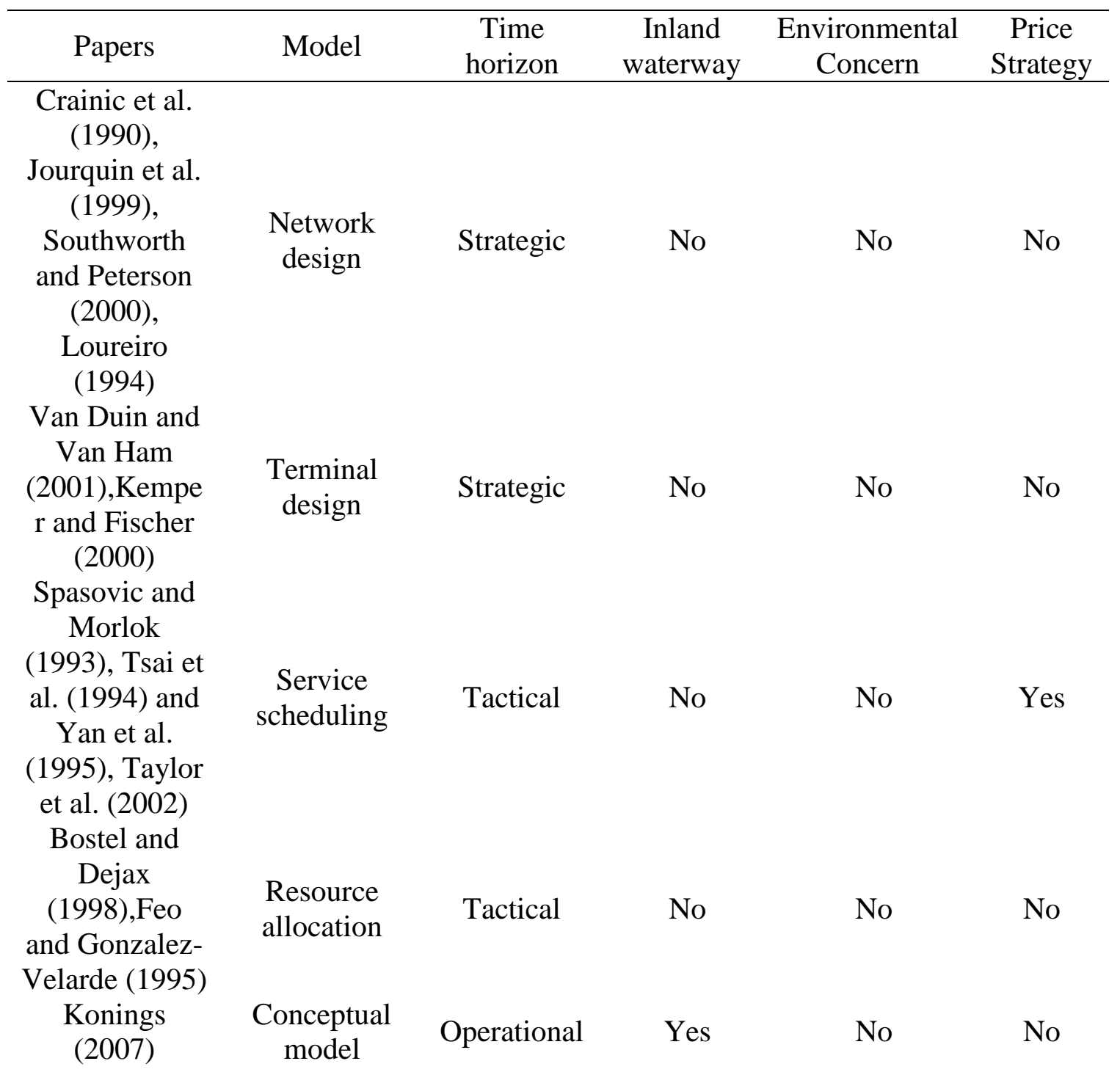




\begin{tabular}{cccccc}
$\begin{array}{c}\text { Dekker et al. } \\
(2012)\end{array}$ & $\begin{array}{c}\text { Network } \\
\text { design }\end{array}$ & Strategic & No & Yes & No \\
$\begin{array}{c}\text { Leal and } \\
\text { D'Agosto } \\
(2011)\end{array}$ & $\begin{array}{c}\text { Network } \\
\text { design }\end{array}$ & Strategic & Yes & Yes & No \\
$\begin{array}{c}\text { Bloemhof et } \\
\text { al. }(2011)\end{array}$ & $\begin{array}{c}\text { Comparative } \\
\text { study }\end{array}$ & Strategic & Yes & Yes & No \\
$\begin{array}{c}\text { Vanek and } \\
\text { Commodity- } \\
\text { based } \\
\text { Morlok (2000) }\end{array}$ & Strategic & Yes & Yes & No \\
$\begin{array}{c}\text { Mallidis et al. } \\
(2012)\end{array}$ & $\begin{array}{c}\text { Supply chain } \\
\text { design }\end{array}$ & Strategic & Yes & Yes & No \\
$\begin{array}{c}\text { Blauwens et } \\
\text { al. (2006) and } \\
\text { Hoen et al. } \\
(2010)\end{array}$ & $\begin{array}{c}\text { Network } \\
\text { design with } \\
\text { inventory }\end{array}$ & Strategic & Yes & Yes & No \\
$\begin{array}{c}\text { Bauer et al. } \\
(2009)\end{array}$ & $\begin{array}{c}\text { Network } \\
\text { design }\end{array}$ & Strategic & No & Yes & No \\
Goel (2010) & $\begin{array}{c}\text { Network } \\
\text { design }\end{array}$ & Strategic & No & Yes & No \\
Janic $(2011)$ & $\begin{array}{c}\text { Stochastic } \\
\text { queuing } \\
\text { model }\end{array}$ & Strategic & No & Yes & No \\
\hline
\end{tabular}

A driving force that government can adopt to enhance people's awareness to protect the environment is the carbon emission tax, which is still under study by researchers and has a long way to go before implementation. Few papers addressed the tax policy problem under the settings of an intermodal transportation system. However, the impact on transportation mode choice cannot be ignored. In this dissertation, we collect and conduct detailed data analysis on a real world network with highway, railway and waterway over multiple states in the US. The intermodal transportation system is optimized with consideration of environment impacts, and the role of waterway is highlighted. In addition, our theoretic and computational analyses on the impacts on transportation mode choices demonstrate the feasibility of implementing a tax policy, and a reasonable tax rate is suggested. 


\subsection{Vehicle Routing Problem}

\subsubsection{Summary}

Another important aspect of transportation is the vehicle routing problem (VRP). There are a large number of articles about the VRP. Laporte (1992) reviewed the basic VRP from three aspects: the definition, exact algorithm and heuristic algorithm. Toth and Vigo (2002) covered the basic and the main variants of VRP developed in the last decades. Exact and heuristic methods are also reviewed in this book. In this dissertation, we only review part of the existing articles that related with our problem.

Two typical time windows in vehicle routing problems (Cordeau et al.,2001) are hard time window and soft time window. A hard time window requires that the vehicle must arrive before the time window limitation. Late arrival is forbidden in this case. A soft time window allows late arrival for each customer. However, a penalty cost will occur if the vehicle does not arrive within the time window constraint.

Lenstra and Rinnooy (1981) pointed out that the Vehicle Routing Problem with Time Windows (VRPTW) is a NP-hard problem. Desaulniers et al. (1998), develop an integer multi-commodity network flow model for the VRPTW considering multiple depots. In their problem, each customer could be served by different depots within a time interval. The exact waiting cost was first taken into account in this type of problem. Column generation with branch-and-bound was used to solve the small and medium size instances while a heuristic method was used for large experiments.

Koskosidis et al. (1992) presented a formulation of the VRP that considers soft time window as constraints. By their definition, there was a penalty cost corresponding to service time of a customer. In other words, the time window could be violated at a cost. A 
new algorithm approach was presented to solve the problem. Based on the generalized assignment heuristic, the problem was decomposed into an assignment problem and some scheduling problems. Computational study based on real world data showed that their algorithm can reduce the time by $50 \%$ more than some simple methods.

Dumas et al. (1991) developed an exact algorithm to solve the pickup and delivery VRP problem with time windows. This problem is concerned with minimizing the travel cost while satisfying the pickup and delivery requests under the time window constraints. The authors presented an algorithm combining a column generation scheme with a constrained shortest path problem. Computational experiments had been done for multiple depots and different kinds of vehicles. Results showed that this algorithm worked for large pickup and delivery problems as well.

There are a large number of papers using Lagrange relaxation-based methods to solve the VRPTW. For instance, in Fisher et al. (1997), two new algorithms for VRPTW were presented: a variable splitting algorithm and a generalized K-tree algorithm. The first algorithm used Lagrange relaxation to split the main problem into several sub-problems that could be solved using existing methods. In the second algorithm, the problem was formulated as a degree constrained K-tree problem. Lagrange relaxation was used to solve the problem. Both approaches have been tested up to 100 customers.

Desrochers et al. (1992) developed a new optimization algorithm to solve the VRPTW. First, the VRPTW was formulated as a set partitioning model. Second, column generation was used to solve the LP relaxation of the set partitioning problem. Dynamic programming was used to calculate each sub-problem to generate the feasible columns. Finally, the set covering model was used instead of the set partitioning formulation. The 
solution of the set covering model provided a lower bound for the set partitioning model that can be solved by branch-and-bound algorithm. Computational study indicated that this algorithm was able to solve large problem with a large number of complex constraints.

Solomon (1987) extended the existing VRP algorithm and designs a computational study for the tour-building algorithm for VRPTW. The algorithm combined the distance and the time dimension in the heuristic process. A set of test problems was developed to evaluate the computational capability of the existing algorithm. Based on the experiments, an insertion heuristic was recommended to combine with the hybrid sweep-insertion approach to get a better solution. His work was extended by Potvin and Rousseau (1993).

Chiang and Russell (1996) developed three simulated annealing algorithms for the VRPTW. Two neighborhood structures were implemented in the first two algorithms and used as the basis for comparison. The first one was $\lambda$-interchange process developed by Osman (1993). The second one was k-node interchange mechanism introduced by Christofides and Beasley (1984). The concept of Tabu list was adopted in the third simulated annealing algorithm. Results showed that the first and third methods performed faster than the second one, although the second method provided better results.

Ombuki et al. (2006) translated the traditional VRPTW a multi-objective VRPTW problem. One objective was minimizing the number of vehicles, while another was minimizing the total travel distance. A genetic algorithm incorporated with a Pareto ranking scheme was applied to solve this problem. Their result provided a good solution and performed well compared with other vehicle-based results in the literature.

Bräysy and Gendreau (2005) conducted a survey of heuristic approaches for the VRPTW. The concept of Pareto optimality was introduced to evaluate and compare the 
traditional heuristic methods and improved search algorithms. Characteristics investigated in the analysis included simplicity, flexibility and robustness. Based on the solution quality and time performance, the algorithms presented in Russell (1995) and Bräysy (2003) were found to be more efficient than other local search algorithms.

Bouthillier and Crainic (2005) presented the parallel cooperative multi-search method to solve the VRPTW. The authors combined four construction heuristics from Bentley (1992) to generate the initial solution. Their methods included two tabu searchbased methods and two evolutionary algorithms. A post-optimization technique was applied to find a feasible solution.

Azi et al. (2010) developed an exact algorithm for the VRPTW, which has two phases. The first phase provided feasible routes while the second phase combined some of these routes to create a working day schedule for a vehicle. Experiments were performed based on an example in Solomon (1987). The result indicated that the deadline constraint had a restriction impact on this algorithm. In other words, this algorithm was very sensitive to the time restriction.

Ren et al. (2010) proposed a vehicle routing problem with time windows considering overtime and multi shifts. Shift dependent heuristic algorithms taking into account of overtime were developed to solve the large-scale problem. An insertion heuristic was used to generate the initial solution while a Tabu Search algorithm was used to improve the result. Their results demonstrated greater saving in terms of total cost and the number of vehicles compared to the method without shift dependence. El-Sherbeny (2010) presented a review of exact, heuristic and metaheuristics methods for VRPTW. 


\subsubsection{Green Vehicle Routing Problem}

Although there is extensive literature about the basic and the variants of vehicle routing problems, the Green Vehicle Routing Problem (GVRP) has only been investigated recently. This problem concerns reducing the energy consumption and the greenhouse gas emission as well as improving the current transportation efficiency, such as recharging of the vehicles (Lin et al. 2014). Papers on this subject with the aim of reducing energy consumptions include D’Agosto and Ribeiro (2004), Kara and Yetis (2007), Xiao et al. (2012), and Kuo (2010). Another aspect of the GVRP is pollution routing. The related literature includes Bektas and Laporte (2011), Maden et al. (2010), Palmer (2007), Fahimnia et al. (2013).

Bektas and Laporte (2011) investigated the effect of load and speed of truck on carbon emissions in their pollution routing problem using a comprehensive emission model. Palmer (2007) integrated carbon emissions with a vehicle routing problem with various speeds. He developed a vehicle routing model that calculates total carbon emissions, transportation time and travel distance to look for more environmentally beneficial routes. This model provided a delivery strategy corresponding to various carbon emission regulations. In addition, the author took into account congestion issues in the freight vehicle routing model. Fuel consumption was modeled by vehicle speed. Digitized road network was used to evaluate the traffic volume which was then applied to estimate carbon emissions. Scenario analysis for traffic volume was conducted to evaluate the proposed method. Experimental results and sensitivity analysis showed that carbon emissions can be potentially reduced by almost $5 \%$ while the total transportation time for the routes increase by $4 \%$ and the vehicle costs increase by $0.5 \%$. 
Fahimnia et al. (2013) developed a non-linear optimization model to investigate the carbon reduction potential and the trade-off between fuel consumption and transportation costs. The cost of air emission and fuel consumption expressions were modeled as functions of travel speed and road roughness in the model. The objective of this model included transportation costs, backlogging/penalty cost, cost of fuel consumption and cost of generated air emissions. The constraints included capacity constraints for supply, production and distribution; balance equations; speed and pollution restrictions. Piecewise linearization and tangent plane approximation were used to transform the model to a mixed integer linear programming model. In order to approximately linearize the objective function, piecewise functions were used to find the carbon emission rates and fuel consumption rate. A series of scenarios for carbon prices were conducted to investigate the effectiveness of this model. Numerical results showed that the contribution of carbon price in overall logistics cost will not increase significantly corresponding to carbon emission rates. However, roughness of road surface is an important factor which has a great impact on fuel consumption. The improvement of it will lead to carbon emission cost reduction as well.

Kwon et al. (2013) focused on the heterogeneous vehicle routing problem while taking carbon emissions into account. The carbon emission cost was calculated from the difference between the upper limit account of carbon emission and the actual carbon used in the logistical system. The environmental cost was incurred when carbon emissions were greater than the upper limit. Here, carbon emissions were estimated based on fuel burned and average emission factors. Then, based on the traditional heterogeneous vehicle routing problem (C-HVRP), the author minimized the sum of the variable operation costs while 
incorporating the environmental cost in the objective function. Tabu search algorithms were used to solve the model. Numerical experiments were conducted to evaluate this Tabu search algorithm. The performance of TS-hybrid algorithms was better than other methods. In addition, sensitivity analyses were performed to the test effects of changing the upper limit of carbon emissions and the unit cost of carbon. Results showed that carbon trading can lead to significant carbon emission reduction without increasing the total operational cost.

Kuo (2010) proposed a fuel consumption model for the vehicle routing problem with time dependent travel speeds. Meanwhile, total transportation time, transportation speed, loading weight and total transportation distance were also calculated while satisfying the 'first-in-first-out' property when given a particular routing plan. This model first divided the routing plan into sub-routes according to the loading weight of vehicles. Simulated annealing algorithm was applied to solve this problem. Solomon's 100-customer Euclidean problem was adopted for test with four travel speeds scenarios. Computational study showed that the proposed method could result in a route with less fuel consumption but more travel time and distances.

Since we will focus on the green vehicle routing problem considering time windows in this dissertation, the related literature about GVRP with time windows is discussed below.

Based on the vehicle routing and scheduling problem with time windowsprobabilistic formulation in Taniguchi et al. (2001), Ando and Taniguchi (2006) presented an application in an actual urban distribution. Different from Taniguchi et al. (2001), which assumed the arrival time to be normal distributed, the actual travel time estimated based on 
data of vehicle information communication systems was used in Ando and Taniguchi (2006). The block density method was applied to simulate traffic flow and to estimate the travel time distribution. Scenario analysis in the impact of different distributions on the proposed model was conducted. Environmental impacts were also compared with the usual operation.

Figliozzi (2011) built a time-dependent vehicle routing model to analyze the impact of average travel speed, congestion level and land on carbon emissions. The model was based on the traditional flow-arc model proposed in Desrochers et al. (1988). Real world data from Portland, OR was implemented in the case study to analyze the trade-off between travel speed, congestion levels, demands and carbon emissions. The results indicated that the level of congestion has significant impact on carbon emissions.

\subsubsection{Research Gap}

The traditional VRPs generally consider objectives to minimize the total travel distance, with a common assumption that travel cost is a linear function of distance. In the real world, there are many other factors that impact on travel cost, e.g. load of vehicles, travel speed, drivers and tax and more. For example, the same vehicle has difference fuel performances at difference speeds. A model considering travel speed as a decision variable has significant impact on application in the real world, but the nonlinear cost function resulting from the consideration of such factors brings a new challenge for solving these models. Among the green VRP literature, the travel speed is treated as either a constant or a deterministic variable without constant range restrictions. In the real world, the possible speed limit on a particular road is not fixed. For example in a road with speed limit of 45 mile/hour, the real speed limit when a vehicle travels on it could be only 30 mile/hour due 
to a heavy traffic. Thus, a stochastic range for speed limit is more practical. Existing papers on green VRP consider the problem of minimizing fuel cost, whose results are different from those traditional VRP. Table 2 shows the comparison of mathematical models of the existing papers. To understand the benefit of a green VRP solution, much analytical work needs to be conducted.

\section{Table 2}

Model comparison of G-VRP papers

\begin{tabular}{|c|c|c|c|c|}
\hline Papers & Model & Objective (Min) & $\begin{array}{c}\text { Time } \\
\text { Window }\end{array}$ & $\begin{array}{l}\text { Various } \\
\text { Travel } \\
\text { Speed }\end{array}$ \\
\hline $\begin{array}{c}\text { Kara et al. (2007) and } \\
\text { Kuo (2010) }\end{array}$ & C-VRP & travel cost & No & No \\
\hline Schneider et al. (2012) & VRPTW & travel distance & Yes & Yes \\
\hline $\begin{array}{c}\text { Maden, W., Eglese, R., \& } \\
\text { Black, D. (2010). }\end{array}$ & VRPTW & travel cost & Yes & No \\
\hline $\begin{array}{l}\text { Bektaş and Laporte } \\
\text { (2011) }\end{array}$ & VRPTW & carbon emission & Yes & $\begin{array}{c}\text { Yes, } \\
\text { assume } \\
\text { travel } \\
\text { speed >= } \\
40 \\
\text { miles/hour }\end{array}$ \\
\hline Fahimnia et al. (2013) & $\begin{array}{c}\text { logistics } \\
\text { planning model }\end{array}$ & travel cost & No & No \\
\hline Kwon et al. (2013) & C-VRP & operations cost & No & Yes \\
\hline Figliozzi (2011) & VRPTW & fleet size & Yes & Yes \\
\hline Xiao et al. (2012) & C-VRP & $\begin{array}{c}\text { fuel } \\
\text { consumption }\end{array}$ & No & No \\
\hline Palmer (2007) & VRPTW & carbon emission & Yes & No \\
\hline $\begin{array}{c}\text { D’Agosto, M., \& Ribeiro, } \\
\text { S. K. (2004). }\end{array}$ & No Model & & & \\
\hline
\end{tabular}

From the Table 2, we can see that there is no paper addressing G-VRP with objective of minimizing carbon emission while considering time window constraint and various travel speed. Especially, there is no existing paper talking about stochastic green 
vehicle routing problem. This dissertation addresses this important research gap, such as the environment impact and trade off under other practical settings. We consider a green VRP with time windows, where the speed limit can be a stochastic value. Such setting is closer to the real world, e.g. the feasible speed limit is random and can follow a function of the number of traffic lights on the road. Also, we minimize both fuel and environmental cost. Minimizing the environmental costs and minimizing the fuel costs could be consistent, but since environmental issues is still an open topic for research today, we conduct a sensitivity analysis to evaluate the impact of travel speed and time window limitations on fuel/environmental cost. 


\section{CHAPTER III}

\section{MULTI-OBJECTIVE INTERMODAL NETWORK DESIGN}

\subsection{Problem Statement}

\subsubsection{Network Setting}

In this section, we present an intermodal network including the entire inland waterway systems across 15 states in the US (Minnesota, Wisconsin, Iowa, Illinois, Missouri, Indiana, Ohio, Pennsylvania, West Virginia, Kentucky, Arkansas, Tennessee, Mississippi, Alabama, Louisiana). Our study is only focused on the shipment of coal. According to the Department of Transportation (DOT) statistics, the primary source of our data, the annual transport volume within these 15 states is approximately 85,444 Ktons. $4.3 \%$ of these volumes are transported through highway, $15.1 \%$ transported through waterway, $53.1 \%$ shipped using railway and $27.5 \%$ using multi-modal transportation. Note that the network model requires detailed information on highway, waterway and railway distance. AcrGIS, a geographical information system (GIS) provided an efficient way to estimate these parameters. We used ESRI's ArcGIS 9.3 software to develop a GISbased intermodal network which consists of three transportation modes. Figures 4 and 5 depict a subset of this network within 15 states because we only focus on OD pairs within these states. The red, blue and green lines represent railway, waterway and highway, respectively. The major interstate highways are: I10, I12, I22, I24, I26, I29, I35, I39, I40, I43, I44, I49, I55, I57, I59, I64, I65, I68-I86, I88, I90 and I99. The major railways are 
BNSF, CSX, Norfolk Southern, and Union Pacific Railroad. The map generated using ArcGIS software provides the distance data for our primary network. In the original form, this network is not suitable for real world coal transportation because only a few origin and destination points are exactly intermodal nodes. Thus, we represent the origin and destination nodes by projecting them onto the closest intermodal nodes. Consequently, the intermodal nodes in our model include origin and destination points. Each existing highway, railway and waterway between a node pair is represented as an arc. The resulting network model of coal transportation in 15 states has 76 nodes and 8,451 arcs.

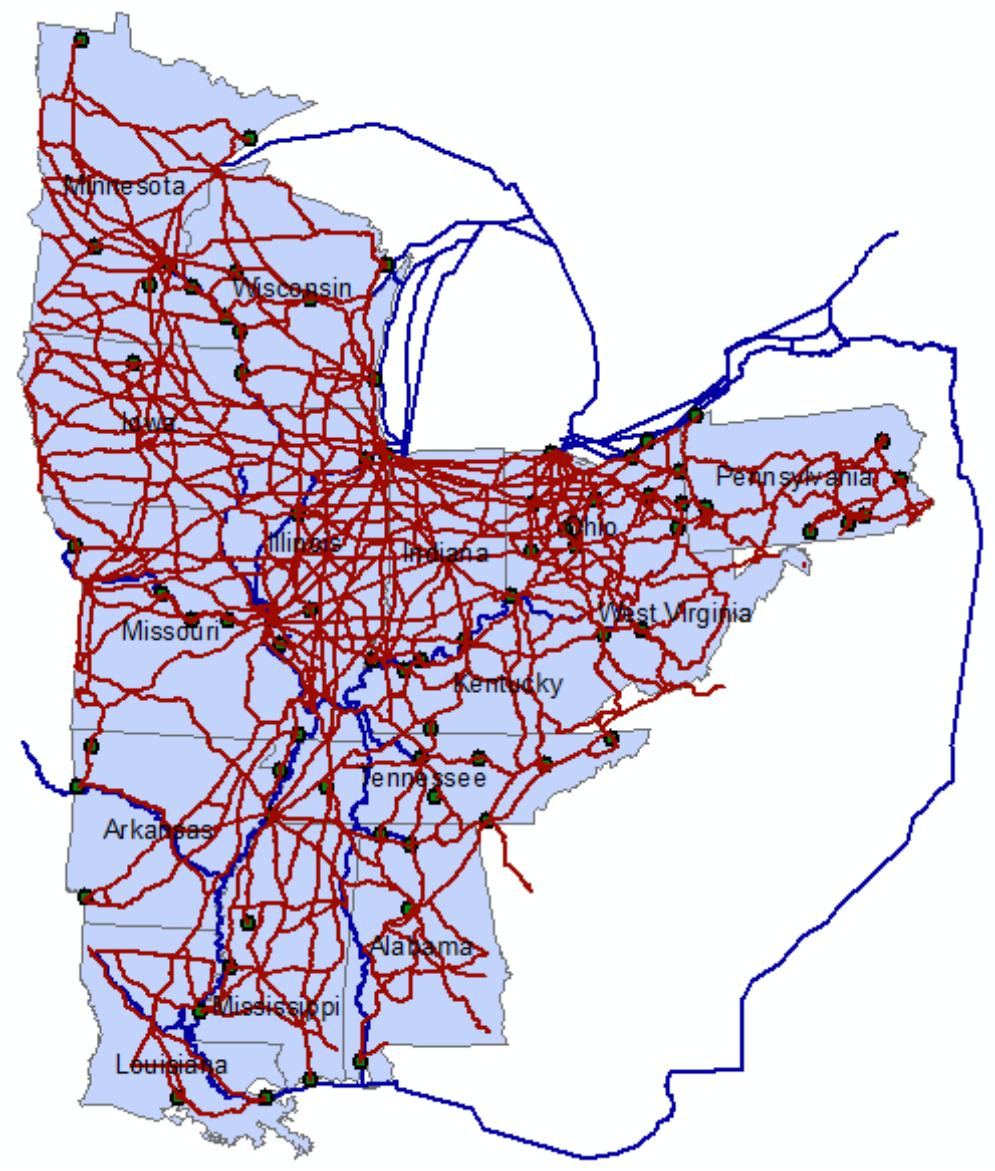

Figure 4. Railway and waterway network 


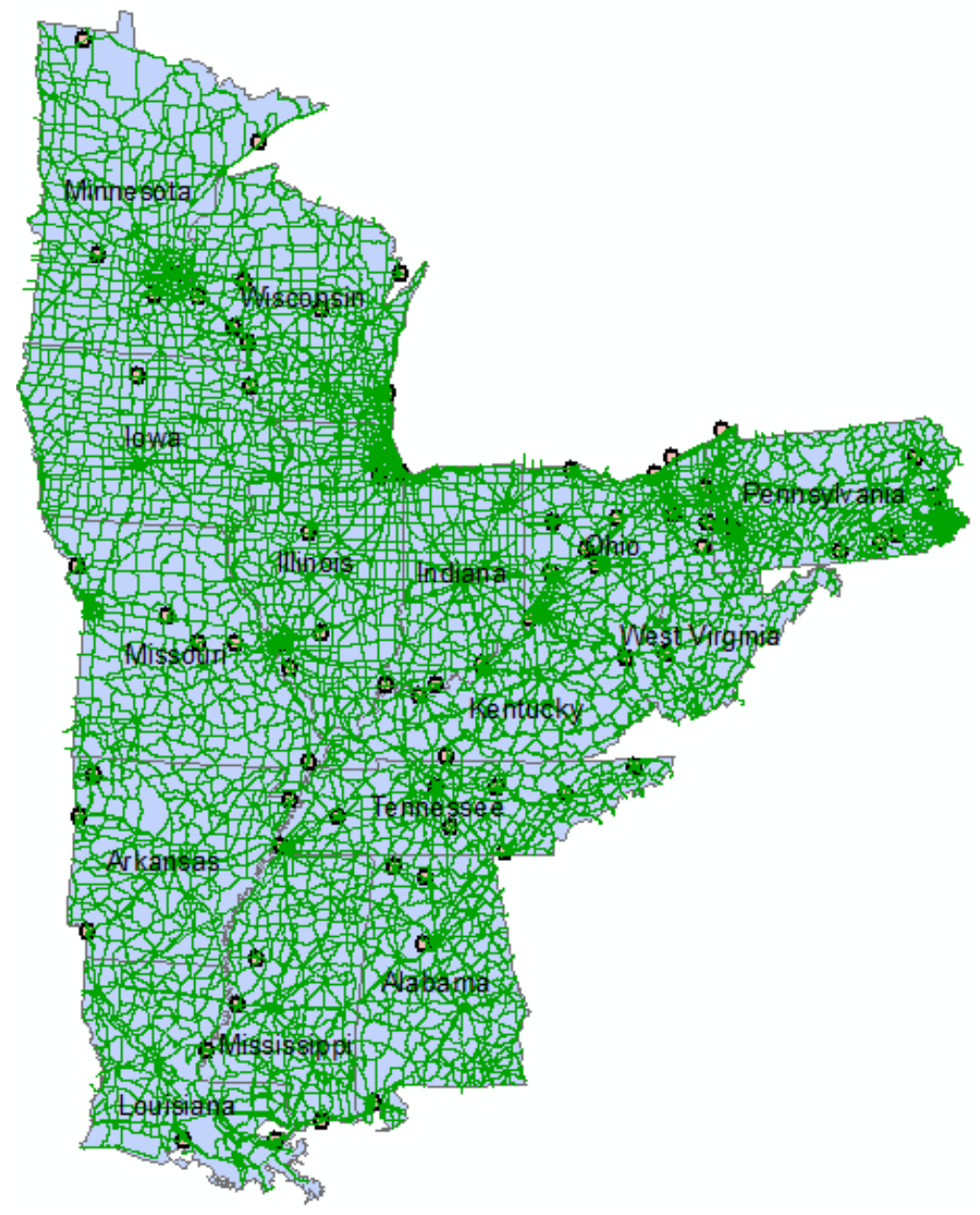

Figure 5. Highway network

The origins and destinations, as well as the demand of each OD pair are obtained from DOT records. Specifically, demand is estimated via the U.S. Department of Transportation OD matrix which contains coal transportation forecast for 2015. The regions defined by DOT are used as our origins and destinations. As previously mentioned, we aggregate demand data for some regions and assign them to the nearest intermodal destination node in our ArcGIS model. The OD pairs that are assigned to intermodal node would potentially make use of the inland waterway system.

To obtain the actual cost, we analyze the statistical data of coal transportation from region to region within these fifteen states for 2015 . The percentages of coal flowing from 
one region to another using different transportation modes are used to estimate the actual flow for 2015. The resulting transportation cost is $\$ 450.8$ million. We assume that the unit transportation cost is proportional to distance. According to the literature, one gallon of fuel is required to ship one ton of cargo an average of 210 miles by highway, 450 miles by railway, and 514 miles by waterway (Wikipedia.org). We assume 1 gallon fuel costs 4 dollars which is used to calculate the unit cost for various transportation modes. Then, the unit transportation cost via truck is $\$ 0.02 /$ ton $/$ mile, railway is $\$ 0.01 /$ ton $/ \mathrm{mile}$, and waterway is $\$ 0.008 /$ ton/mile. For waterway, the capacity between two nodes is assumed to be the minimum capacity of the locks between these two nodes. For highway, a full-width highway typically could carry 2,000 cars per hour, and one car can carry 25 tons. We assume each highway has the same capacity. The annual highway capacity between two nodes can now be calculated as follows:

$$
\operatorname{Cap}_{i j 2}=2,000 * 25 * 24 * 365 / 1000=438,000 \text { Ktons }
$$

For railway, a modern train consists of an average of 100 cars, while each car has a capacity of $286,000 \mathrm{lbs}$ or 125.5 tons. Thus the average capacity of a train is approximately 12,500 tons. Suppose there is one train between two nodes per day, the capacity between these two nodes is calculated as:

$$
\operatorname{Cap}_{i j 3}=12,500 * 365 / 1000=4,562.5 k t o n s
$$

Because we only consider coal transportation in our study, all vehicles, rail cars and barges are assumed to be fully loaded.

\subsubsection{Carbon Emission Functions}

The carbon emission functions for the three different transportation modes are

derived in this section using the approach in Hickman et al., (1999). The average speed for 
each mode is taken into consideration to estimate the emission function because we only consider annual demands. The notations used in the carbon emission function are shown in Appendix II.

For highway, we assume there is only one type of vehicle: diesel truck without catalysts. Because a full truckload truck can carry 25 tons and the average speed of a full truckload $V_{i j}$ is assumed to be 47 miles per hour (75.6 kilometers/hour) (including traffic jams or queues at intersections), carbon emission for roads can be calculated as follows:

$$
\begin{aligned}
& E^{h o t}=765-7.04 V+0.000632 V^{3}+\frac{8334}{V} \\
& =765-7.04 * 75.6+0.000632 * 75.6^{3}+\frac{8334}{75.6}=616.09
\end{aligned}
$$

Where

$$
\begin{aligned}
& \varepsilon=1.27-\frac{0.483}{V}=1.27-\frac{0.483}{75.6}=1.26 \\
& E^{\text {start }}=\omega \times(f(V)+g(T)-1) \times h(d) \\
& =182.57 *(-0.0458 * 25+1.9163) * \frac{1-e^{-\frac{3.95 d}{0.24 * 75.6+0.09}}}{1-e^{-3.95}} \\
& =143.58 *\left(1-e^{-0.22 d}\right) \\
& f^{E}=\sum_{i=1}^{I} \sum_{j=1}^{J}\left(E^{h o t} \varepsilon+E^{s t a r t}\right) N_{i j} D_{i j} \\
& =\left(31.14+5.74 *\left(1-e^{-0.22 D_{i j m}}\right)\right) * \sum_{(O, D)} x_{i j m}^{O D} * D_{i j m}, \text { for } m=1 \text { (truck mode) }
\end{aligned}
$$

\section{Where:}

$f^{E}:$ Total emission $(\mathrm{g})$

$E^{h o t}:$ The emission produced when the engine is hot $(\mathrm{g} / \mathrm{km})$

$V$ : The average speed travelled by the each vehicle $(\mathrm{km} / \mathrm{h})$ 
$\varepsilon$ : Load correction factor function

$E^{\text {start }}:$ The emission when the engine is cold $(\mathrm{g} / \mathrm{km})$

$N_{i j}$ : The number of vehicles between node $i$ and $j$

$D_{i j}$ : The average distance travelled between node $i$ and $j(\mathrm{~km})$

For railway, we make the following assumptions: (1) The average speed of train is 40 miles/h; (2) The mean distance between stops is 100 kilometers; (3) the brake specific emission factor (BSEF) for $\mathrm{CO}_{2}$ is assumed to be $42 \mathrm{~g} / \mathrm{kWh}$ (Pan et.al, 2010). Carbon emission of railway can thus be calculated as:

$$
\begin{aligned}
& f^{E}=\sum_{i=1}^{I} \sum_{j=1}^{J} 0.0036 W S E C \times \frac{T k m_{i j}}{T p t} \times B S E F \times D_{i j} \\
& =0.0036 *\left(0.019 * \frac{64.4^{2}}{\ln (64.4)}+63\right) * \frac{\sum_{(O, D)} x_{i j m}^{O D}}{0.73} * 42 * D_{i j m} \\
& =\frac{0.684}{\ln (100)} * \frac{\sum_{(O, D)} x_{i j m}^{O D}}{0.73} * 42 * D_{i j m}+0.2268 * \frac{\sum_{(O, D)} x_{i j m}^{O D}}{0.73} * 42 * D_{i j m} \\
& =17 \sum_{(O, D)} x_{i j m}^{O D} * D_{i j m}, \text { for } m=2(\text { rail mode })
\end{aligned}
$$

Where:

WSEC: weight specific energy consumption $(\mathrm{kj} / \mathrm{ton}-\mathrm{km})$

$T k m_{i j}$ : the amount of freight transported between node $i$ and $j$

Tpt: the load factor of the train, (tonne-freight/total train tonne)

$B S E F$ : brake specific emission factor of energy produced ( $\mathrm{g} / \mathrm{kWh})$

For waterway, the cargo capacity (maximum load) of a general cargo vessel for inland waterways is 3,840 ton. The fuel emission of $\mathrm{CO}_{2}$ is $3,200 \mathrm{~kg} / \mathrm{ton}$. The average speed of general cargo ship is 14.29 knots (26.5 kilometers/h). Carbon emission for waterway can be calculated as follows: 
$f^{E}=\sum_{i=1}^{I} \sum_{j=1}^{J} S_{i j} F \frac{D_{i j}}{24 V}$

$=0.8 *(9.8197+0.00143 * 3840) * 3200 * 1000 * \frac{\sum_{(O, D)} x_{i j m}^{O D}}{3840} * \frac{D_{i j m}}{24 * 26.5}$

$=16.05 \sum_{(O, D)} x_{i j m}^{O D} * D_{i j m}$, for $\mathrm{m}=3$ (river mode)

Where:

$S_{i j}$ : Daily consumption of ship between node $i$ and $j$

$F:$ Average emission factor

\subsection{Mathematical Models}

\subsubsection{Definitions and Notations}

Consider a network $G=(N, A)$, where $N$ is the set of nodes and $A$ is the set of $\operatorname{arcs}$ that includes waterway, highway and railway. Given a fixed demand, we not only intend to optimize the transportation cost for each company, but also aim to reduce the carbon emissions in the entire network. The optimization constraints are: (a) material flow demand constraints, (b) the flow balance constraints for each transportation mode, (c) the freight system capacity constraints, (d) the carbon emission restriction constraints, (e) the nonnegativity constraints, and, (f) the time penalty constraints. Note that the unit time penalty cost is defined as $\alpha$ which is used to simulate the actual transportation cost.

The notation used in the models is as follows.

$\mathrm{N}$ : Set of nodes in the distribution network

$f_{O D}$ : Quantity of consignment coal required to be transport from an origin node $O$ to a destination node $D, O \in N, D \in N, O \neq D$

$M$ : Set of transportation modes 
$c^{m}$ : Unit cost to transport one ton of coal one mile via mode $m$

$D_{i j m}$ : Distance between node $i$ and $j$ when using transportation mode $m, i \neq j$

$\operatorname{Cap}_{i j m}$ : Maximum capacity between node $i$ and $j$ when using transportation mode $m, i \neq$

$j, i=1,2 \ldots N, j=1,2 \ldots N$

$h_{i j m}=\left\{\begin{array}{l}1, \operatorname{Cap}_{i j m}>0 \\ 0, \text { otherwise }\end{array}\right.$

$v_{m}$ : Average travel speed in mode $m$

$x_{i j m}^{O D}$ : Quantity of coal representing the $(O, D)$ consignment that is transported from node $i$

to $j$ using mode $m, i \neq j$

$\alpha$ : Unit time penalty cost

$\beta$ : Carbon tax (dollars per ton)

\subsubsection{Boundary Models}

For the network described in Section 3.1, the transportation cost is $C_{0}=\$ 454,3$ million, and carbon emission volume, $E_{0}=915,957$ tons. They are calculated based on the collected data.

We first consider a typical minimum cost problem, where the total transportation cost is minimized while the flow balance and capacity restrictions are satisfied. The model is formulated as (1) - (6). Model 1 would provide a lower bound on the transportation cost in the network, and thus help to evaluate the efficiency of current logistics performance.

Model 1:

Min.

$\sum_{(O, D)} \sum_{i \in N} \sum_{j \in N} \sum_{m \in M} c^{m} D_{i j m} x_{i j m}^{O D}$

S.T. 


$$
\begin{aligned}
& \sum_{j \in N} \sum_{m \in M} x_{i j m}^{O D}=f_{O D}, \quad \forall i=O, i \neq j, \forall(O, D) \text { pair } \\
& \sum_{i \in N} \sum_{m \in M} x_{i j m}^{O D}=f_{O D}, \quad \forall j=D, i \neq j, \forall(O, D) \text { pair } \\
& \sum_{j \in N} \sum_{m \in M} x_{j i m}^{O D}=\sum_{j \in S} \sum_{m \in M} x_{i j m}^{O D}, \forall i \neq O, i \neq D, \text { and } i \neq j, \forall(O, D) \text { pair } \\
& \sum_{(O, D)} x_{i j m}^{O D} \leq \operatorname{Cap}_{i j m}, i \in N, j \in N, i \neq j, m \in M \\
& x_{i j m}^{O D} \geq 0, i \in N, j \in N, i \neq j, m \in M, \forall(O, D)
\end{aligned}
$$

The objective function calculates the total transportation cost, which is impacted by the arcs that material travels on and the transportation model adopted. Constraints (2) and (3) guarantee that flows from the origin and to the destination are equal to the required consignment quantity for each OD pair respectively. Constraint (4) is the flow balance constraint which requires that the in-flow and out-flow are the same for every transit node. Note that these flow balance constraints are defined based on each O-D pair. Different OD pairs cannot be aggregated at a node, because the material flow of an O-D pair coming to a node cannot be mixed with material flow from another O-D pair. Constraint (5) restricts that the total material flow on an arc cannot exceed the capacity for the particular transportation mode. Constraint (6) guarantees the non-negativity of the flow variables.

Based on the optimal solution of Model 1, transportation cost $C_{1}$ is obtained directly from the objective value, and carbon emission volume $E_{1}$ can be calculated as $E_{1}=$ $\sum_{i \in N} \sum_{j \in N} \sum_{m \in M} f^{E}\left(D_{i j m}, \sum_{(O, D)} x_{i j m}^{O D}\right)$, where the $f^{E}$ is the carbon emission function as defined in section 3.1.2.

Focusing on cost reduction could lead to an increase in carbon emission. Thus, a constraint based on current carbon emission volume will help obtain a solution with 
potentially higher on transportation cost, but by maintaining an upper bound on carbon emission to current levels, see constraint (7). The total transportation cost and carbon emission at the optimum of Model 2 are $C_{2}$ and $E_{2}$ respectively.

Model 2:

Min. Objective (1)

S.T.

$\sum_{i \in N} \sum_{j \in N} \sum_{m \in M} f^{E}\left(D_{i j m}, \sum_{(O, D)} x_{i j m}^{O D}\right) \leq E_{0}$

Constraints (2) - (6)

From another aspect, we are also interested in how best the carbon emission can be controlled. Model 3 minimizes the total emission with flow balance and capacity restrictions the same as Model 1. At the optimum, the objective value is the carbon emission $E_{3}$ and total transportation cost $C_{3}$ can be calculated based on flows as $C_{3}=$ $\sum_{(O, D)} \sum_{i \in N} \sum_{j \in N} \sum_{m \in M} c^{m} D_{i j m} x_{i j m}^{O D}$. And $E_{0}$ is calculated based on the collected data.

Model 3:

Min.

$\sum_{i \in N} \sum_{j \in N} \sum_{m \in M} f^{E}\left(D_{i j m}, \sum_{(O, D)} x_{i j m}^{O D}\right)$

S.T.

Constraints (2) - (6) 
It is possible that Model 3 yields a solution with unrealistically low carbon emission. Model 4 therefore introduces constraint (9), a constraint that ensures the transportation cost cannot exceed a maximum, restricts the total cost of an optimal solution cannot exceed the budget. In fact, constraint (9) in Model 4 ensures that the transportation cost cannot exceed the budget that is current incurred. Model 4 minimizes the total emission with an additional current cost restriction to achieve a less-aggressive lower bound for carbon emission. The total transportation cost and carbon emission at the optimum of Model 4 are $C_{4}$ and $E_{4}$ respectively.

Model 4:

Min. Objective (8)

S.T.

$\sum_{(O, D)} \sum_{i \in N} \sum_{j \in N} \sum_{m \in M} C_{i j m} x_{i j m}^{O D} \leq C_{0}$

Constraints (2) - (6)

In summary, the optimal solutions of the above four models have relationships as shown below.

$C_{1} \leq C_{2} \leq C_{0} \geq C_{4} \leq C_{3}$ and $E_{1} \geq E_{2} \leq E_{0} \geq E_{4} \geq E_{3}$.

The gaps between current carbon emission and bound values indicate the potential improvement one can obtain by adjusting the material flows. Along with relationships between corresponding transportation costs, it is realized that opportunities may exist for reducing cost and emission at the same time. Detailed numerical analysis is conducted in 
section 4. Because the current transportation flow is not optimal, a policy that reallocates flows to reduce the economic and environmental costs simultaneously, is studied in this Chapter.

\subsubsection{Multi-objective Intermodal Transportation Model}

To control the carbon emission associated with transportation, one possible approach is for authority to collect a pollution tax. Before studying the impact of a pollution tax, we first need to understand and model decision maker behavior. Without any carbon tax, it is possible that a transportation company might simply choose the least cost route. However, the least cost route might require more transportation time. With an assumed time penalty parameter, model 5 simulates decision maker choice in the transportation network.

\section{Model 5:}

Min.

$$
\begin{aligned}
& \sum_{(O, D)} \sum_{i \in N} \sum_{j \in N} \sum_{m \in M} c^{m} D_{i j m} x_{i j m}^{O D}+\alpha \sum_{(O, D)} \sum_{i \in N} \sum_{j \in N} \sum_{m \in M}\left(\frac{D_{i j m}}{v_{m}}-\right. \\
& \left.\min _{m}\left\{\frac{D_{i j m}}{h_{i j m} v_{m}}\right\}\right) x_{i j m}^{O D}
\end{aligned}
$$

\section{S.T. Constraints (2) - (6)}

Objective (10) minimizes the distance based transportation cost and the time cost simultaneously. If people do not choose the fastest way on an arc, there is extra time penalty cost generated. Even though different individuals may have different time preferences, a unique $\alpha$ value represents an average level to simulate the behavior of the entire group. The proper $\alpha$ value can be obtained by comparing the actual transportation cost and the resulting value of the first term in the objective (10) at optimum. 
With a fixed unit time penalty, the impact of pollution policy can be evaluated based on Model 6. Assume that tax is linear on the carbon emission volume with a coefficient $\beta$. Objective (11) in Model 6 additionally considers the environmental cost that people have to pay, and aims to minimize it with transportation as well as time costs.

Model 6:

Min.

$\sum_{(O, D)} \sum_{i \in N} \sum_{j \in N} \sum_{m \in M} c^{m} D_{i j m} x_{i j m}^{O D}+\alpha \sum_{(O, D)} \sum_{i \in N} \sum_{j \in N} \sum_{m \in M}\left(\frac{D_{i j m}}{v_{m}}-\right.$

$\left.\min _{m}\left\{\frac{D_{i j m}}{h_{i j m} v_{m}}\right\}\right) x_{i j m}^{O D}+\beta \sum_{i \in N} \sum_{j \in N} \sum_{m \in M} f^{E}\left(D_{i j m}, \sum_{(O, D)} x_{i j m}^{O D}\right)$

\section{S.T. Constraints (2) - (6)}

The optimum transportation cost and carbon emission for Model 6 are $C_{6}$ and $E_{6}$ respectively. By adjusting $\beta$, a tax policy based on $\beta$ can be obtained with an expectation that $E_{6}<E_{0}$ and $C_{6}+\beta E_{6} \leq \gamma C_{0}$, where $\gamma$ is a subjective tolerance of the decision maker and $\gamma \geq 1$. Detailed numerical analysis is conducted in section 3.3.4.

\subsection{Numerical Results Based on Model 1}

\subsubsection{Example 1:3x3 OD pairs}

We use 3x3 OD pairs to verify this model. The network model is presented in Figure 6. The optimal result of total transportation cost is $\$ 58,057.02$. The material flow of each arc is shown in Table 1. 


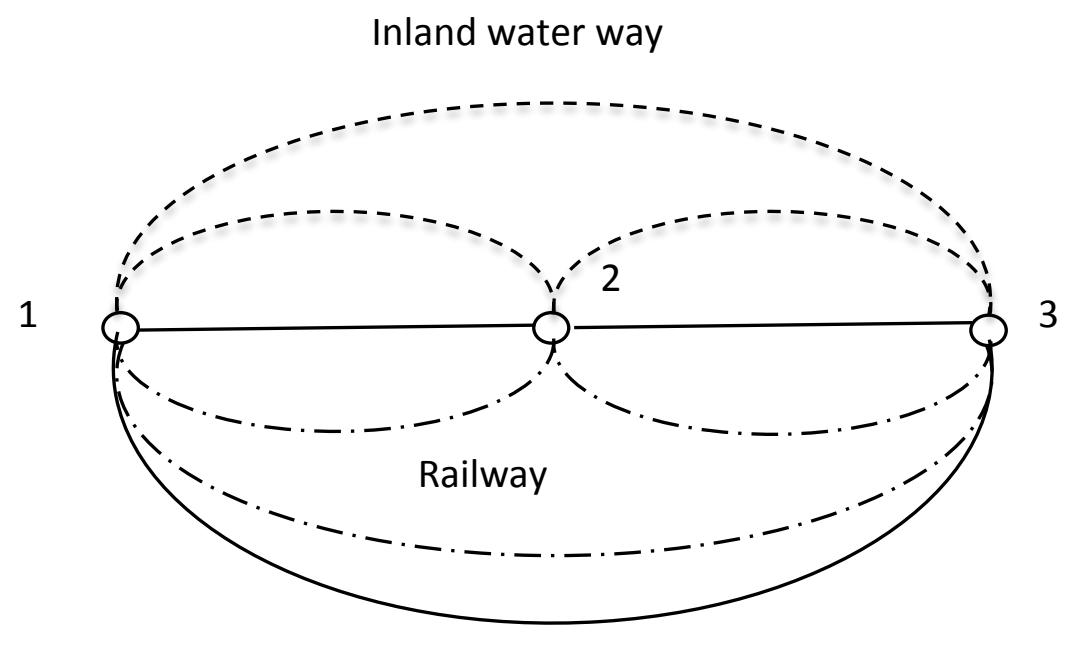

Highway

Figure 6. 3x3 OD pairs network

Table 3

$\underline{\text { Result of } 3 \times 3 \text { OD pairs }}$

Fixed

Original Destination Demand Transportation Transportation

\begin{tabular}{cccccccc} 
& $\begin{array}{c}\text { Node } \\
\text { O }\end{array}$ & $\begin{array}{c}\text { Node } \\
\text { D }\end{array}$ & (Ktons) & $\begin{array}{c}\text { mode } \\
\text { m }\end{array}$ & $\begin{array}{c}\text { Path } \\
\mathrm{i}\end{array}$ & j & $\begin{array}{c}\text { Value } \\
\text { (Ktons) }\end{array}$ \\
\hline $\mathrm{X}$ & 1 & 2 & 10,000 & 1 & 1 & 2 & 10,000 \\
$\mathrm{X}$ & 1 & 3 & 3,000 & 1 & 1 & 2 & 3,000 \\
$\mathrm{X}$ & 1 & 3 & 3,000 & 1 & 2 & 3 & 2,768 \\
$\mathrm{X}$ & 1 & 3 & 3,000 & 2 & 2 & 3 & 232 \\
$\mathrm{X}$ & 2 & 1 & 2,000 & 1 & 2 & 1 & 2,000 \\
$\mathrm{X}$ & 2 & 3 & 9,000 & 1 & 2 & 3 & 9,000 \\
$\mathrm{X}$ & 3 & 2 & 4,000 & 1 & 3 & 2 & 4,000 \\
\hline
\end{tabular}

From Table 3, we can see that this lower level (the base model which minimizes the transportation cost) model can help each individual select the most economical way to ship their commodities. For example, for node 1 to node 2, the fixed demand is 10,000 ktons, the most economic transportation method is to ship all commodities from node 1 to node 2 using waterway. For node 1 to node 3, the fixed demand is 3,000 ktons. The most economical way is to first ship 3,000 ktons from node 1 to node 2 using waterway, then 
ship 2,768 ktons from node 2 to node 3 using waterway while shipping 232ktons from node 2 to node 3 using highway.

\subsubsection{Example 2: Ohio River Case}

In Figure 7, nodes A through I represent eight ports along the Ohio River, where highway, railway and waterway are considered in this example. Note that Railway exists only between Cincinnati and Louisville.

The optimal result of this case is $\$ 2,410,038$ while the material flow of each arc is shown in Appendix I.

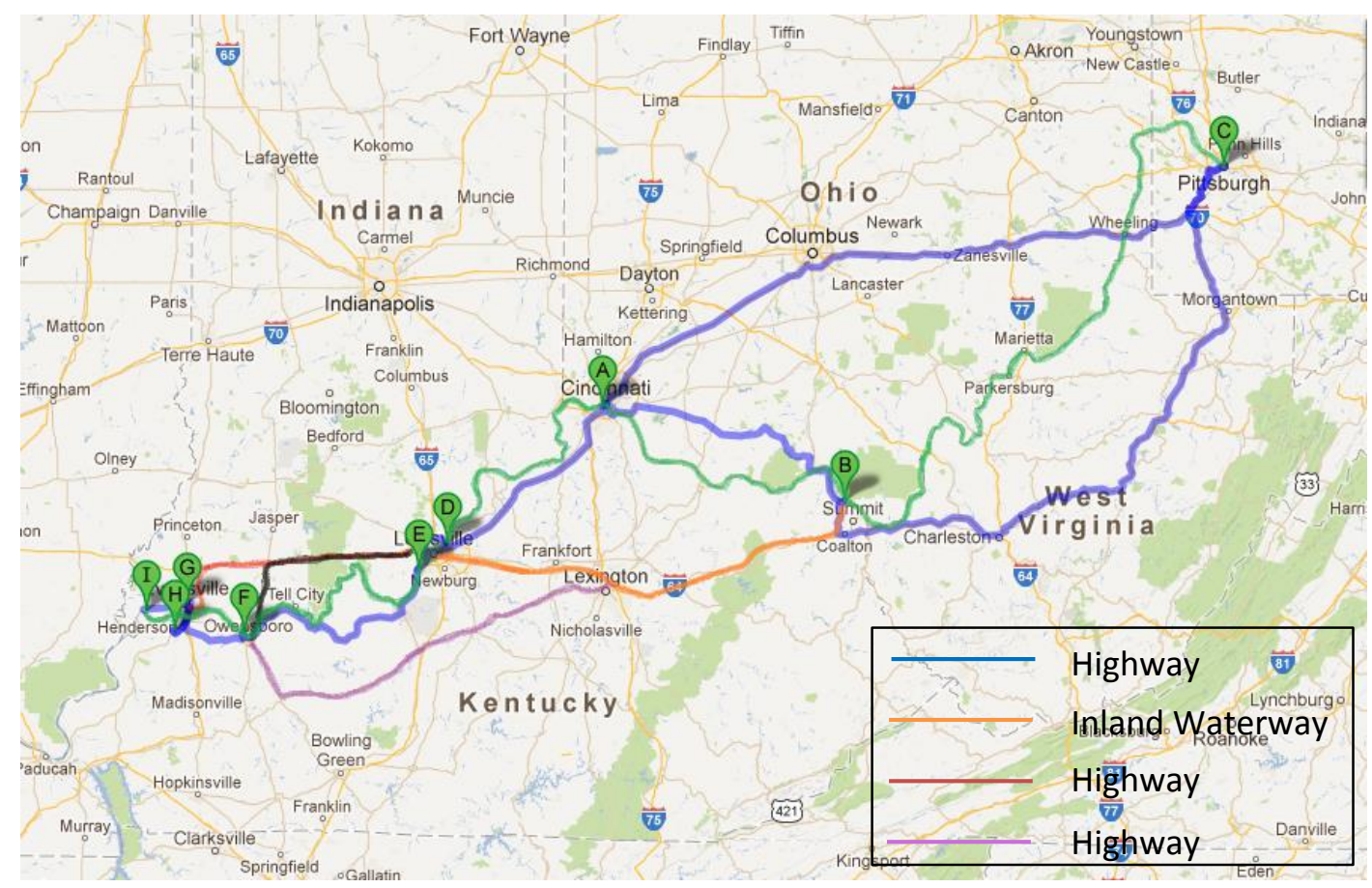

Figure 7. Ohio River Network

\subsubsection{Sensitivity Analysis Based on Ohio River Case}

There are three variables to change, and each of them has seven scenarios. These variables and their levels are: the waterway capacity was increased $0 \%, 5 \%, 10 \%, 15 \%$, $20 \%, 25 \%, 30 \%$; the highway capacity was increased $0 \%, 5 \%, 10 \%, 15 \%, 20 \%, 25 \%, 30 \%$; 
the railway capacity was increased $0 \%, 5 \%, 10 \%, 15 \%, 20 \%, 25 \%, 30 \%$. We will implement these scenarios to the models in section 3.2.

The scenarios and outcomes for increasing capacity of waterway, highway and railway are shown in Table 4-6 respectively.

\section{Table 4}

Outcomes for increasing waterway capacity

\begin{tabular}{lcccc}
\hline & $\begin{array}{c}\text { Percent } \\
\text { Percent Increase } \\
\text { in Waterway } \\
\text { Capacity }\end{array}$ & $\begin{array}{c}\text { Percent Increase } \\
\text { in Highway } \\
\text { Capacity }\end{array}$ & $\begin{array}{c}\text { in } \\
\text { Railway } \\
\text { Capacity }\end{array}$ & $\begin{array}{c}\text { Total } \\
\text { Transportation } \\
\text { Cost }\end{array}$ \\
\hline Scenario 1 & $0 \%$ & $0 \%$ & $0 \%$ & $2,410,038$ \\
Scenario 2 & $5 \%$ & $0 \%$ & $0 \%$ & $2,405,633$ \\
Scenario 3 & $10 \%$ & $0 \%$ & $0 \%$ & $2,401,227$ \\
Scenario 4 & $15 \%$ & $0 \%$ & $0 \%$ & $2,396,835$ \\
Scenario 5 & $20 \%$ & $0 \%$ & $0 \%$ & $2,392,451$ \\
Scenario 6 & $25 \%$ & $0 \%$ & $0 \%$ & $2,388,067$ \\
Scenario 7 & $30 \%$ & $0 \%$ & $0 \%$ & $2,383,683$ \\
\hline
\end{tabular}

Table 5

Outcomes for increasing highway capacity

\begin{tabular}{lcccc}
\hline & $\begin{array}{c}\text { Percent } \\
\text { Increase } \\
\text { in } \\
\text { Percent Increase } \\
\text { in Waterway } \\
\text { Capacity }\end{array}$ & $\begin{array}{c}\text { Percent } \\
\text { Highway } \\
\text { Capacity }\end{array}$ & $\begin{array}{c}\text { Increase in } \\
\text { Railway } \\
\text { Capacity }\end{array}$ & $\begin{array}{c}\text { Total Transportation } \\
\text { Cost }\end{array}$ \\
\hline Scenario 1 & $0 \%$ & $0 \%$ & $0 \%$ & $2,410,038$ \\
Scenario 2 & $0 \%$ & $5 \%$ & $0 \%$ & $2,410,038$ \\
Scenario 3 & $0 \%$ & $10 \%$ & $0 \%$ & $2,410,038$ \\
Scenario 4 & $0 \%$ & $15 \%$ & $0 \%$ & $2,410,038$ \\
Scenario 5 & $0 \%$ & $20 \%$ & $0 \%$ & $2,410,038$ \\
Scenario 6 & $0 \%$ & $25 \%$ & $0 \%$ & $2,410,038$ \\
Scenario 7 & $0 \%$ & $30 \%$ & $0 \%$ & $2,410,038$ \\
\hline
\end{tabular}




\section{Table 6}

Outcomes for increasing railway capacity

\begin{tabular}{lllrl}
\hline & & & \multicolumn{3}{l}{$\begin{array}{l}\text { Percent } \\
\text { Increase }\end{array}$} \\
& $\begin{array}{l}\text { Percent Increase } \\
\text { in Waterway } \\
\text { Capacity }\end{array}$ & $\begin{array}{l}\text { Percent Increase } \\
\text { in Highway } \\
\text { Capacity }\end{array}$ & $\begin{array}{l}\text { in } \\
\text { Railway } \\
\text { Capacity }\end{array}$ & \multicolumn{1}{l}{$\begin{array}{l}\text { Total } \\
\text { Transportation } \\
\text { Cost }\end{array}$} \\
\hline Scenario 1 & $0 \%$ & $0 \%$ & $0 \%$ & $2,410,038$ \\
Scenario 2 & $0 \%$ & $0 \%$ & $5 \%$ & $2,409,655$ \\
Scenario 3 & $0 \%$ & $0 \%$ & $10 \%$ & $2,409,272$ \\
Scenario 4 & $0 \%$ & $0 \%$ & $15 \%$ & $2,408,888$ \\
Scenario 5 & $0 \%$ & $0 \%$ & $20 \%$ & $2,408,505$ \\
Scenario 6 & $0 \%$ & $0 \%$ & $25 \%$ & $2,408,122$ \\
Scenario 7 & $0 \%$ & $0 \%$ & $30 \%$ & $2,407,739$ \\
\hline
\end{tabular}

The strategies are compared in Figure 8. From Figure 8, we can see that with percent of capacity increasing, total transportation cost decreases significantly when waterway capacity is increased. Thus, the investment in waterways reduces transportation cost. In this network, waterway and railway are both fully utilized while highway is not. When capacity of waterway is increased to $30 \%$, the total transportation cost becomes $\$ 2,383,683$ which was greatly reduced compared to investment on other transportation modes. 


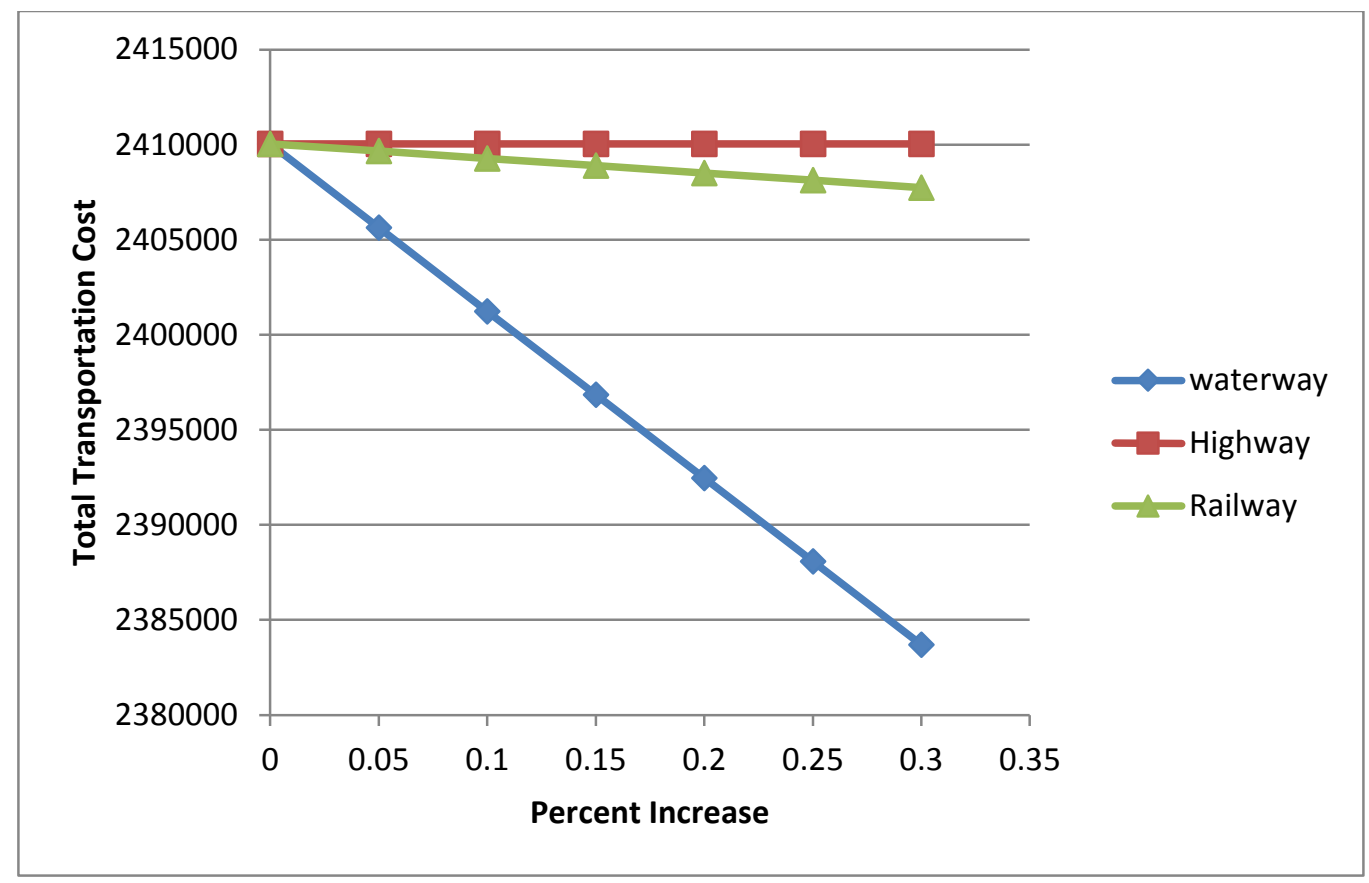

Figure 8. Strategies comparison

\subsection{Scenario Analysis}

\subsubsection{Boundary Cases}

The optimal solution indicates the total transportation cost can be reduced to \$ 340.3 million, and the corresponding emission is 727,183 tons. More specifically, 30.4 percent cargo is transported using railway, 2.4 percent using highway and 67.2 percent using multi-modal transportation. This is the optimal solution of model 1 without considering a carbon tax and time penalty cost. This is the ideal situation that the government agencies may prefer to achieve. The reason for that is that inland waterway transport is a more economical and environmentally friendly mode than railway and road transportation. In simpler terms, the government can reduce carbon emission by 188,774 tons if 67.2 percent of coal is transported using multi-modal transportation, whereas, carrier 
companies can save $\$ 114.03$ million compared to the actual cost. The example of optimal route of model 1 is shown in Figure 9 and Table 7.

From Figure 9 and Table 7, it can be seen that, if the demand between Charleston to Louisville is 2,590 Ktons, the company can first ship 2,590 Ktons from Charleston to Huntington using railway; then ship 2,590 Ktons from Huntington to Cincinnati using waterway; finally transport these cargo from Cincinnati to Louisville using waterway. Similarly, if the demand between Columbus to Louisville is 896 Ktons, the resulting optimal route is: first using highway from Columbus to Cincinnati, then using waterway from Cincinnati to Louisville using waterway.

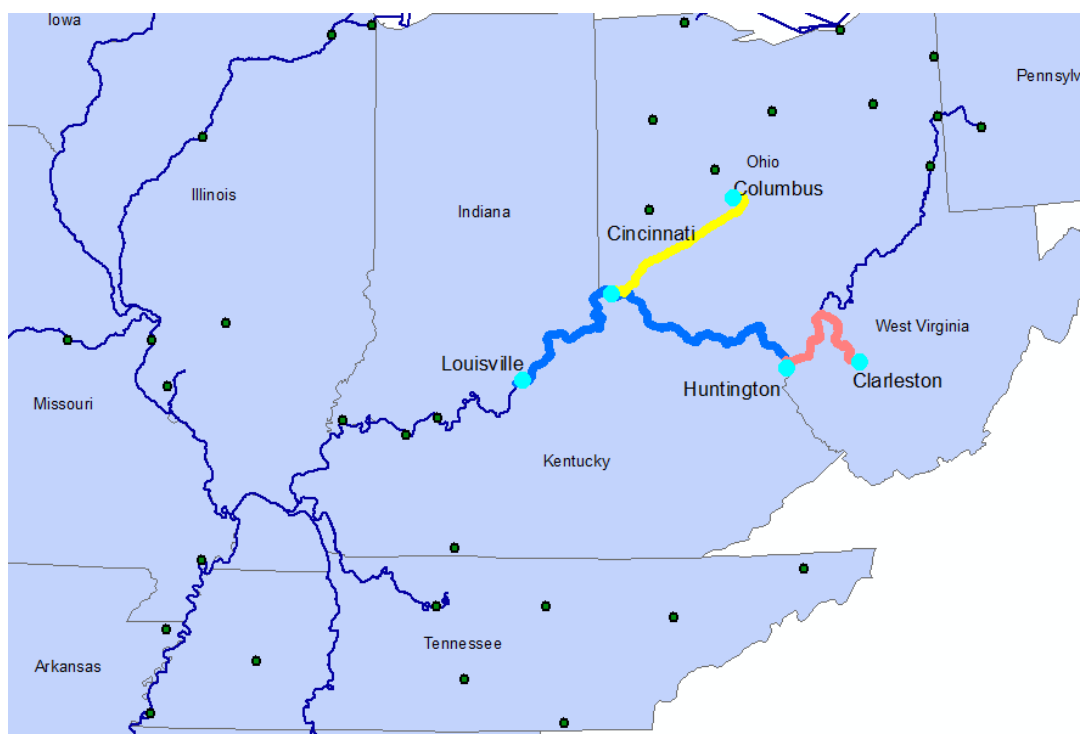

Figure 9. Model 1 optimal route snapshot 


\section{Table 7}

Model 1 optimal solution associated with Figure 9

\begin{tabular}{cccccccc}
\hline Origin & Destination & $\begin{array}{c}\text { Fixed } \\
\text { Demand } \\
\text { (Ktons) }\end{array}$ & Intermodal Node & Mode & $\begin{array}{c}\text { Value } \\
\text { (Ktons) }\end{array}$ \\
\hline \multirow{2}{*}{ x Charleston } & Louisville & $2,589.978$ & Huntington & Cincinnati & W & $2,589.98$ \\
& & & Cincinnati & Louisville & W & 2589.98 \\
& & & Columbus & Cincinnati & H & 895.51 \\
x Columbus & Louisville & 895.507 & Cincinnati & Louisville & W & 895.51 \\
& & & & & & & \\
\hline
\end{tabular}

However, the reality is that many companies may not choose the optimal route due to various reasons. Among these, time performance is a critical one. In the next section, we first use unit time penalty parameter to simulate the actual cost of carrier companies. Based on the estimated actual transportation routes, the trade-off between total costs (transportation cost and environment cost) and carbon emission is presented. When the carbon tax changes, the freight route choice and corresponding mode sharing in the intermodal system also change.

\subsubsection{Carbon Emission Tax Policy}

To find the best time penalty coefficient to simulate the real world route selection decision, we ran the optimization of Model 5 multiple times with different $\alpha$ values. As $\alpha$ changes, the model solution yields different network flows with varying transportation costs (the first term of objective (10); without time penalty cost). Figure 10 shows that increasing the $\alpha$ value will drive the solutions away from the optimal solution of Model 1 . When $\alpha$ equals to 1.65 , the resulting transportation cost is the same as the actual total cost. 
Then, the optimal solution of Model 5 with $\alpha=1.65$ is treated as the real network situation for the following tax policy analysis.

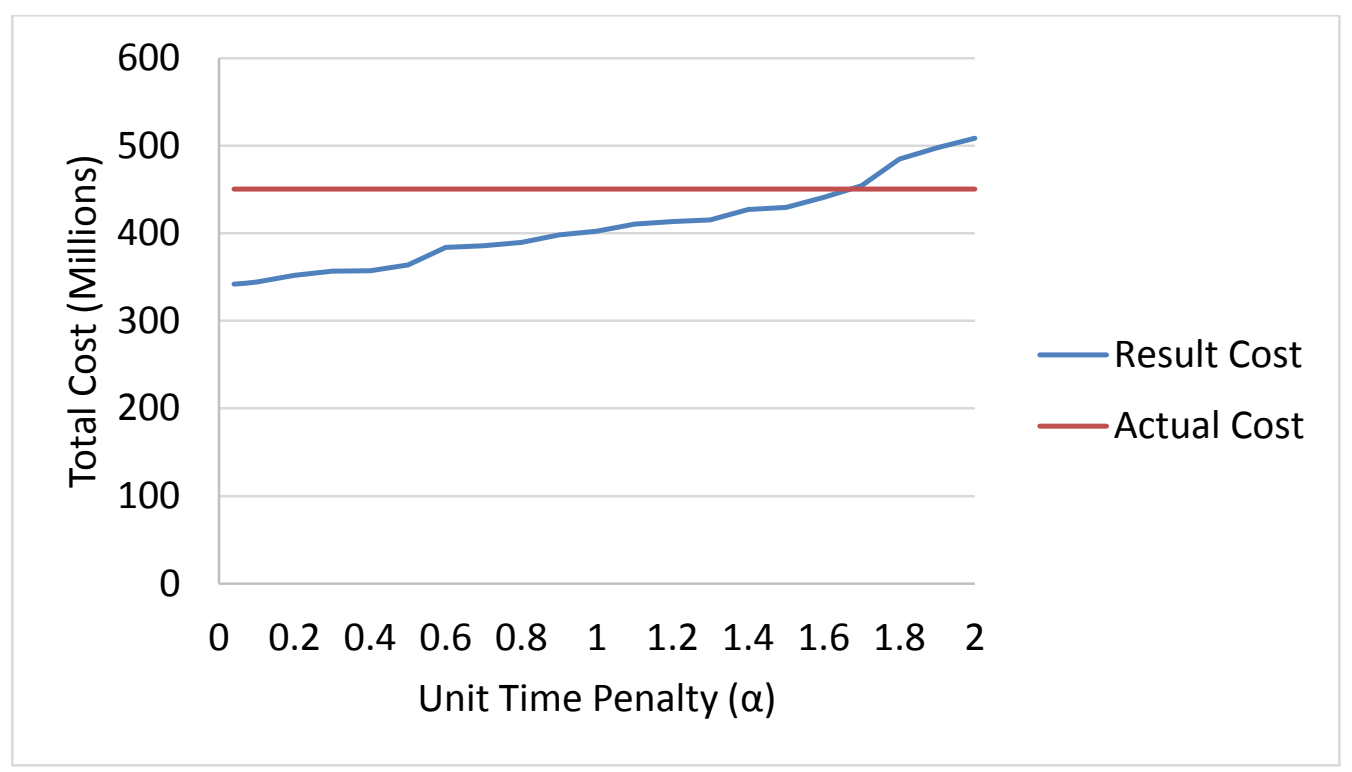

Figure 10. Unit Time Penalty Cost Estimation

\section{Table 8}

Estimation of carbon emission tax policy

\begin{tabular}{|c|c|c|c|c|c|c|c|c|}
\hline $\begin{array}{l}\text { Tax } \\
\text { (\$/ton) }\end{array}$ & $\begin{array}{l}\mathrm{TC} \\
(\mathrm{M})\end{array}$ & $\begin{array}{l}\mathrm{EC} \\
(\mathrm{M})\end{array}$ & $\begin{array}{l}\text { Time } \\
\text { Penalty } \\
\text { (M) }\end{array}$ & $\begin{array}{l}\text { Time } \\
\text { Penalty } \\
\text { Increase }\end{array}$ & $\begin{array}{l}\text { Payable } \\
\text { Cost } \\
\text { (M) }\end{array}$ & $\begin{array}{l}\text { Payable } \\
\text { Cost } \\
\text { Change }\end{array}$ & $\begin{array}{l}\text { Emission } \\
\text { (ton) }\end{array}$ & $\begin{array}{l}\text { Emission } \\
\text { Decrease }\end{array}$ \\
\hline 0 & 454.3 & 0 & 0.1 & 0 & 454.3 & 0 & 915,956 & 0 \\
\hline 1 & 442.9 & 0.9 & 0.1 & $9.9 \%$ & 443.8 & $-2.32 \%$ & 900,520 & $-1.69 \%$ \\
\hline 2 & 442.9 & 1.8 & 0.1 & $9.9 \%$ & 444.7 & $-2.12 \%$ & 900,520 & $-1.69 \%$ \\
\hline 3 & 442.9 & 2.7 & 0.1 & $9.9 \%$ & 445.6 & $-1.93 \%$ & 900,520 & $-1.69 \%$ \\
\hline 4 & 442.9 & 3.6 & 0.1 & $9.9 \%$ & 446.5 & $-1.73 \%$ & 900,520 & $-1.69 \%$ \\
\hline 5 & 442.9 & 4.5 & 0.1 & $9.9 \%$ & 447.4 & $-1.53 \%$ & 900,520 & $-1.69 \%$ \\
\hline 6 & 442.9 & 5.4 & 0.1 & $9.9 \%$ & 448.3 & $-1.33 \%$ & 900,520 & $-1.69 \%$ \\
\hline 7 & 442.9 & 6.3 & 0.1 & $9.9 \%$ & 449.2 & $-1.13 \%$ & 900,520 & $-1.69 \%$ \\
\hline 8 & 442.9 & 7.2 & 0.1 & $9.9 \%$ & 450.1 & $-0.93 \%$ & 900,520 & $-1.69 \%$ \\
\hline 9 & 442.9 & 8.1 & 0.1 & $9.9 \%$ & 451 & $-0.74 \%$ & 900,520 & $-1.69 \%$ \\
\hline 10 & 442.9 & 9 & 0.1 & $9.9 \%$ & 451.2 & $-0.54 \%$ & 900,520 & $-1.69 \%$ \\
\hline 11 & 442.9 & 9.9 & 0.1 & $9.9 \%$ & 452.8 & $-0.34 \%$ & 900,520 & $-1.69 \%$ \\
\hline 12 & 442.5 & 11 & 0.1 & $10.3 \%$ & 453.2 & $-0.23 \%$ & 899,884 & $-1.76 \%$ \\
\hline 13 & 442.5 & 12 & 0.1 & $10.3 \%$ & 454.2 & $-0.04 \%$ & 899,884 & $-1.76 \%$ \\
\hline 14 & 442.5 & 13 & 0.1 & $10.3 \%$ & 455.1 & $0.16 \%$ & 899,884 & $-1.76 \%$ \\
\hline
\end{tabular}

(TC: Transportation Cost; EC: Environmental Cost) 
Model 6 is used to estimate the trade-off between payable cost (transportation cost and environmental cost) and carbon emission. We varied the carbon tax from $\$ 0$ to $\$ 14 /$ ton based on the actual transportation route. With the introduction of carbon tax, the government can force the carriers to consider alternative transportation routes when shipping cargo.

The solutions of Model 6 with $\alpha=1.65$ and different carbon emission tax are shown in Table 8 (X. Duan and S. Heragu, 2015). The first row is the same as the optimal solution of Model 5, which is the case without carbon emission tax. As the tax $\beta$ changes, network flows are selected differently. All the percentages are calculated by comparing with the case of $\beta=0$. Due to the properties of network, network flows will not change until changes achieve a certain amount. For instance, when tax $\beta$ increases from $\$ 0$ to $\$ 1 /$ ton, there was a decrease in the overall amount of transportation cost (from $\$ 454.3$ million to $\$ 442.9$ million), payable cost (from $\$ 454.3$ million to $\$ 443.8$ million, $2.321 \%$ ) and carbon emission (from 915,956 tons to 900,520 tons, $1.685 \%$ ). Meanwhile, time penalty cost increase $9.923 \%$ compared to the base model 5 . However, when tax $\beta$ increases from $\$ 1 /$ ton to $\$ 11 /$ ton, there is no significant difference in the transportation cost and carbon emission. Until carbon tax reaches $\$ 12 /$ ton, the transportation cost continuous to decrease from $\$ 442.9$ million to $\$ 442.4$ million.

The payable cost does not exceed the current transportation cost until the carbon tax increases to $\$ 14 /$ ton. Thus, a tax of $\$ 13 /$ ton does not necessarily bring more costs to people if more routing optimization work is involved. At the same time, the carbon emission has been reduced by $1.755 \%$ directly, and government collects $\$ 11.7$ million in taxes, which again can be used for environment improvement. The only disadvantage is 
the delivery time delay of $10.29 \%$. This actually may not generate penalty cost, because an elastic margin of the delivery time in the current real case always exists. Where delivery times are important, a tax of $\$ 11 /$ ton is a policy option, which has the same time delay as the case of $\$ 1 /$ ton but would generate more tax revenue. On the other hand, if more time delay tolerance is allowed and people can accept an increase in total payable costs, the carbon tax can be more than $\$ 13 /$ ton.

\subsection{Summary}

In this chapter, we analyzed a real world intermodal network, which includes highway, railway and inland waterway and covers 15 states in the US. Current transportation pattern choice, network flows and corresponding carbon emission data are collected and reported. With the classic carbon emission function, a set of mathematical programming models are built for further analysis. Four boundary models are built to evaluate how much an extra policy can potentially improve the network flows in terms of economic and environmental costs, and motivate us to seek a policy that can improve both simultaneously. The analytical results are also demonstrated by data-based scenario analysis. An intermodal transportation model is thus built with the objective of minimizing the economic cost, time penalty and carbon emission together. The time penalty is introduced to simulate the real world group behavior through the mathematical model, and a proper penalty coefficient is found via numerical study. The sensitivity analysis of carbon emission tax policy shows that multiple taxes apply for improving the economic transportation cost and controlling the carbon emission. The breakeven point for carbon emission tax is $\$ 13 /$ ton, which can minimize environmental impact without increasing transportation costs. 


\section{CHAPTER IV}

\section{DETERMINISTIC GREEN VEHICLE ROUTING}

\subsection{Problem Statement}

In this chapter, we address the environmental issue using operations research from a operational perspective. There are many variants of vehicle routing problem: the Capacitated Vehicle Routing Problem (CVRP), Vehicle Routing Problem with Time Windows (VRPTW), Green Vehicle Routing (GVRP), and so on. In this dissertation, we

proposed a green vehicle routing problem with the objective of minimizing the fuel consumption. This problem is related with Pollution Routing Problem (PRP) which was first proposed by Bektas and Laporte (2011).

There are two types of factors that affect the cost of each route according to Bektas and Laporte (2011). The first type includes travel distance, vehicle loads, travel speed and so on. The second type of factor is related to salary of drivers, taxes and other related factors. In much of the VRP literature, the objective is to minimize travel distance which is considered the most important factor that is directly related with transportation cost. There are only a few papers on fuel consumption optimization. For example, Xiao et al. (2012) considered fuel consumption rate in the basic capacitated vehicle routing problem. However, time windows are not considered in this paper. Time planning is important according to Palmer (2007). It is pointed out that carbon emission can be reduced up to 5\% 
based on time planning. Bektas and Laporte (2011) include time windows in their PRP model. But the trade-off between environmental cost and economic cost under soft time window restriction has not been investigated until now. More importantly, travel speed is usually considered as a constant in much of the literature. However, Lin et al. (2014) highlight that impact of the speed of vehicle on emission reduction should not be ignored. Based on the real traffic condition, the vehicle can avoid congested roads. Thus, a new environmental-friendly route is generated while the total greenhouse emissions can be reduced as well. To the best of our knowledge, there is no paper concerning stochastic speed of vehicles among existing literature that is related with green vehicle routing problem.

In this chapter, we present a green vehicle routing optimization model which is an extension of the recent studies of pollution routing problem with the objective of minimizing fuel consumption. The first model is developed to determine the optimal delivery route under the given time window restriction and vehicle capacities while minimizing total carbon emission. This model extends the work of Xiao et al. (2012) by considering time window restrictions. The fuel consumption formulation is developed based on the weight of the vehicle, travel speed and distance while the speed of vehicle is not included in Xiao et al. (2012). The impact of time windows on fuel consumption is investigated by the comparison of results of sensitivity analysis experiments based on model 1 . The expected value of the travel speed is adopted in model 1 and the basic models while stochastic travel speed is considered in Chapter 5 . The trade-off between routes with the shortest distance and the least fuel consumption is investigated under three models. 
These models provide an extensive analysis between economic cost and environmental cost from an operational perspective.

\subsection{GVRP Models}

\subsubsection{Problem Formulation}

Consider a vehicle routing problem defined over a network $G=(V, A)$ where $V=$ $\{0,1,2, \ldots, n\}$ is the node set, 0 is the depot and $A=\{(i, j): i, j \in V, i \neq j\}$ is the set of arcs. We consider a set of vehicles, each of which has certain capacity limitation. Each customer has different demands and specified time windows that need to be satisfied. If a vehicle does not arrive within the time window as a customer requested, a penalty cost is incurred.

Parameters and Notations:

$d_{i j}$ is the distance from node $i$ to node $j$,

$V_{i j}$ is the speed limit of traveling from node $i$ to node $j$,

$q_{i}$ is the demand of node $i$,

$t s_{i}$ is the service time spent at node $i$,

$T_{i}$ is the desired time of arrival at node $i$ (Note that the starting time at the depot is

0),

$N$ is the number of vehicles (trucks),

$C_{0}$ is the weight of an empty vehicle,

$C$ is the weight capacity of a vehicle,

$f\left(d_{i j}, y_{i j}, v_{i j}\right)$ is the carbon emission formula, the fuel consumption is assumed to be proportional to carbon emission,

The parameters for emission function is:

$E_{i j}^{h o t}$ is the emission produced when the engine is hot from node $i$ to node $j$, 
$\varepsilon_{i j}$ is load correction factor function from node $i$ to node $j$,

$E_{i j}^{\text {start }}$ is the emission when the engine is cold from node $i$ to node $j$,

$\omega_{i j}$ is the reference excess emission from node $i$ to node $j$ (at $20^{\circ} \mathrm{C}$ and $20 \mathrm{~km} / \mathrm{h}$ ),

$\mathrm{T}_{i j}$ is the temperature $\left({ }^{\circ} \mathrm{C}\right)$,

$g_{i j}\left(\mathrm{~T}_{i j}\right)$ is the temperature function,

$h_{i j}\left(\mathrm{~d}_{i j}\right)$ is the distance function,

Decision variables:

$x_{i j}$ is a binary variable indicating whether or not the arc from node $i$ to node $j$ is selected,

$y_{i j}$ is the total weight of a vehicle when it travels from node $i$ to node $j$,

$v_{i j}$ is the travel speed from node $i$ to node $j$,

$t_{i}$ is the arrival time at node $i$.

\section{Model 1}

Min

$\sum_{i} \sum_{j} x_{i j} f\left(d_{i j}, y_{i j}, v_{i j}\right)$

S.T.

$\sum_{j=0, j \neq i}^{n} x_{i j}=1, \forall i=1, \ldots, n$

$\sum_{j=1}^{n} x_{0 j} \leq N$

$\sum_{j=0, j \neq i}^{n} x_{i j}-\sum_{j=0, j \neq i}^{n} x_{j i}=0, \forall i=0, \ldots, n$

$\sum_{j=0, j \neq i}^{n} y_{j i}-\sum_{j=0, j \neq i}^{n} y_{i j}=q_{i}, \forall i=1, \ldots, n$

$y_{i j} \leq\left(C_{0}+\mathrm{C}\right) x_{i j}, \forall i, j=0, \ldots, n,(i \neq j)$

$y_{i j} \geq C_{0} x_{i j}, \forall i, j=0, \ldots, n,(i \neq j)$ 


$$
\begin{aligned}
& t_{i}+t s_{i}+\frac{d_{i j}}{v_{i j}}-t_{j} \leq M\left(1-x_{i j}\right), \forall i=0, \ldots, n, j=1, \ldots, n,(i \neq j) \\
& t_{0}=0 \\
& 0 \leq t_{i} \leq T_{i}, \forall i=1, \ldots, n \\
& 0 \leq v_{i j} \leq V_{i j}, \forall i, j=0, \ldots, n,(i \neq j) \\
& x_{i j} \in\{0,1\}, \forall i, j=0, \ldots, n
\end{aligned}
$$

where $M$ is a large constant.

The objective of this model is to minimize carbon emission. Constraints (1), (2) and (3) are classical VRP constraints, which guarantees all tours start from and end at the depot. Constraint (4) ensures the demand flow is balanced at each customer node. The loaded truck weight has a range as restricted in constraints (5) and (6), according to the vehicle capacity and empty vehicle weight. Constraint (7) enforces the time window restriction. Constraint (8) models the arriving time at each node with 0 as the starting time at the depot. The position of $v_{i j}$ in the objective (the carbon emission formula) and constraint (7) lead this model to be nonlinear. The nonlinearity in the objective depends on the carbon emission formula.

\section{Basic Model 1: Minimize Carbon Emission}

Min

$\sum_{i} \sum_{j} x_{i j} f\left(d_{i j}, y_{i j}, v_{i j}\right)$

S.T. Constraints (1) - (6) and (11)

Where the decision variables are: $x_{i j}, y_{i j}$

\section{Basic Model 2: Minimize Travel Distance}

Min

$\sum_{i} \sum_{j} x_{i j} d_{i j}$ 
S.T. Constraints (1) - (6) and (11)

\subsubsection{Carbon Emission Estimation}

Fuel consumption and carbon emission for each vehicle depends on several factors:

load, travel speed, travel distance. Fuel consumption is assumed to be proportional to carbon emission.

As in Chapter 3, we assume the vehicle type is diesel truck without catalysts and its workload is around 25 tons. Also, the temperature is assumed to be $25^{\circ} \mathrm{C}$. The carbon emission can be calculated as follows:

$$
\begin{aligned}
& E_{i j}^{h o t}=765-7.04 \mathrm{v}_{i j}+0.000632 \mathrm{v}_{i j}^{3}+\frac{8334}{\mathrm{v}_{i j}} \\
& \varepsilon_{i j}=1.27-\frac{0.483}{\mathrm{v}_{i j}} \\
& E_{i j}^{\text {start }}=\omega_{i j} \times\left(f\left(\mathrm{v}_{i j}\right)+g\left(\mathrm{~T}_{i j}\right)-1\right) \times h\left(\mathrm{~d}_{i j}\right)
\end{aligned}
$$

Where

$$
\begin{aligned}
& \omega_{i j}=182.57 \\
& f\left(\mathrm{v}_{i j}\right)=1 \\
& g\left(\mathrm{~T}_{i j}\right)=-0.0458 \mathrm{~T}_{i j}+1.9163=-0.0458 * 25+1.9163=0.7713 \\
& h\left(\mathrm{~d}_{i j}\right)=\frac{1-e^{-\frac{3.95 \mathrm{~d}_{i j}}{0.24 * \mathrm{v}_{i j}+0.09}}}{1-e^{-3.95}}
\end{aligned}
$$

The starting emission, which is the emission when the vehicle engine is cold, only happens at the beginning of a trip. For a routing problem, it becomes constant regardless of the route options. Thus, we only consider the running emission $E_{i j}^{\text {hot }}$ in the objective of a vehicle routing formulation. 


$$
\begin{aligned}
f_{i j}=E_{i j}^{h o t} & \varepsilon_{\mathrm{ij}} N_{i j} D_{i j} \\
& =\left(765-7.04 \mathrm{v}_{i j}+0.000632 \mathrm{v}_{i j}^{3}+\frac{8334}{\mathrm{v}_{i j}}\right)\left(1.27-\frac{0.483}{\mathrm{v}_{i j}}\right) * y_{i j} * d_{i j}
\end{aligned}
$$

\subsection{Solution Approach}

Because the objective function is a nonlinear function based on distance, travel speed and vehicle load, this problem becomes one of a class of challenging optimization problems, as it involves optimization of nonlinear functions along with integer variables. According to Bonami et al. (2012), a mixed integer nonlinear problem (MINLP) is an NPHard problem. Even if we restrict our model to have only nonlinear functions without integer variables, most nonlinear problems (NLP) are also known to be NP-hard (B. Murtagh and M. Saunders, 1993). To solve the problem, it is important to investigate the convexity of the nonlinear problem. In particular, it is necessary to find the conditions under which the carbon emission function is convex.

\subsubsection{Convexity Analysis}

To analyze the convexity of the nonlinear problem, we calculate the derivative of the objective function. First, it is clearly to understand the linearity on $y_{i j}$ and $d_{i j}$, respectively. Then, we only need to consider $f_{i j}\left(\mathrm{v}_{i j}\right)$. The plot of $f$ is shown in Figure 11.

$$
f_{i j}\left(\mathrm{v}_{i j}\right)=\left(765-7.04 \mathrm{v}_{i j}+0.000632 \mathrm{v}_{i j}^{3}+\frac{8334}{\mathrm{v}_{i j}}\right)\left(1.27-\frac{0.483}{\mathrm{v}_{i j}}\right)
$$




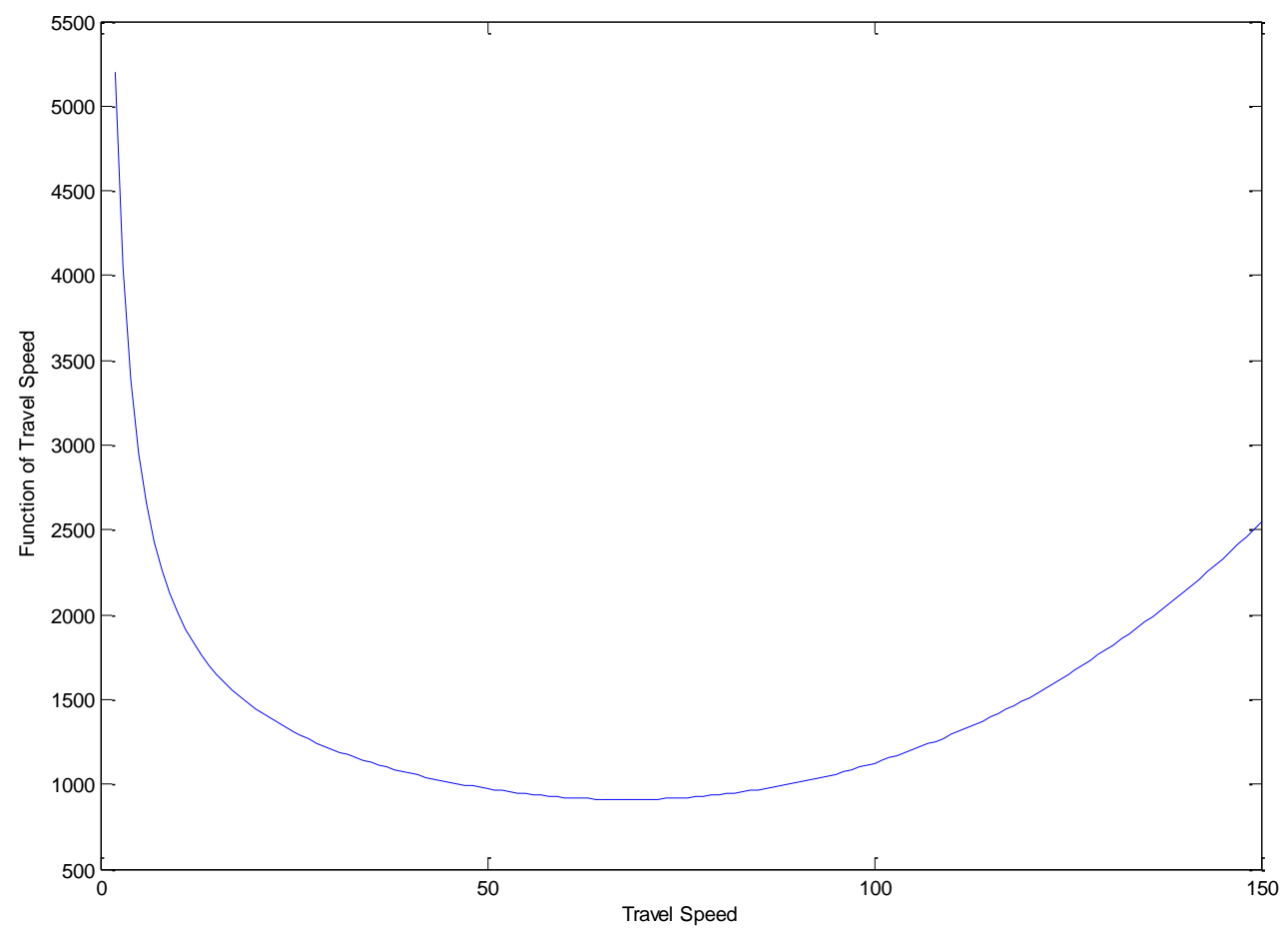

Figure 11. Plot of function of travel speed

The first derivative is:

$$
\begin{aligned}
\frac{\partial f}{\partial v}=-8.9408 & +\frac{8050.64}{v^{3}}+0.00240792 v^{2}-\frac{10214.7}{v^{2}}-0.000610512 v \\
& +\frac{4.44089 \times 10^{-16}}{v}
\end{aligned}
$$

The second derivative is:

$h=\frac{\partial^{2} f}{\partial v \partial v}=-0.000610512-\frac{24151.9}{v^{4}}+\frac{20429.4}{v^{3}}-\frac{4.44089 \times 10^{-16}}{v^{2}}+0.00481584 v$

It can be calculated that, $\frac{\partial^{2} f}{\partial v \partial v}>0$ when $v>1.18221$. Note, the emission formula $E_{i j}^{h o t}$ is an experimental formula which is meaningful only for certain practically reasonable speed range. And, $1.18221 \mathrm{mph}$ is a value small enough to be a reasonable lower bound of the practical speed range. In summary, the emission objective function is convex within the 
practically reasonable speed range, i.e. when $v>1.18221$. Moreover, the plot of second derivative of $f$ is shown below.

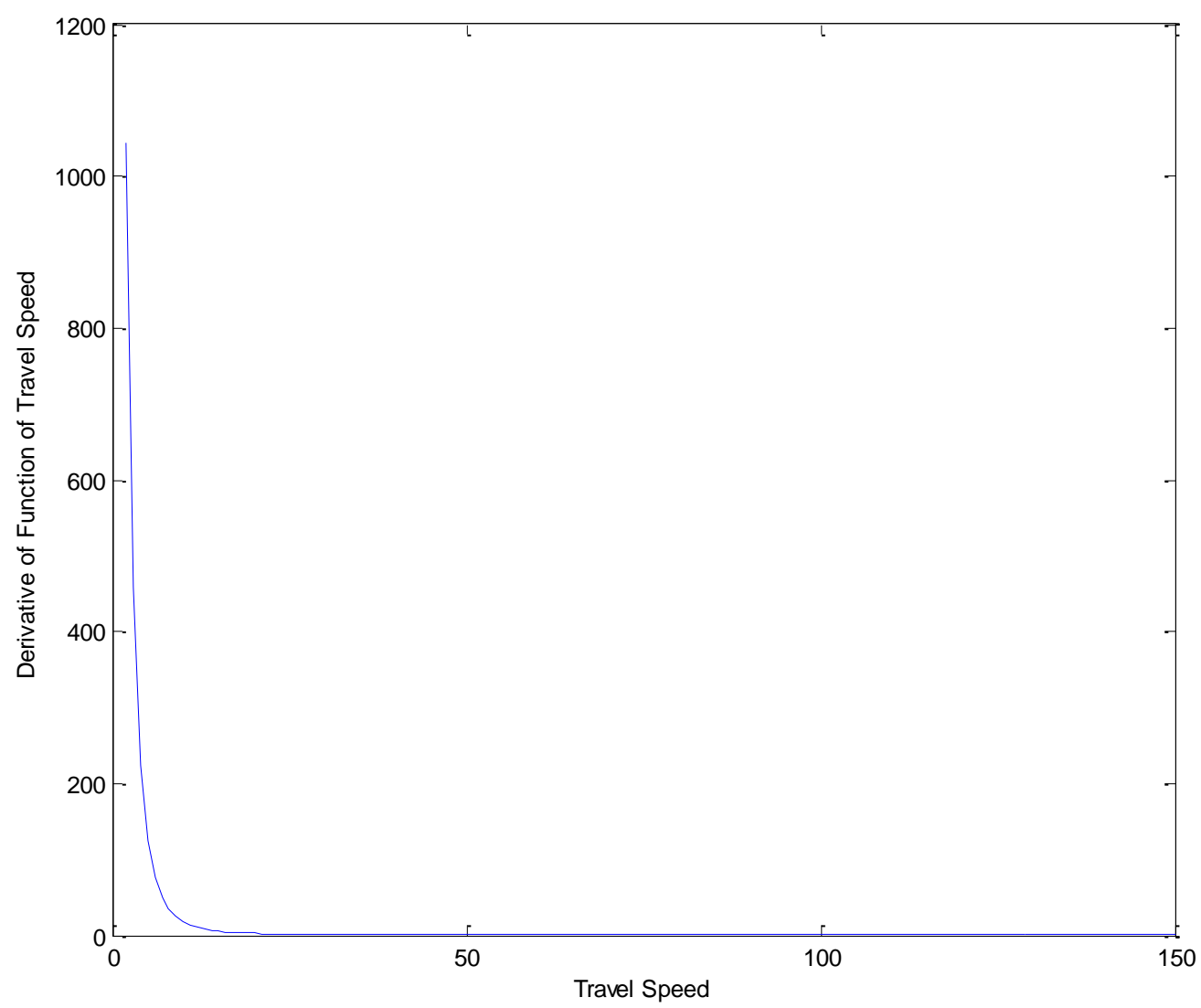

Figure 12. Plot of derivative of function $f$

According to Figure 12, the second derivative of $f$ is non-negative when $v \in$ $(1.18221, \infty)$. In addition, the second derivative of $f$ is always non-negative regardless of the value of $d$ and $y$. Thus, it can be proved that $f$ is convex when travel speed is greater than 1.18221 kilometers/hour because we do not consider the condition that $v$ is less than 1.18221 kilometers/hour. Because $y$ is non-decreasing, according to the properties of convex function, the objective function is convex on $y \in(0, \infty), d \in(0, \infty)$ and $v \in$ $(1.18221, \infty)$ 


\subsubsection{Heuristic Algorithms for Large Scale Optimization Problems}

In this section, we develop an algorithm to solve the deterministic green vehicle routing problem. The complicating factor in the solution procedure is the variability in the travel speed. To improve the route, we have to check the capacity constraint and time window constraint first. However, the time window constraint depends upon the travel speed. At that point, we have to assign a proper value to travel speed. Heuristics that are used to solve the classical VRP cannot be directly applied for our problem. We therefore solve the problem by ordering the arc based on the product of the weight and distance. The reason is that carbon emission formulation depends largely on weight multiplied by distance. Then we assign value to travel speed on the arc with largest product of weight and distance until the time window constraint is not satisfied.

The initial route is generated based on a savings heuristic. The first part of this algorithm is to generate an initial solution based on the Clarke and Wright savings algorithm (Clarke and Wright, 1964) with additional restriction of time window and capacity constraints. In the traditional savings algorithm, the savings are calculated based on distance and time. In this paper, we calculate the savings based on fuel consumption and carbon emission. The second part of the algorithm is to improve the initial solution using Tabu search.

The algorithm for initial solution is shown below:

1. Set $v i j=v i j *($ maximum speed on that road $)$

2. Calculate the saving for each pair $(i, j)$ of demand points:

$$
s(i, j)=f(d(D, i), v(D, i), y(D, i))+f(d(D, j), v(D, j), y(D, j))-f(d(i,
$$

$j), v(i, j), y(i, j))$ 
3. Rank savings in the descending order of magnitude to create a "savings list." Repeat step 4 for each saving $s(i, j)$ in the list, beginning with the largest one.

4. If no constraint is violated by including $(i, j)$ in a route, and

(a) If neither $i$ nor $j$ is contained by any existing route, a new route is created with link $(i, j)$ as the initial arc;

(b) If one and only one of these two points, $i$ or $j$, is contained by an existing route and the visiting order from the depot in the route is the same as the order of traversal of points, link $(i, j)$ is added to the corresponding route.

(c) If both $i$ and $j$ are contained by two different existing routes and the visiting order from the depot in the route is the same as the order of traversal of points, these two routes are merged with link $(i, j)$.

5. After the savings list of $s(i, j)$ has been exhausted through steps 3 and 4 , each point that has not been assigned creates a single route that starts from the depot and visits the particular unassigned point and finally ends at the depot.

6. A solution of the VRP consists of the routes created in steps 3-5. Based on this solution, calculate $f(d(i, j), v(i, j), y(i, j))=\min (f n(d(i, j), v n(i, j), y(i, j)), n=$ $1 \ldots n)$ for each arc.

In the second stage, we use a Tabu search algorithm to improve the route. The 2opt algorithm is used to generate the neighborhoods. For each iteration, Tabu search moves to the best neighbor. The evaluation criterion is based on the objective function (the total carbon emission). The improvement algorithm is illustrated in Figure 13 and explained next. 
1. Initialize parameters, i.e., initial tour, incumbent cost, current cost, Tabu list, maximum saving, maximum move. The initial tour is generated based on the savings algorithm. The current cost is calculated based on the initial tour.

2. Generate a route using 2-opt algorithm based on the initial tour.

3. Calculate weight of loaded vehicle for each arc on the initial route.

4. If the capacity constraint is satisfied, go to step 5. Otherwise, go to step 2.

5. Set the travel speed equal to the travel speed limit. If the time window constraint is satisfied, go to step 6. Otherwise, go to step 2.

6. Rank the arcs in the route under consideration in descending order of the product of weight and distance. Save each arc in weight*distance list based on that order.

7. Choose a proper speed for an arc starting from the largest weight multiply by distance. The evaluation criteria for choosing a proper speed is the objective function (choosing a speed with smallest carbon emission). Assign the chosen speed to that arc.

8. If the time window constraint is satisfied, delete the arc from the weight*distance list and go to step 7. Otherwise, set the travel speed of the latest chosen arc equal to the travel speed limit and go to step 9.

9. Calculate the cost of the route. If the current move is not in the Tabu list and current cost minus neighbor cost is greater than the maximum savings, set the maximum savings equal to the current cost minus the neighbor cost. Record that move as the maximum move and record the neighbor route as the new tour. If the current move is in the Tabu list, set the maximum savings equal to the current cost minus neighbor cost if neighbor cost is less than incumbent cost and the current cost minus neighbor cost is greater 
than the maximum savings. Record that move as the maximum move and record the neighbor route as the new tour. Go to step 2 until 2-opt algorithm is terminated.

10. Set the final new tour as the current route and the current cost minus the maximum savings as the current cost. Add the maximum move into the Tabu list. If the current cost is less than incumbent cost, set the incumbent cost equal to the current cost and let the incumbent tour equal to the current tour.

11. Repeat this algorithm until CPU time exceeds a preset threshold. 


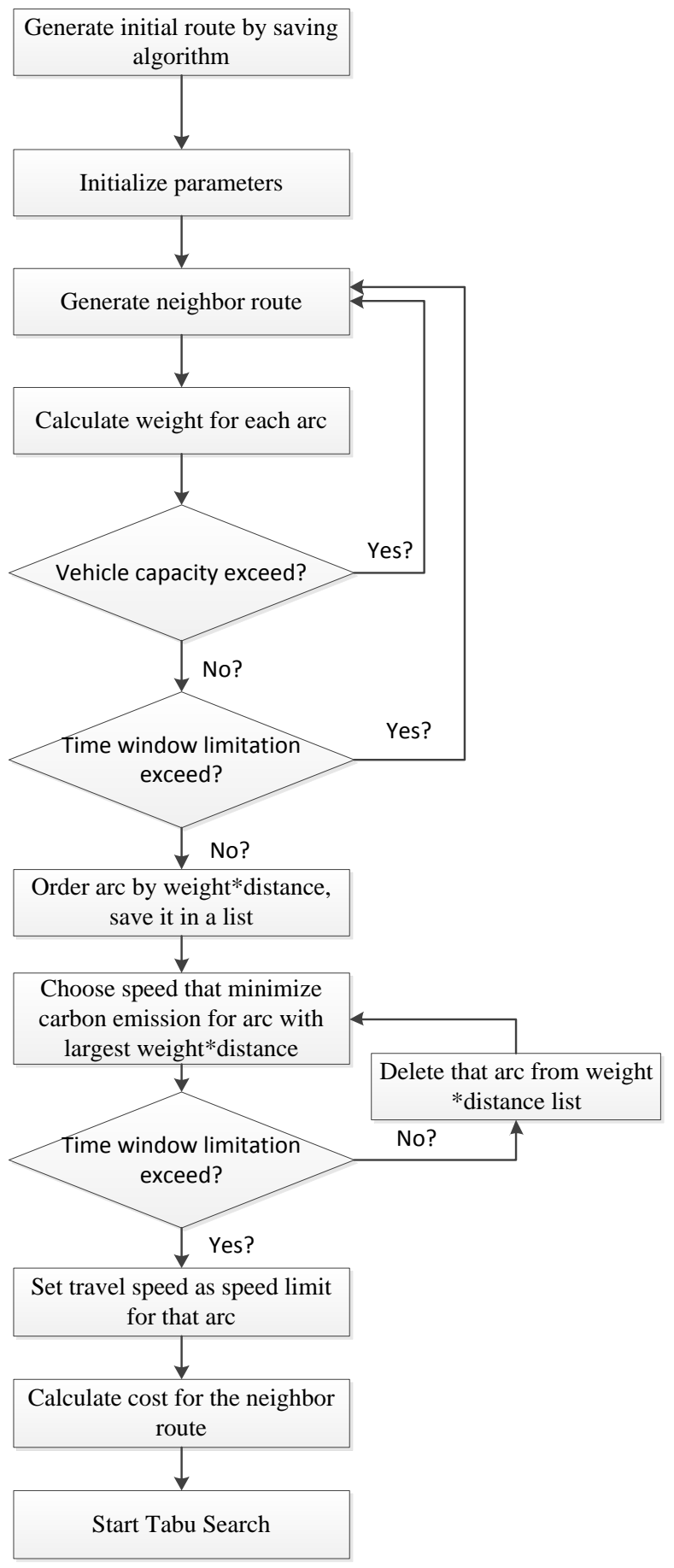

Figure 13. Algorithm for G-VRP

To investigate the quality of the solution obtained from our heuristic algorithm, we also solve our problem using GAMS. The solver that is used to solve MINLP in GAMS is BONMIIN (Basic Open-source Nonlinear Mixed Integer Programming), which is an open 
source solver that is used to solve mixed integer nonlinear program problems. The BONMIIN was developed by Carnegie Mellon University and IBM Research (Rosenthal, R. E., 2004). It implements branch-and-bound, branch-and-cut, and outer approximation algorithms. The default algorithm is branch-and-bound.

\subsection{Computational Study and Sensitivity Analysis}

This section presents the results of numerical experiments designed to assess the performance of our proposed heuristics by comparing them with solutions obtained by GAMS on randomly generated small problem instances. First, we describe the parameters used in the proposed methods and the generation of the test instances. Then, the computational results are presented to compare the quality of the solution obtained by our proposed heuristic and GAMS. At the end of this section, a real world case is introduced and sensitivity analysis of the impact of time window constraints, travel speed, speed limit on the solution are conducted based on the real world case.

Analyses are carried out with real world cases based on two basic models. In one of them, the travel speed is fixed and in the other, there is no time window constraint. Further analyses are conducted to study the impact of different parameters based on the proposed model where travel speed is considered as variable and time window constraint is included.

All experiments are performed on a processor with $2.67 \mathrm{GHz}$ speed and 4GB RAM. CPLEX 12.0 with default settings is used to solve the basic models with deterministic travel speed. GAMS win64 24.3.1 is used to solve Model1. All algorithms are coded in C\#. 


\subsubsection{Parameter Setting}

For the experiments, test instances are generated based on the consideration of the impact of the time window constraint and the travel speed limit. Six sets of ten instances each are generated which result in a total of 60 instances. We use seven nodes which represent randomly selected depot and customers in the US. The location information which includes longitude and latitude is randomly generated based on a uniform distribution. The road distance is obtained based on the longitude and latitude of each node. The weight of the empty vehicle is set to 6,000 lb. The capacity of each vehicle is set to 4,259 $\mathrm{lb}$. The service time at each node is assumed to be 2 hours for each node. The demand of each customer is randomly generated between 0 and 1,000 $1 \mathrm{~b}$ according to a uniform distribution. We consider three types of time window constraints in this experiment: no time window, loose time window and tight time window. To explore the impact of travel speed limit on the heuristic algorithm, we consider two types of speed limit. The first speed limit is set according to the actual speed limit. The second type of speed limit is generated randomly between 10 miles/hour and 70 miles/hour. Thus, there are six general scenario categories in our experiment. The small instance general structure is shown in Table 9. This table presents the lower bound and upper bound of time windows and the type of speed limit for each scenario. The proposed algorithm was implemented in C\#. We ran the algorithm 100 times with 1,000 iterations for each instance. The solver used in GAMS is BONMIN. The parameters that used in the experiments are given in Table 10 . 


\section{Table 9}

$\underline{\text { Small instance general structure }}$

\begin{tabular}{cccc}
\hline \multirow{2}{*}{ Scenario } & \multicolumn{2}{c}{ Time window (hours) } & Speed Limit \\
\cline { 2 - 3 } & Lower Bound & Upper Bound & \\
S1 & 0 & $600-900$ & Maximum \\
S2 & 0 & $6-48$ & Maximum \\
S3 & 0 & $3-36$ & Maximum \\
S4 & 0 & $600-900$ & Random \\
S5 & 0 & $6-48$ & Random \\
S6 & 0 & $3-36$ & Random \\
\hline
\end{tabular}

\section{Table 10}

Parameter setting

\begin{tabular}{ccc}
\hline & & Typical \\
Notation & Description & Values \\
\hline $\mathrm{C}$ & Capacity Vehicle (lb) & 6,000 \\
$\mathrm{~N}$ & Vehicle Number & 5 \\
$C_{0}$ & Capacity of Empty Vehicle (lb) & 4,259 \\
& The reference excess emission (at $20^{\circ} \mathrm{C}$ and 20 & \\
$\mathrm{~T}$ & $\mathrm{~km} / \mathrm{h})$ & 182.57 \\
\hline
\end{tabular}

\subsubsection{Heuristic Performance}

This section presents the performance of the deterministic vehicle routing problem using our heuristic algorithm. Computational experiments are conducted to compare the quality of solutions obtained by our proposed heuristic algorithm with the solutions obtained through commercial software GAMS. The computational results are shown in Table 11-15. We compared three measures of the solution quality obtained by GAMS with BONMIN solver, revised savings algorithm and improved Tabu search. In these tables, the objective function value and average running time (in seconds) that is required to solve all instances of each set are summarized. We also listed the differences between the revised savings algorithm, improved Tabu search and GAMS respectively. The initial solution 
obtained by the revised savings algorithm and the improved solution obtained by the improved Tabu Search are compared with GAMS via absolute percent error. In some scenarios, especially cases with tight time window constraint, there is no feasible solution. We only present results with feasible solution in these tables.

\section{Table 11}

$\underline{\text { Heuristic performance for a tight time window with maximum speed limit }}$

\begin{tabular}{cccccccccc}
\hline & \multicolumn{3}{c}{ GAMS } & \multicolumn{3}{c}{$\begin{array}{c}\text { Revised Saving } \\
\text { Algorithm }\end{array}$} & \multicolumn{3}{c}{ Improved Tabu Search } \\
\cline { 2 - 10 } Node & \multicolumn{2}{c}{ Obj. } & $\begin{array}{c}\text { Run } \\
\text { Time }\end{array}$ & Obj. & Diff. & $\begin{array}{c}\text { Run } \\
\text { Time }\end{array}$ & Obj. & Diff. & $\begin{array}{c}\text { Run } \\
\text { Time }\end{array}$ \\
\hline & & & & & & & & \\
1 & $16,611.8$ & $1,002.1$ & $17,729.2$ & 6.7 & 0 & $14,947.9$ & - & 10.0 & 8.5 \\
2 & $10,615.7$ & 90.5 & $11,174.8$ & 5.3 & 0 & $10,547.6$ & -0.6 & 24 \\
3 & $11,259.0$ & 196.6 & $16,894.1$ & 50.1 & 0 & $11,014.8$ & -2.2 & 20 \\
4 & $10,561.9$ & 123.3 & $12,204.1$ & 15.6 & 0 & $10,445.4$ & -1.1 & 9.8 \\
5 & $15,398.1$ & 100.0 & $19,056.2$ & 23.8 & 0 & $16,065.6$ & 4.3 & 2.3 \\
6 & $11,701.3$ & 151.6 & $14,655.0$ & 25.2 & 0 & $11,726.1$ & 0.2 & 3.3 \\
7 & $17,137.7$ & 460.1 & $18,913.3$ & 10.4 & 0 & $17,549.8$ & 2.4 & 8.4 \\
8 & $14,420.5$ & 144.0 & $17,282.5$ & 19.9 & 0 & $14,420.6$ & 0.0 & 7.4 \\
9 & $12,819.6$ & 207.9 & $15,137.2$ & 18.1 & 0 & $12,074.5$ & -5.8 & 19 \\
10 & $12,520.5$ & 241.3 & $14,570.6$ & 16.4 & 0 & $12,457.8$ & -0.5 & 11 \\
\hline Avg. & & 271.7 & & 19.1 & & & -1.3 & 11.4 \\
\hline
\end{tabular}

\section{Table 12}

Heuristic performance for a loose time window with maximum speed limit

\begin{tabular}{|c|c|c|c|c|c|c|c|c|}
\hline \multirow{2}{*}{ Node } & \multicolumn{2}{|c|}{ GAMS } & \multicolumn{3}{|c|}{$\begin{array}{l}\text { Revised Saving } \\
\text { Algorithm }\end{array}$} & \multicolumn{3}{|c|}{ Improved Tabu Search } \\
\hline & Obj. & $\begin{array}{l}\text { Run } \\
\text { Time }\end{array}$ & Obj. & Diff. & $\begin{array}{l}\text { Run } \\
\text { Time }\end{array}$ & Obj. & Diff. & $\begin{array}{l}\text { Run } \\
\text { Time }\end{array}$ \\
\hline 1 & $20,239.2$ & $1,001.0$ & $16,633.8$ & -17.8 & 0 & $14,514.5$ & -28.3 & 3.7 \\
\hline 2 & N/A & $2,304.1$ & $13,588.4$ & N/A & 0 & $13,588.4$ & N/A & 0.0 \\
\hline 3 & $11,138.7$ & 100.9 & $12,638.7$ & 13.5 & 0 & $11,935.3$ & 7.2 & 5.1 \\
\hline 4 & $11,483.1$ & 123.8 & $12,469.4$ & 8.6 & 0 & $11,477.4$ & -0.1 & 21.1 \\
\hline 5 & $13,384.4$ & $1,006.5$ & $12,798.0$ & -4.4 & 0 & $12,410.8$ & -7.3 & 3.5 \\
\hline 6 & $10,679.3$ & 203.3 & $12,569.9$ & 17.7 & 0 & $10,598.0$ & -0.8 & 11.9 \\
\hline 7 & $15,731.1$ & $1,005.0$ & $16,642.3$ & 5.8 & 0 & $15,654.0$ & -0.5 & 4.8 \\
\hline 8 & $31,610.8$ & $1,034.4$ & $17,400.2$ & -45.0 & 0 & $16,102.3$ & -49.1 & 6.5 \\
\hline
\end{tabular}




\begin{tabular}{ccccccccc}
9 & $16,217.1$ & 263.0 & $17,246.5$ & 6.4 & 0 & $16,472.0$ & 1.6 & 6.6 \\
10 & $9,282.3$ & 340.0 & $11,042.8$ & 19.0 & 0 & $9,282.3$ & 0.0 & 6.4 \\
11 & $13,163.4$ & 55.8 & $15,561.1$ & 18.2 & 0 & $13,106.9$ & -0.4 & 4.9 \\
\hline Avg. & & 676.2 & & 2.2 & & & -7.8 & 6.8 \\
\hline
\end{tabular}

\section{Table 13}

Heuristic performance for no time window with maximum speed limit

\begin{tabular}{|c|c|c|c|c|c|c|c|c|}
\hline \multirow{2}{*}{ Node } & \multicolumn{2}{|c|}{ GAMS } & \multicolumn{3}{|c|}{$\begin{array}{l}\text { Revised Saving } \\
\text { Algorithm }\end{array}$} & \multicolumn{3}{|c|}{ Improved Tabu Search } \\
\hline & Obj. & $\begin{array}{l}\text { Run } \\
\text { Time }\end{array}$ & Obj. & Diff. & $\begin{array}{l}\text { Run } \\
\text { Time }\end{array}$ & Obj. & Diff. & $\begin{array}{l}\text { Run } \\
\text { Time }\end{array}$ \\
\hline 1 & $13,205.6$ & 56.6 & $16,899.2$ & 8.0 & 0 & $13,205.6$ & 0 & 29.9 \\
\hline 2 & 8,19 & 72.9 & $10,205.7$ & 24.6 & 2 & 8 & & 20.8 \\
\hline 3 & $11,153.3$ & 39.9 & $11,985.9$ & 7.5 & 0 & & 0 & 15.8 \\
\hline 4 & & 8 & 14,28 & 24.4 & 0 & & & 20.1 \\
\hline 5 & $12,44 \varepsilon$ & 59 & $17,823.3$ & 43.2 & 0 & 12 , & & 19.9 \\
\hline 6 & $10,509.4$ & 49.5 & $12,052.2$ & 14.7 & 0 & $10,286.7$ & 0 & 24.3 \\
\hline 7 & $12,560.8$ & 223.7 & $13,386.9$ & 6.6 & 0 & $12,560.8$ & 0 & 38.8 \\
\hline 8 & $13,327.6$ & 87 & $14,187.2$ & 6.5 & 0 & $14,074.7$ & 0 & 33.9 \\
\hline 9 & & & & 7.6 & . & & & 26.8 \\
\hline 10 & $13,937.1$ & 125.8 & $14,689.8$ & 5.4 & 0 & 13,4 & U & 15.7 \\
\hline Avg. & & 86.4 & & 16.8 & & & 0.0 & 24.6 \\
\hline
\end{tabular}

Tables 11, 12 and 13 show the scenarios of combination of maximum speed limit and tight time window, loose time window, no time window constraints respectively. It is noted that the performance of the improved Tabu Search is better than GAMS in all instances, on average with gap of $7.76 \%, 1.33 \%, 0.00 \%$. The difference of the three scenarios listed in Table 11-13 is that $\mathrm{S} 1$ problems have a tight time window, $\mathrm{S} 2$ problems have a loose time window while $\mathrm{S} 3$ problem have no time window. For scenarios with tight time windows, the improved heuristic performs best with the average reduction of $7.76 \%$. For scenarios with loose time windows and no time windows, the performance of improved Tabu search and GAMS are almost same. For the cases that GAMS cannot find the feasible solution which are not shown in these tables, the proposed heuristic also performs well. In 
general, the revised savings algorithm performs worse than both GAMS and improved Tabu search. As we can see from Tables 11-13, the revised saving algorithm is faster than GAMS and improved Tabu search. The improved Tabu search has the second best performance in terms of running times. Tables 11-13 also reveal that CPU time for GAMS is almost 10 times as the improved Tabu Search. Scenario 4 is not shown here because GAMS did not provide a feasible solution in any of the cases.

\section{Table 14}

Heuristic performance for loose time window with random speed limit

\begin{tabular}{|c|c|c|c|c|c|c|c|c|}
\hline \multirow{2}{*}{ Node } & \multicolumn{2}{|c|}{ GAMS } & \multicolumn{3}{|c|}{$\begin{array}{c}\text { Revised Saving } \\
\text { Algorithm }\end{array}$} & \multicolumn{3}{|c|}{ Improved Tabu Search } \\
\hline & Obj. & $\begin{array}{l}\text { Run } \\
\text { Time }\end{array}$ & Obj. & Diff. & $\begin{array}{l}\text { Run } \\
\text { Time }\end{array}$ & Obj. & Diff. & $\begin{array}{l}\text { Run } \\
\text { Time }\end{array}$ \\
\hline 1 & $16,573.7$ & 83.7 & $17,149.2$ & 3.5 & 0 & $16,570.0$ & 0 & 3.2 \\
\hline 2 & $12,058.4$ & 672.1 & $12,463.4$ & 3.4 & 0 & $12,038.7$ & 0 & 2.4 \\
\hline 3 & $14,111.9$ & 913.5 & $14,272.9$ & 1.1 & 0 & $13,882.3$ & 0 & 4.9 \\
\hline 4 & $12,130.2$ & 53.5 & $16,018.0$ & 32.1 & 0 & 11,6 & 0 & 6.7 \\
\hline 5 & $12,994.4$ & 200.0 & $13,801.7$ & 6.2 & 0 & 12 , & 0 & 8.3 \\
\hline 6 & $14,137.7$ & 918.7 & $16,561.2$ & 17.1 & 0 & $14,183.2$ & 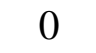 & 6.7 \\
\hline 7 & $12,399.1$ & 126.7 & $14,310.4$ & 15.4 & 0 & $13,166.1$ & 0 & 9.4 \\
\hline 8 & $10,736.1$ & 121.8 & $13,702.0$ & 27.6 & 0 & $10,736.1$ & 0 & 9.2 \\
\hline 9 & $12,035.8$ & 108.5 & $12,924.7$ & 7.4 & 0 & $11,606.0$ & 0 & 3.7 \\
\hline 10 & $10,236.8$ & 38.6 & $11,186.9$ & 9.3 & 0 & $10,558.9$ & 0 & 6.4 \\
\hline Avg. & & 323.7 & & 12.3 & & & 0 & 6.1 \\
\hline
\end{tabular}

\section{Table 15}

Heuristic performance for no time window with random speed limit

\begin{tabular}{ccrccccccr}
\hline & \multicolumn{2}{c}{ GAMS } & \multicolumn{3}{c}{$\begin{array}{c}\text { Revised Saving } \\
\text { Algorithm }\end{array}$} & \multicolumn{3}{c}{ Improved Tabu Search } \\
\cline { 2 - 9 } Node & \multirow{2}{*}{ Obj. } & Run & \multirow{2}{*}{ Time } & Obj. & Diff. & $\begin{array}{c}\text { Run } \\
\text { Time }\end{array}$ & Obj. & Diff. & $\begin{array}{c}\text { Run } \\
\text { Time }\end{array}$ \\
\hline & $14,846.1$ & 84.6 & $15,803.4$ & 6.5 & 0.0 & $14,257.7$ & 0.0 & 9.5 \\
2 & $11,958.9$ & 105.1 & $13,186.4$ & 10.3 & 0.0 & $11,948.4$ & 0.0 & 8.7 \\
3 & $10,013.2$ & 66.7 & $10,013.3$ & 0.0 & 0.0 & $10,011.9$ & 0.0 & 15.8 \\
4 & $16,564.6$ & 102.4 & $17,487.2$ & 5.6 & 0.0 & $16,339.0$ & 0.0 & 9.2 \\
5 & $16,109.5$ & 73.9 & $16,962.3$ & 5.3 & 0.2 & $15,625.9$ & 0.0 & 17.4
\end{tabular}




\begin{tabular}{crrrccccr}
6 & $11,271.5$ & 80.0 & $12,388.3$ & 9.9 & 0.0 & $11,270.0$ & 0.0 & 9.5 \\
7 & $14,310.0$ & 67.7 & $14,441.8$ & 0.9 & 0.0 & $14,292.9$ & 0.0 & 14.8 \\
8 & $15,940.9$ & 74.3 & $18,047.4$ & 13.2 & 0.0 & $15,922.4$ & 0.0 & 13.2 \\
9 & $12,739.7$ & 117.8 & $12,750.7$ & 0.1 & 0.0 & $12,415.9$ & 0.0 & 16.2 \\
10 & $12,947.4$ & 91.6 & $13,678.4$ & 5.7 & 0.0 & $13,016.9$ & 0.0 & 6.9 \\
\hline Avg. & & 86.4 & & 5.7 & & & 0.0 & 12.1 \\
\hline
\end{tabular}

Tables 14 and 15 show the comparison of performance of improved heuristic with GAMS based on scenarios 4-6. It is shown that average difference between improved Tabu search and GAMS is very small for these three scenarios. For the small-scale (7-node) problems, the carbon emission is on average 0.01 lower than that obtained from GAMS for scenario 6. However, the performance of the revised savings algorithm is worse than GAMS for all scenarios. The run time of GAMS is still the largest.

From Tables 14 and 15, it is noticed that the computational time of GAMS is sensitive to the problem data. For instance, the computational time of GAMS varies from 38.57 seconds to 918.68 seconds. On the contrary, our improved Tabu search is very fast. The longest running time is only 38.8 seconds and the average running time is around 12.08 seconds. The improved Tabu search also gives very close results to GAMS on the problems with loose time window constraints and for problems with no time window constraints. The average run time for large cases is shown in Table 16.

\section{Table 16}

$\underline{\text { Average run time for large cases }}$

\begin{tabular}{ccc}
\hline Node & $\begin{array}{c}\text { Average Carbon Emission } \\
\text { (ton) }\end{array}$ & $\begin{array}{c}\text { Average Running } \\
\text { Time }\end{array}$ \\
\hline 25 & $68,630.54$ & 20.4 \\
30 & $69,784.38$ & 20.6 \\
30 & $70,503.82$ & 20.6 \\
30 & $119,284.67$ & 20.6 \\
35 & $128,425.37$ & 21.1 \\
40 & $98,355.36$ & 21.4
\end{tabular}




\begin{tabular}{ccc}
45 & $145,095.20$ & 22.5 \\
50 & $174,199.01$ & 24.5 \\
55 & $158,795.32$ & 25.4 \\
60 & $204,560.45$ & 26.6 \\
70 & $273,112.27$ & 32.6 \\
80 & $296,295.52$ & 42.5 \\
90 & $205,503.68$ & 53.1 \\
100 & $232,922.91$ & 76.2 \\
110 & $420,579.65$ & 98 \\
120 & $270,425.92$ & 139.8 \\
140 & $522,988.66$ & 227.5 \\
150 & $499,614.32$ & 297.5 \\
200 & $514,588.73$ & 763.6 \\
\hline
\end{tabular}

\subsubsection{Results for instances without time window constraints}

In this section, a larger and more realistic example was devised based on a practical case of a chemical supply company. The depot is an actual distribution center of the chemical company. The locations of customers are generated based on actual customers around this distribution center. The parameters are given as Table 10. One depot and 13 demand nodes are considered in the experiments. The location and demand information used in the experiments are given in Table 17. The demand for each node is generated according to a real-world, gas distribution company. We first perform experiments based on the two basic models. The speed is considered as constant and only one vehicle is used in the first basic experiment. Time window restrictions are not considered here.

Then, we perform experiments based on our proposed model and conduct sensitivity analysis on the effect of travel speed, time windows and travel speed limit in the further experiments. The travel speed is considered as variable. The speed limit is set according to the actual highway speed limit. Diesel trucks without catalysts are used to ship cargo to the customers. 


\section{Table 17}

$\underline{\text { Location and demand information }}$

\begin{tabular}{cccc}
\hline Node & Latitude & Longitude & $\begin{array}{c}\text { Demand } \\
(\mathrm{ib})\end{array}$ \\
\hline 0 & 38.586455 & -90.1777 & 0 \\
1 & 38.359281 & -91.4895 & 289.51 \\
2 & 37.951446 & -91.7849 & 83.33 \\
3 & 37.6594 & -91.5711 & 10.08 \\
4 & 38.562725 & -90.4608 & 10.08 \\
5 & 38.2932 & -90.703 & 10.08 \\
6 & 38.6133 & -90.314 & 33.33 \\
7 & 38.415133 & -90.4412 & 10.08 \\
8 & 38.63838 & -90.2651 & 666.67 \\
9 & 38.6576 & -90.5064 & 83.33 \\
10 & 38.652689 & -90.5079 & 10.08 \\
11 & 38.668274 & -90.6196 & 183.33 \\
12 & 38.67359 & -90.4699 & 100 \\
13 & 38.232078 & -90.5645 & 10.08 \\
14 & 38.4455 & -90.4045 & 10.08 \\
\hline
\end{tabular}

A map of depot and customer nodes is shown in Figure 14. The circled node is the depot. Other nodes are the customer nodes. The depot is located in St. Louis while the customer nodes are created based on the location around this city. 


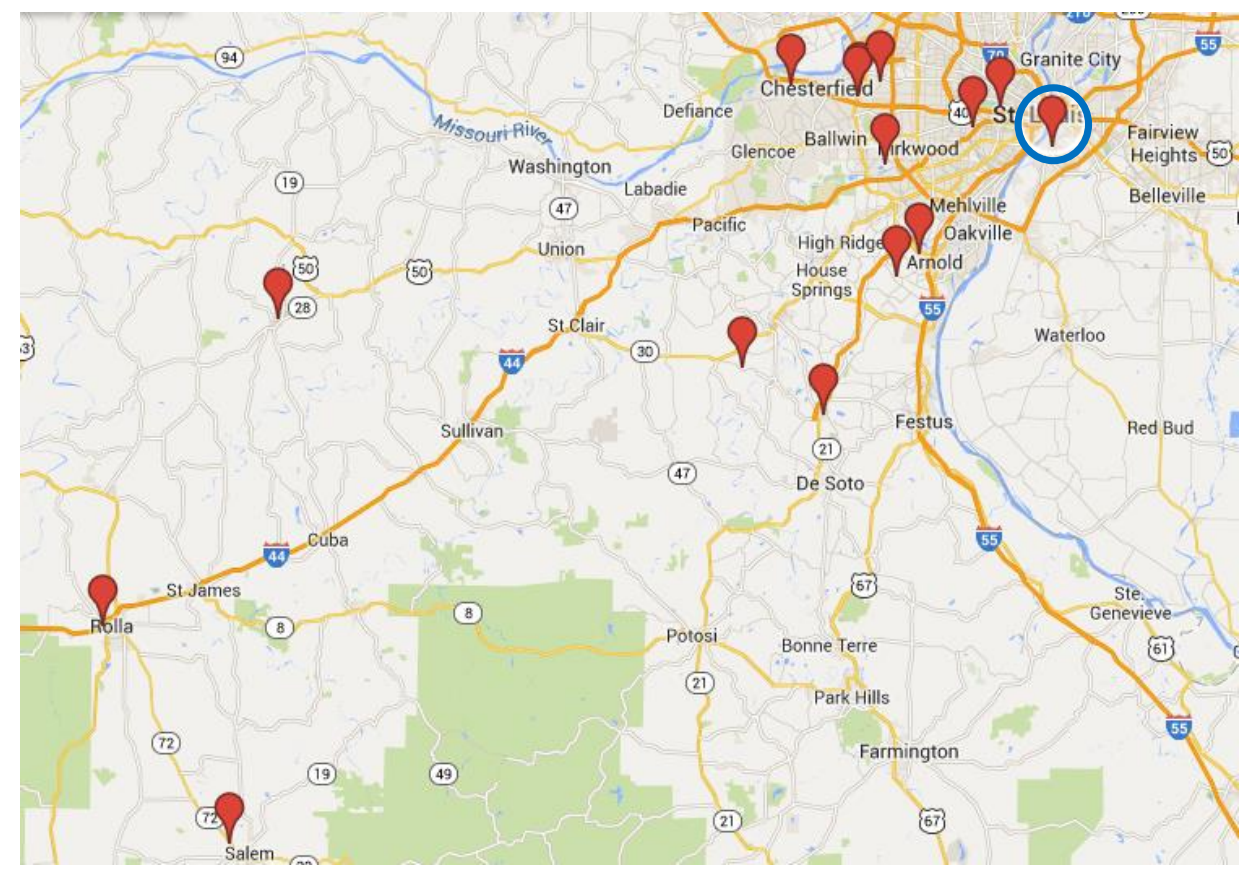

Figure 14. Map of depot and customers

Experiments are designed based on two scenarios: with and without time window constraints. The result of scenario without time window constraint is provided in Table 18. We analyze the impact of travel speed by comparing the three models: two basic models and our proposed model. As mentioned before, we assume travel speed is constant in these two basic models. Based on the comparison, we intend to investigate the difference of the total carbon emission and travel distance. The results are shown in Table 19.

\section{Table 18}

$\underline{\text { Result of our proposed model without time window constraint }}$

\begin{tabular}{ccccc}
\hline Arc & $\begin{array}{c}\text { Weight } \\
(\mathrm{lb})\end{array}$ & $\begin{array}{c}\text { Travel } \\
\text { Speed } \\
(\mathrm{mile} / \mathrm{h})\end{array}$ & $\begin{array}{c}\text { Distance } \\
\text { (mile) }\end{array}$ & $\begin{array}{c}\text { Carbon } \\
\text { Emission } \\
\text { (ton) }\end{array}$ \\
\hline 0,8 & $5,769.08$ & 42.25 & 294.86 & $2,493.60$ \\
8,6 & $5,102.42$ & 42.25 & 152.79 & $1,142.81$ \\
6,12 & $5,069.08$ & 42.25 & 432.87 & $3,216.57$ \\
12,9 & $4,969.08$ & 42.25 & 103.74 & 755.64 \\
9,10 & $4,885.75$ & 42.25 & 19.74 & 141.36 \\
10,11 & $4,875.67$ & 42.25 & 260.37 & $1,860.96$
\end{tabular}




\begin{tabular}{ccccc}
11,1 & $4,692.33$ & 42.25 & 2587.67 & $17,799.23$ \\
1,2 & $4,402.83$ & 42.25 & 1918.39 & $12,381.45$ \\
2,3 & $4,319.49$ & 42.25 & 1428.15 & $9,042.93$ \\
3,5 & $4,309.41$ & 42.25 & 4086.38 & $25,814.27$ \\
5,13 & $4,299.33$ & 42.25 & 522.56 & $3,293.39$ \\
13,7 & $4,289.25$ & 42.25 & 825.18 & $5,188.39$ \\
7,14 & $4,279.17$ & 42.25 & 161.61 & $1,013.76$ \\
14,4 & $4,269.08$ & 42.25 & 489.01 & $3,060.22$ \\
4,0 & $4,259.00$ & 42.25 & 722.73 & $4,512.20$ \\
\hline & & Total & $14,006.05$ & $91,716.79$ \\
\hline
\end{tabular}

Table 19

Comparison of three models

\begin{tabular}{rllllll}
\hline & \multicolumn{2}{c}{ Basic Model 2 } & \multicolumn{2}{c}{ Basic Model 1 } & \multicolumn{2}{c}{ Proposed Model } \\
\cline { 2 - 7 } Nodes & $\begin{array}{l}\text { Distance } \\
\text { (mile) }\end{array}$ & $\begin{array}{l}\text { Carbon } \\
\text { Emission } \\
\text { (ton) }\end{array}$ & $\begin{array}{l}\text { Distance } \\
\text { (mile) }\end{array}$ & $\begin{array}{l}\text { Emission } \\
\text { (ton) }\end{array}$ & $\begin{array}{l}\text { Distance } \\
\text { (mile) }\end{array}$ & $\begin{array}{l}\text { Carbon } \\
\text { Emission } \\
\text { (ton) }\end{array}$ \\
\hline 14 & $14,006.05$ & 135,418 & $14,006.05$ & 108,782 & $14,006.05$ & $91,716.79$ \\
\hline
\end{tabular}

The results in Table 18 indicate that one vehicle is required to serve the 13 customers for which no time window constraint would apply. The selected travel speed is 42.25 miles/hour. The total carbon emission is $91,716.79$ ton while the total travel distance is 14,006.05 miles. From Table 19, we can see that the travel distances of three models are almost the same. But the carbon emission of basic model 1 whose objective is to minimize carbon emission is 108,782 ton. Compared to the results of basic model 2 (with objective of minimizing distance), carbon emission is decreased by $19.67 \%$ (from 135,418 ton to 108,782 ton). Additionally, a decrease by $15.69 \%$ in objective value is obtained when comparing our proposed model with basic model 1 . The carbon emission is decreased by $32.27 \%$ when comparing our model with basic model 2.

Figure 15 shows the optimal route for the basic model 1 (consider travel speed as constant and without time window limitation) and our proposed model. The reason the 
optimal route for these two models are the same is because the time window constraint is not included in these two models. With a loose time range, the improvement of the optimal solution is generated based on the optimization on the travel speed on each route. That is also the reason why the resulting travel speed for each arc presented in Table 18 are all 42.25 miles/hour. We will present the speed sensitivity analysis in Figure 17. Figure 16 show the optimal route for basic model 2 with the objective of minimizing travel distance. The optimal route in both Figure 15 and Figure 16 is from A to P. A is the beginning node while $\mathrm{P}$ is the end node. Node $\mathrm{A}$ and $\mathrm{P}$ are both depots and have the same location. It can be shown that although the travel distance is almost the same in both figures, the route directions are opposite.

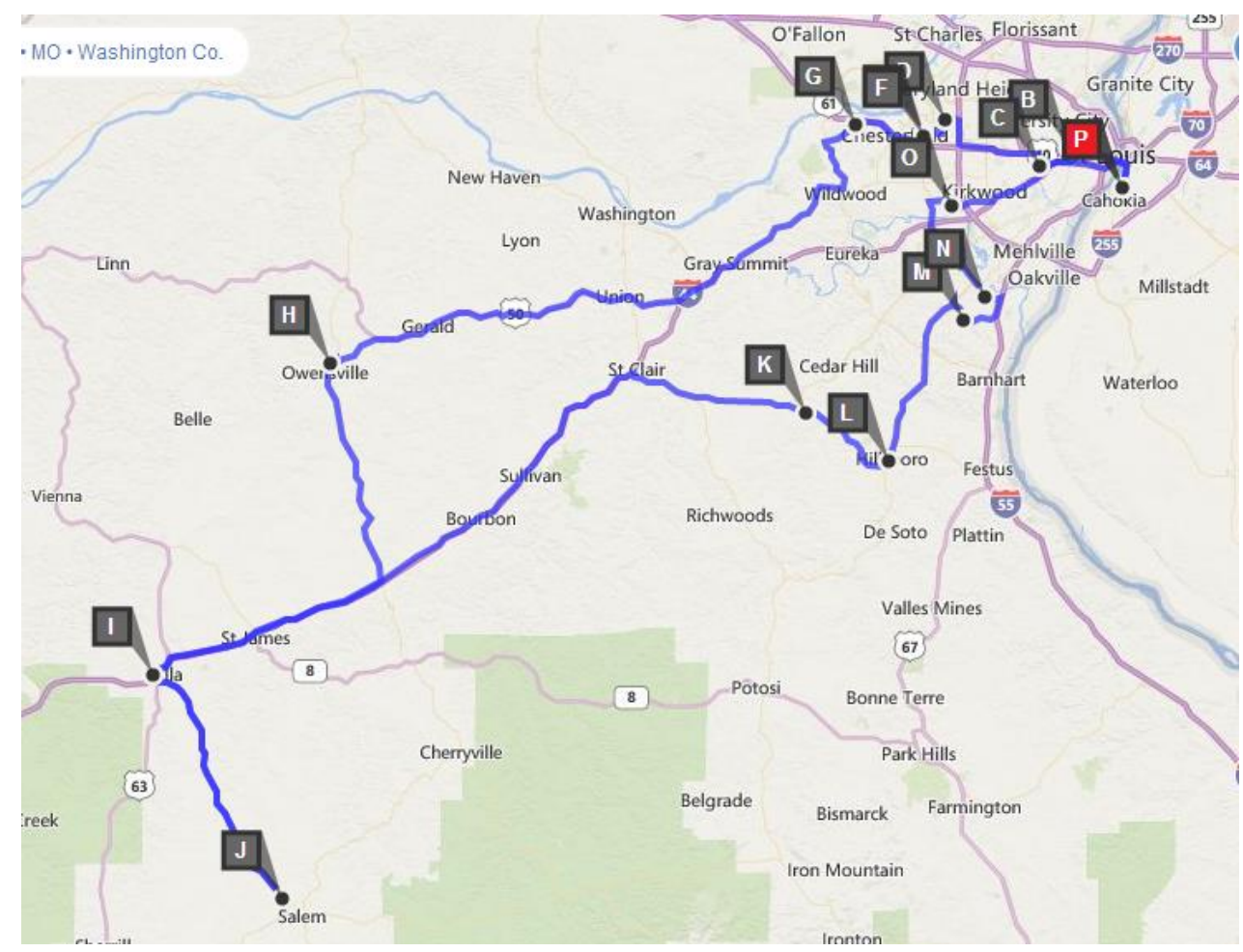

Figure 15. Near-optimal route for basic model 1 and our proposed model 


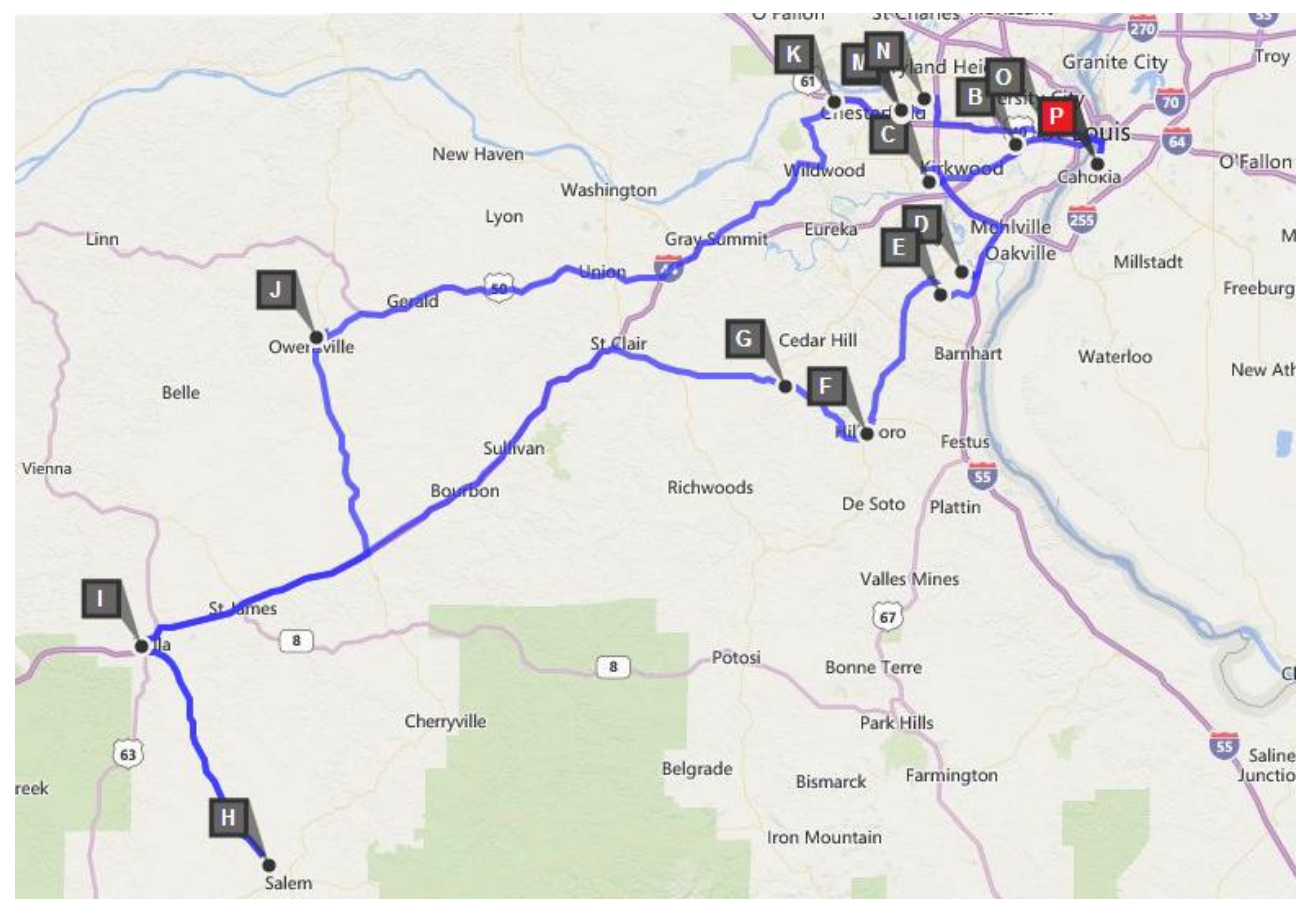

Figure 16. Near-optimal route for basic model 2

Sensitivity analysis is conducted to investigate the impact of travel speed on carbon emission based on the basic model 1. The graph in Figure 17 indicates that as the travel speed increases from 0 to roughly 42 miles/hour, the total carbon emission decreases by almost $59.47 \%$. However, when the travel speed continues to increase from 42 miles to 80 miles/hour, the total carbon emission increases by almost $47.93 \%$. This result illustrates that the total carbon emission depends heavily on the travel speed while 42 miles/hour will provide us the lowest carbon emission. Thus, it may be beneficial to treat travel speed as a variable and suggest appropriate travel speed for each route so that decision makers can minimize the total fuel consumption and carbon emission. 


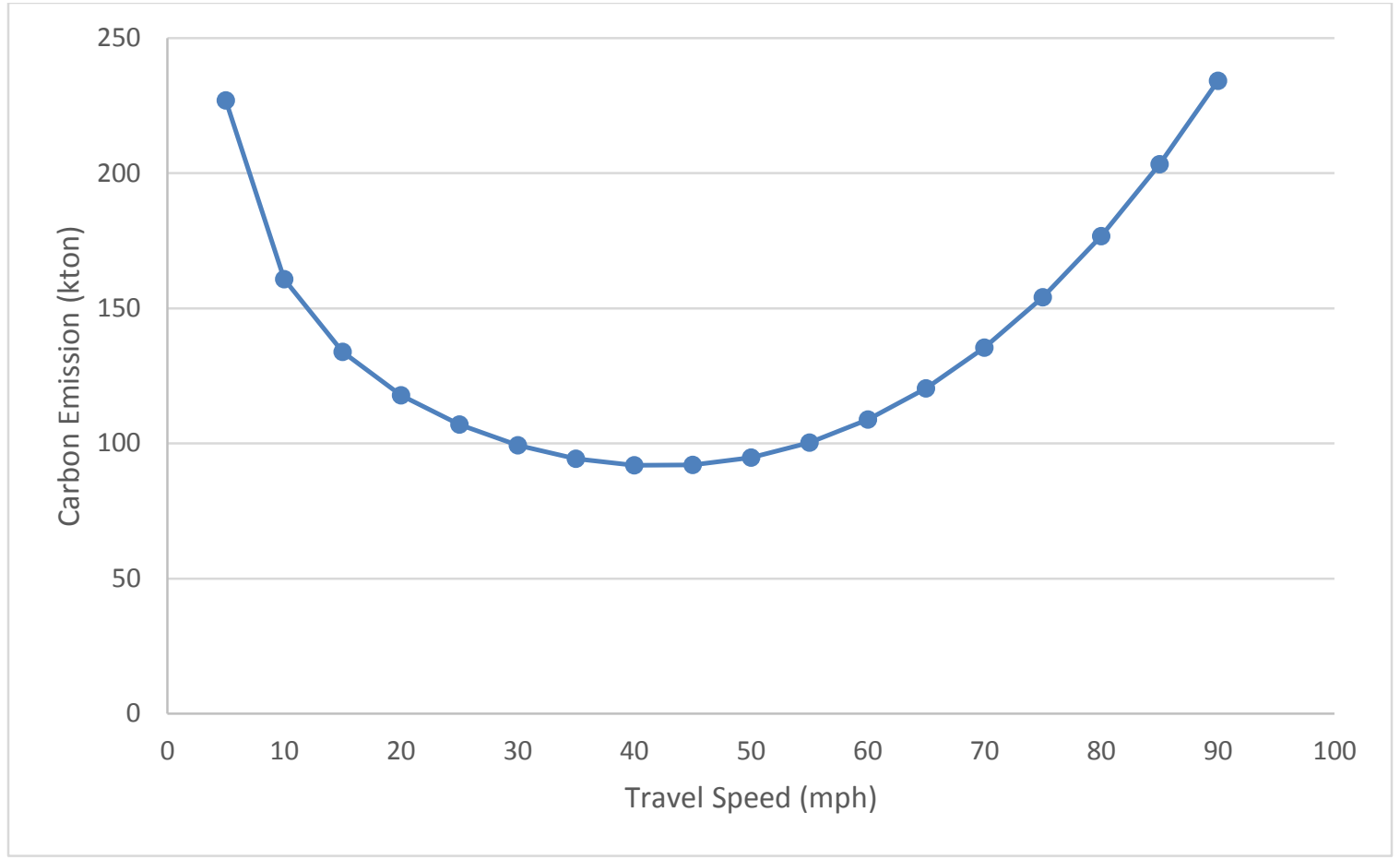

Figure 17. Sensitivity analysis on travel speed

\subsubsection{Results for instances with time window constraints}

In this section, we discuss a case with time window limitation. The location of the depot and customers are the same as that in section 4.3. The demand and due dates for each customer are provided in Table 19. The result of scenario with time window constraint is provided in Table 20.

\section{Table 20}

$\underline{\text { Parameter Setting }}$

\begin{tabular}{cccc}
\hline ID & Demand & $\begin{array}{c}\text { Due } \\
\text { Time }\end{array}$ & $\begin{array}{c}\text { Service } \\
\text { Time }\end{array}$ \\
\hline 0 & 0 & 99,999 & 0 \\
1 & 289.51 & 236 & 2 \\
2 & 83.33 & 184 & 2 \\
3 & 10.08 & 182 & 2 \\
4 & 10.08 & 201 & 2 \\
5 & 10.08 & 75 & 2
\end{tabular}




\begin{tabular}{cccc}
6 & 33.33 & 185 & 2 \\
7 & 10.08 & 51 & 2 \\
8 & 666.67 & 52 & 2 \\
9 & 83.33 & 51 & 2 \\
10 & 10.08 & 190 & 2 \\
11 & 183.33 & 80 & 2 \\
12 & 100 & 88 & 2 \\
13 & 10.08 & 245 & 2 \\
14 & 10.08 & 90 & 2 \\
\hline
\end{tabular}

\section{Table 21}

$\underline{\text { Result of proposed model with time window constraints }}$

\begin{tabular}{ccccc}
\hline Arc & $\begin{array}{c}\text { Weight } \\
(\mathrm{lb})\end{array}$ & $\begin{array}{c}\text { Travel } \\
\text { Speed } \\
(\mathrm{mile} / \mathrm{h})\end{array}$ & $\begin{array}{c}\text { Distance } \\
\text { (mile) }\end{array}$ & $\begin{array}{c}\text { Carbon Emission } \\
\text { (ton) }\end{array}$ \\
\hline 0,8 & $5,345.83$ & 42.25 & 294.86 & $2,310.65$ \\
8,6 & $4,679.17$ & 42.25 & 152.79 & $1,048.02$ \\
6,12 & $4,645.83$ & 42.25 & 432.87 & $2,948.00$ \\
12,9 & $4,545.83$ & 42.25 & 103.74 & 691.28 \\
9,10 & $4,462.5$ & 42.25 & 19.74 & 129.11 \\
10,11 & $4,452.42$ & 42.25 & 260.37 & $1,699.41$ \\
11,4 & $4,269.08$ & 42.25 & 565.58 & $3,539.46$ \\
4,0 & 4,259 & 42.25 & 722.73 & $4,512.20$ \\
0,14 & $4,682.25$ & 45.36 & 827.98 & $5,712.74$ \\
14,7 & $4,672.17$ & 59.65 & 161.61 & $1,304.48$ \\
7,13 & $4,662.09$ & 60.00 & 825.18 & $6,688.67$ \\
13,5 & 4,652 & 59.65 & 522.56 & $4,199.78$ \\
5,3 & $4,641.92$ & 42.25 & 4086.38 & $27,806.07$ \\
3,2 & $4,631.84$ & 42.25 & 1428.15 & $9,696.83$ \\
2,1 & $4,548.51$ & 42.25 & 1918.39 & $12,791.12$ \\
1,0 & 4,259 & 42.25 & 3654.94 & $22,818.69$ \\
\hline & & Total & 15977.87 & $107,896.53$ \\
\hline & & & &
\end{tabular}

The results in Table 21 indicate that two vehicles are required to serve the same number of customers while satisfying their due-date requirement. The total carbon emission is $107,896.53$ tons. For the first route, the travel speeds are all chosen as 42.25 miles/hour because the time window limitation is relatively loose. For the second route, 
the travel speed of arcs $(14,7),(7,13),(13,5)$ are close to the travel speed limit while travel speed on other arcs are chosen as close as the 68 miles/hour which is the suggested appropriate travel speed as shown in Figure 17. The optimal route is shown in Figure 18. We note that the first tour shown in Figure 18 is Q-B-C-D-E-F-G-H-Q which is also represented as 0-8-6-12-9-10-11-4-0 in Table 21. The second tour is Q-J-K-L-M-N-O-P-Q which is also represented as 0-14-7-13-5-3-2-1-0.

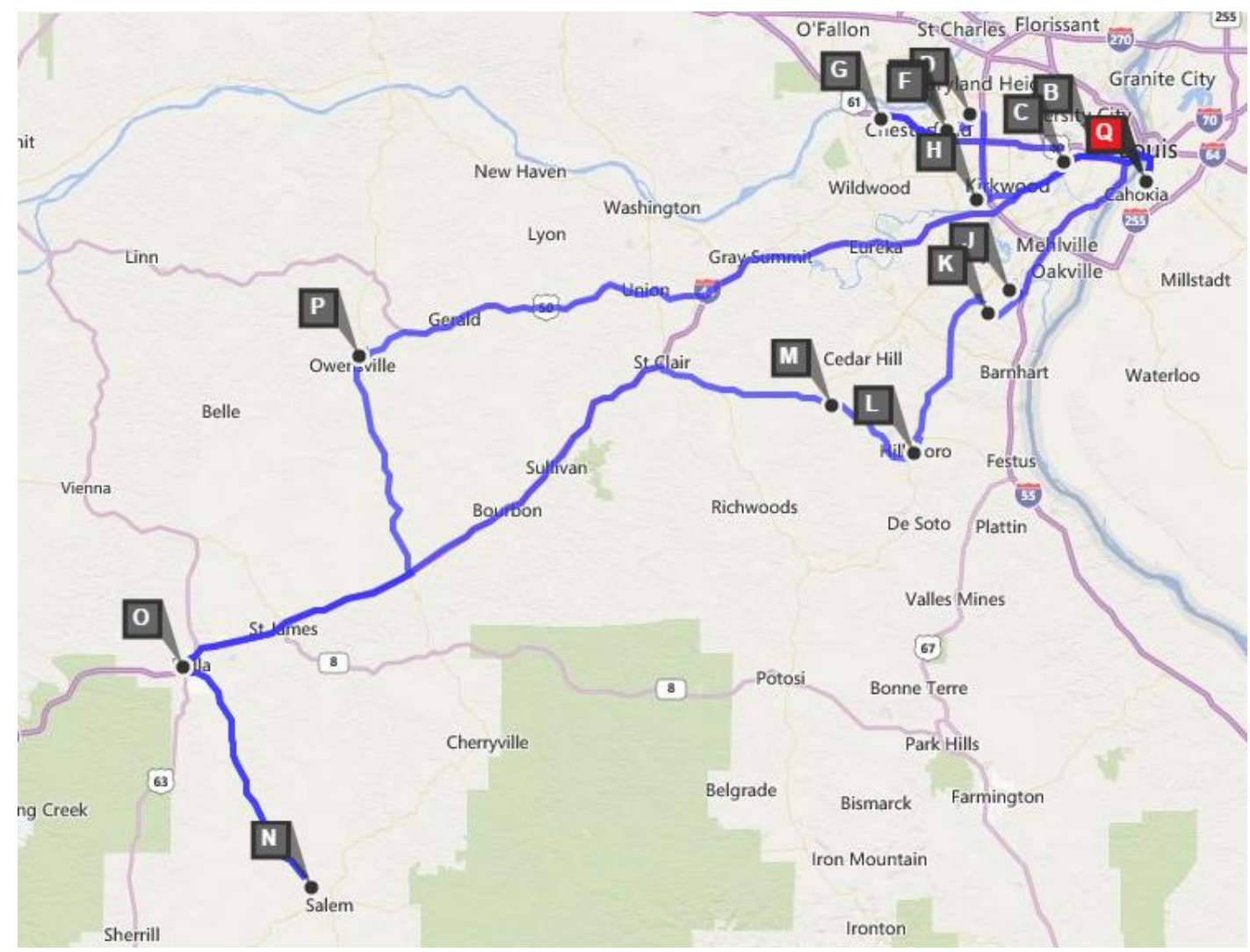

Figure 18. Optimal route for our proposed model with time window limitation

We also investigate the impact of time windows in the following section. We still use the distance and demand data of the 14-node instance. The due -date and service time for each node are initially set as the same as those in Table 20. We use a multiplicative factor to narrow down the corresponding time window for each node. The decrease range is $5 \%-25 \%$ in the decrement of $5 \%$ to ensure that there is feasible solution when we tighten 
the time window constraint. The results of the experiments are shown in Table 22-26. It is shown that there is a significant difference between the result with and without time window constraints. The carbon emission in Table 21 increase $17.64 \%$ comparing with the result in Table 18.

With the reduction of the range of time window, the total carbon emission increases significantly. For example, when the time window is narrowed down to $25 \%$, there is a noticeable increase in carbon emission. This observation indicates there is an opportunity to reduce carbon emissions when the time window constraint is loose. The optimal travel speed for this case will be chosen as close as the appropriate travel speed that provides us the lowest carbon emission as shown in Figure 17. When the time window constraint becomes tight, the opportunities for carbon emission reduction become small because the alternative solutions for travel speed and optimal route is restrictive. For instance, the result shown in Table 25 suggests a $13.65 \%$ carbon emission reduction compared to the result in Table 26.

In particular, it is shown that the optimal routes from Table 22 to Table 26 are the same. The reduction of carbon emission is based on the optimization of the travel speed on each route. For instance, the optimal travel speed of arc $(3,2)$ is 60.24 miles/hour under $20 \%$ narrowing scenario whereas the optimal travel speed of the same arc is 48.47 miles/hour under the 5\% narrowing scenario. The results shown in Table 22 indicate a $4 \%$ carbon emission reduction compared to the result shown in Table 25 while the total distances are the same. 


\section{Table 22}

$\underline{\text { Result when Alpha }=0.95}$

\begin{tabular}{ccccc}
\hline Arc & $\begin{array}{c}\text { Weight } \\
(\mathrm{lb})\end{array}$ & $\begin{array}{c}\text { Travel } \\
\text { Speed } \\
(\text { miles/h) }\end{array}$ & $\begin{array}{c}\text { Distance } \\
\text { (mile) }\end{array}$ & $\begin{array}{c}\text { Carbon } \\
\text { Emission } \\
\text { (ton) }\end{array}$ \\
\hline 0,8 & $5,345.83$ & 42.25 & 294.86 & $2,310.65$ \\
8,6 & $4,679.17$ & 42.25 & 152.79 & $1,048.02$ \\
6,12 & $4,645.83$ & 42.25 & 432.87 & 2,948 \\
12,9 & $4,545.83$ & 42.25 & 103.74 & 691.28 \\
9,10 & $4,462.5$ & 42.25 & 19.74 & 129.11 \\
10,11 & $4,452.42$ & 42.25 & 260.37 & $1,699.41$ \\
11,4 & $4,269.08$ & 42.25 & 565.58 & $3,539.46$ \\
4,0 & 4,259 & 42.25 & 722.73 & $4,512.2$ \\
0,14 & $4,682.25$ & 60.00 & 827.98 & $6,740.36$ \\
14,7 & $4,672.17$ & 59.65 & 161.61 & $1,304.48$ \\
7,13 & $4,662.09$ & 60.00 & 825.18 & $6,688.67$ \\
13,5 & 4,652 & 60.00 & 522.56 & $4,226.59$ \\
5,3 & $4,641.92$ & 42.25 & 4086.38 & $27,806.1$ \\
3,2 & $4,631.84$ & 49.09 & 1428.15 & $9,950.45$ \\
2,1 & $4,548.51$ & 42.25 & 1918.39 & $12,791.1$ \\
1,0 & 4,259 & 42.25 & 3654.94 & $22,818.7$ \\
\hline & & Total & 15977.87 & 109,205 \\
\hline
\end{tabular}

Table 23

$\underline{\text { Result when Alpha }=0.9}$

\begin{tabular}{ccccc}
\hline Arc & $\begin{array}{c}\text { Weight } \\
(\mathrm{lb})\end{array}$ & $\begin{array}{c}\text { Travel } \\
\text { Speed } \\
(\text { miles/h) }\end{array}$ & $\begin{array}{c}\text { Distance } \\
\text { (mile) }\end{array}$ & $\begin{array}{c}\text { Carbon } \\
\text { Emission } \\
\text { (ton) }\end{array}$ \\
\hline 0,8 & $5,345.83$ & 42.25 & 294.86 & $2,310.65$ \\
8,6 & $4,679.17$ & 42.25 & 152.79 & $1,048.02$ \\
6,12 & $4,645.83$ & 42.25 & 432.87 & 2,948 \\
12,9 & $4,545.83$ & 42.25 & 103.74 & 691.28 \\
9,10 & $4,462.5$ & 42.25 & 19.74 & 129.11 \\
10,11 & $4,452.42$ & 42.25 & 260.37 & $1,699.41$ \\
11,4 & $4,269.08$ & 42.25 & 565.58 & $3,539.46$ \\
4,0 & 4,259 & 42.25 & 722.73 & $4,512.2$ \\
0,14 & $4,682.25$ & 60.00 & 827.98 & $6,740.36$
\end{tabular}




\begin{tabular}{ccccc}
14,7 & $4,672.17$ & 59.65 & 161.61 & $1,304.48$ \\
7,13 & $4,662.09$ & 60.00 & 825.18 & $6,688.67$ \\
13,5 & 4,652 & 59.65 & 522.56 & $4,199.78$ \\
5,3 & $4,641.92$ & 44.12 & 4086.38 & $27,857.2$ \\
3,2 & $4,631.84$ & 59.65 & 1428.15 & $11,428.1$ \\
2,1 & $4,548.51$ & 42.87 & 1918.39 & $12,793.4$ \\
1,0 & 4,259 & 42.25 & 3654.94 & $22,818.7$ \\
\hline & & Total & 15977.87 & 110,709 \\
\hline
\end{tabular}

\section{Table 24}

$\underline{\text { Result when Alpha }=0.85}$

\begin{tabular}{ccccc}
\hline Arc & $\begin{array}{c}\text { Weight } \\
(\mathrm{lb})\end{array}$ & $\begin{array}{c}\text { Travel } \\
\text { Speed } \\
\text { (miles/h) }\end{array}$ & $\begin{array}{c}\text { Distance } \\
\text { (mile) }\end{array}$ & $\begin{array}{c}\text { Carbon } \\
\text { Emission } \\
\text { (ton) }\end{array}$ \\
\hline 0,8 & $5,345.83$ & 42.25 & 294.86 & $2,310.65$ \\
8,6 & $4,679.17$ & 42.25 & 152.79 & $1,048.02$ \\
6,12 & $4,645.83$ & 42.25 & 432.87 & 2,948 \\
12,9 & $4,545.83$ & 42.25 & 103.74 & 691.28 \\
9,10 & $4,462.5$ & 42.25 & 19.74 & 129.11 \\
10,11 & $4,452.42$ & 42.25 & 260.37 & $1,699.41$ \\
11,4 & $4,269.08$ & 42.25 & 565.58 & $3,539.46$ \\
4,0 & 4,259 & 42.25 & 722.73 & $4,512.2$ \\
0,14 & $4,682.25$ & 59.65 & 827.98 & $6,697.6$ \\
14,7 & $4,672.17$ & 60.00 & 161.61 & $1,312.81$ \\
7,13 & $4,662.09$ & 59.65 & 825.18 & $6,646.24$ \\
13,5 & 4,652 & 60.00 & 522.56 & $4,226.59$ \\
5,3 & $4,641.92$ & 49.09 & 4086.38 & $28,533.4$ \\
3,2 & $4,631.84$ & 59.65 & 1428.15 & $11,428.1$ \\
2,1 & $4,548.51$ & 45.36 & 1918.39 & $12,858.1$ \\
1,0 & 4,259 & 42.25 & 3654.94 & $22,818.7$ \\
\hline & & Total & 15977.87 & 111,400 \\
\hline
\end{tabular}




\section{Table 25}

$\underline{\text { Result when Alpha }=0.8}$

\begin{tabular}{ccccc}
\hline Arc & $\begin{array}{c}\text { Weight } \\
(\mathrm{lb})\end{array}$ & $\begin{array}{c}\text { Travel } \\
\text { Speed } \\
(\mathrm{miles} / \mathrm{h})\end{array}$ & $\begin{array}{c}\text { Distance } \\
\text { (mile) }\end{array}$ & $\begin{array}{c}\text { Carbon } \\
\text { Emission } \\
\text { (ton) }\end{array}$ \\
\hline 0,8 & $5,345.83$ & 42.25 & 294.86 & $2,310.65$ \\
8,6 & $4,679.17$ & 42.25 & 152.79 & $1,048.02$ \\
6,12 & $4,645.83$ & 42.25 & 432.87 & $2,948.00$ \\
12,9 & $4,545.83$ & 42.25 & 103.74 & 691.28 \\
9,10 & $4,462.50$ & 42.25 & 19.74 & 129.11 \\
10,11 & $4,452.42$ & 42.25 & 260.37 & $1,699.41$ \\
11,4 & $4,269.08$ & 42.25 & 565.58 & $3,539.46$ \\
4,0 & $4,259.00$ & 42.25 & 722.73 & $4,512.20$ \\
0,14 & $4,682.25$ & 60.00 & 827.98 & $6,740.36$ \\
14,7 & $4,672.17$ & 60.00 & 161.61 & $1,312.81$ \\
7,13 & $4,662.09$ & 60.00 & 825.18 & $6,688.67$ \\
13,5 & $4,652.00$ & 59.65 & 522.56 & $4,199.78$ \\
5,3 & $4,641.92$ & 55.30 & 4086.38 & $30,541.77$ \\
3,2 & $4,631.84$ & 60.00 & 1428.15 & $11,501.05$ \\
2,1 & $4,548.51$ & 47.85 & 1918.39 & $13,013.34$ \\
1,0 & $4,259.00$ & 42.25 & 3654.94 & $22,818.69$ \\
\hline & & Total & 15977.87 & $113,694.61$ \\
\hline
\end{tabular}

Table 26

$\underline{\text { Result when Alpha }=0.75}$

\begin{tabular}{ccccc}
\hline Arc & $\begin{array}{c}\text { Weight } \\
(\mathrm{lb})\end{array}$ & $\begin{array}{c}\text { Travel } \\
\text { Speed } \\
(\mathrm{miles} / \mathrm{h})\end{array}$ & $\begin{array}{c}\text { Distance } \\
\text { (mile) }\end{array}$ & $\begin{array}{c}\text { Carbon } \\
\text { Emission }\end{array}$ \\
\hline 0,8 & $5,345.83$ & 60.00 & 294.86 & $2,740.58$ \\
8,6 & $4,679.17$ & 60.00 & 152.79 & $1,243.01$ \\
6,12 & $4,645.83$ & 60.00 & 432.87 & $3,496.52$ \\
12,9 & $4,545.83$ & 60.00 & 103.74 & 819.90 \\
9,11 & $4,462.50$ & 60.00 & 258.92 & $2,008.88$ \\
11,10 & $4,279.17$ & 60.00 & 260.37 & $1,937.18$ \\
10,4 & $4,269.08$ & 60.00 & 374.04 & $2,776.30$ \\
4,0 & $4,259.00$ & 60.00 & 722.73 & $5,351.75$ \\
0,14 & $4,682.25$ & 60.00 & 827.98 & $6,740.36$ \\
14,7 & $4,672.17$ & 60.00 & 161.61 & $1,312.81$ \\
7,13 & $4,662.09$ & 60.00 & 825.18 & $6,688.67$
\end{tabular}




\begin{tabular}{ccccc}
13,1 & $4,652.00$ & 60.00 & 3030.49 & $24,511.15$ \\
1,2 & $4,362.50$ & 60.00 & 1918.39 & $14,550.67$ \\
2,3 & $4,279.17$ & 60.00 & 1428.15 & $10,625.34$ \\
3,5 & $4,269.08$ & 60.00 & 4086.38 & $30,330.82$ \\
5,0 & $4,259.00$ & 60.00 & 1902.30 & $14,086.31$ \\
\hline & & Total & 16780.79 & $129,220.25$ \\
\hline
\end{tabular}

We also investigate the impact of travel speed by conducting experiments comparing a fixed speed with various speeds for each arc under the time window constraint. Fourteen levels of constant travel speed with 5 mile/hour increment are used to design the experiments. The results shown in Table 27 indicate that 40 mile/hour (68 kilometers/hour) provides the lowest total carbon emission which is the same as the scenario without time window constraint. The total carbon emission of various speed in Table 21 saves $1.27 \%$ compared to the lowest carbon emission in Table 27 . The savings is relatively small compared to the scenarios without time window constraint.

\section{Table 27}

$\underline{\text { Results of different average speeds with time window constraint }}$

\begin{tabular}{cc}
\hline $\begin{array}{c}\text { Constant Speed } \\
\text { (mile/hour) }\end{array}$ & $\begin{array}{c}\text { Carbon Emission } \\
\text { (ton) }\end{array}$ \\
\hline 15 & $351,606.09$ \\
20 & $223,935.60$ \\
25 & $203,145.60$ \\
30 & $166,221.10$ \\
35 & $115,758.73$ \\
40 & $109,268.06$ \\
45 & $109,392.57$ \\
50 & $109,562.83$ \\
55 & $115,919.32$ \\
60 & $125,703.46$ \\
65 & $139,155.86$ \\
70 & $156,533.89$ \\
75 & $178,102.01$ \\
80 & $204,132.20$ \\
\hline
\end{tabular}


The impact of travel speed limit is investigated in Figure 19. This experiment can provide a good suggestion for public agencies when they study the impact of the congestion on carbon emission. We note that carbon emission increases significantly when travel speed limit is below 30 miles per hour. The total carbon emission almost doubles when travel speed limit drops from 20 miles/hour to 5 miles/hour.

This result indicates congestion has a great impact on carbon emissions in the real world. We will investigate the congestion on carbon emission based on a stochastic model in the future.

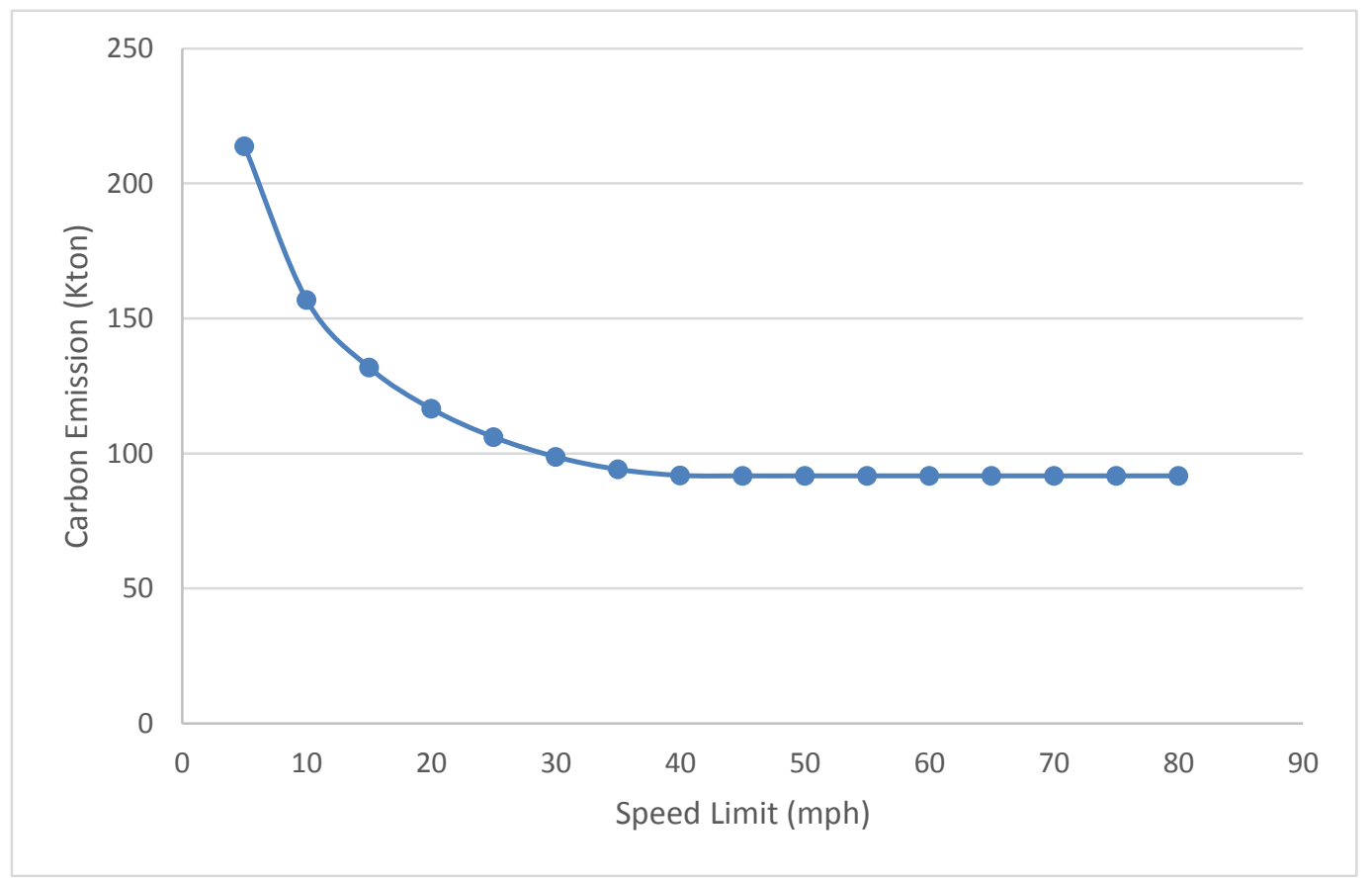

Figure 19. Effect of Speed Limit

\subsection{Summary}

In this section, an extended Green Vehicle Routing problem is formulated based on the pollution routing problem. The objective of this model is to minimize the total carbon emission which is considered as a nonlinear function of vehicle load, travel speed and travel 
distance. A heuristic algorithm based on the Clarke and Wright Savings heuristic and Tabu Search is proposed to solve this problem. Computational experiments are conducted to compare the performance of our proposed heuristic algorithm with GAMS. To investigate the impact of travel speed and time window constraint, six scenarios with different combinations of travel speed and time window ranges are introduced. The results show that the improved heuristic performs better than GAMS with the average reduction of $7.76 \%$.

A real world case is conducted to further investigate the impact of travel speed, time window limitation and travel speed limit (congestion). Experiments with time window constraint and without time window constraint are designed to conduct the sensitivity analysis. Under the no time window scenario, the extended G-VRP achieves $15.69 \%$ carbon emission reduction compared to the basic G-VRP without significant increase in travel distance. A reduction of $32.27 \%$ in carbon emissions is achieved when compared to the basic VRP. The opportunities for carbon emission reduction are more apparent when the time window constraint is loose, whereas is relatively small when the time window range is relatively narrow. Experiments on travel speed limit indicate congestion has a great impact on carbon emissions which yield potential reduction of carbon emission. The congestion effects on carbon emission will be investigated based on a stochastic model in the future. 


\section{CHAPTER V}

\section{STOCHASTIC GREEN VEHICLE ROUTING PROBLEM}

\subsection{Problem Statement}

\subsubsection{Robust GVRP Example}

To provide some insight into the importance of the stochastic green vehicle routing problem, we use a four-node instance with a single uncapacitated vehicle to show the difference between the solution of stochastic green vehicle routing problem and the deterministic vehicle routing problem where the random variable is replaced by its mean value. As shown in Figure 20, node 0 is the depot while node 1, 2, 3 are customers. We assume a homogeneous demand pattern as each customer has a demand of one unit. The service time at depot is zero, while other node has service time of one hour. The distance between two adjacent nodes on horizontal or vertical lines is 62.5 miles and is 88.4 miles on a diagonal arc. Time window limitation is not considered in this instance, which means that the vehicle can travel as slow as possible within the travel speed limitation.

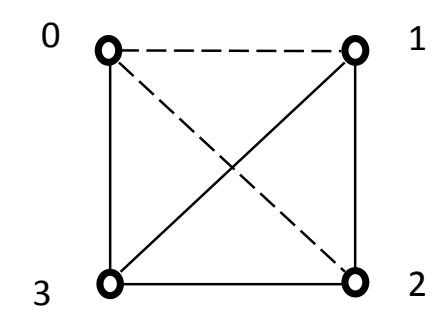

Figure 20. Four-node instance 
If we consider a constant travel speed limit for each arc, for example, $68 \mathrm{mph}$, the optimal route will be $(0,3,2,1,0)$, which leads to the minimum total distance as well as the minimum total cost. However, if the speed limit on each arc is random, for example, following a truncated normal distribution, the optimal route may be different. Take an extreme instance. If the travel speed limit on arc $(0,1)$ is extremely small which may make the fuel cost of traveling on it become very large, the optimal tour will be $(0,2,1,3,0)$.

Consider a scenario that there are two arcs between nodes $\mathrm{O}$ and $\mathrm{D}$ with the same distance but different actual speed limits: the actual speed limit of the first arc is always 45 miles per hour, and the second limit is random with mean of 45 miles per hour and standard deviation of 10 miles per hour. Assume that optimal speed without any limit restriction is 40 miles per hour. For the first arc, the optimal speed is always available and thus the cost is $f(40)$. For the second arc, if the speed limit is greater than 40 in an instance, the vehicle will travel with speed 40 miles per hour; however, if the speed limit is smaller than $40 \mathrm{mph}$ in an instance, the optimal speed is less than $40 \mathrm{mph}$ and fuel cost raises correspondingly. With different distribution assumptions, the average optimal costs are shown in Table 28.

\section{Table 28}

The average optimal costs with different distribution assumptions

\begin{tabular}{lc}
\hline Distribution Type & Optimal Cost \\
\hline Uniform $(30,60)$ & $f(38.7)$ \\
Truncated normal $(45,10,30,60)$ & $f(39.2)$ \\
Inverse-gamma $(3,90)$ & $f(36.7)$ \\
\hline
\end{tabular}

In the real world, the actual speed limit $V_{i j}$ on a fraction of path is random. For example, on a road with speed limit of 45 mile/hour, the actual limit may only be 30 
mile/hour due to the heavy traffic. Assume that $V_{i j}$ is a random value with distribution $N(\mu, \sigma)$ for each link $i j$, we will revisit the VRPTW and analyze the solutions.

To solve the stochastic VRPTW with fuel consumption, the problem is modeled as a two-stage stochastic program. The general form of two stage stochastic program can be formulated as follows (Birge and Louveaux, 1997):

Minimize

$$
c^{T} x+Q(x)
$$

Subject to

$$
\begin{aligned}
& A x \leq b, \\
x & \geq 0
\end{aligned}
$$

The second stage problem is stated as:

$$
\begin{gathered}
Q(x)=E_{\xi} Q(x, \xi) \\
Q(x, \xi)=\min \left\{q^{T} y \mid W y+T x \geq h\right\}
\end{gathered}
$$

Where

$x$ is the decision variable and $c$ denotes the cost parameter in the first stage problem. $\xi$ is a random vector which provides information for the decision variable y in the second stage problem. $h$ and $W$ is a fixed vector, $T$ is a random matrix. $E_{\xi}$ represents the expectation operator.

The two stage stochastic model is built based on the deterministic VRPTW with fuel consumption model in Section 4.2. The speed limit is assumed to vary. For each scenario $s$, there is an actual speed limit when we consider travel congestion in the real world. In the beginning of first stage model, the travel speed $v_{i j}$ is assumed to be realized, and $v_{i j}$ is equal to the posted maximum speed limit. The first stage model will provide a 
feasible route based on the given travel speed. Let $x_{i j}$ be a binary variable to indicate whether to choose the link from node $i$ to node $j$. The first stage decisions include whether or not to choose a link $\left(x_{i j}\right)$, the amount a truck should carry in that link $\left(y_{i j}\right)$, and the arriving time at node $i\left(t_{i}\right)$. We do not consider the uncertainty in the travel speed in first stage, so we do not know whether or not the route chosen from the first stage model is optimal.

In reality, because the travel speed is uncertain, the travel speed $v_{i j}$ is considered as the decision variable in the second stage model. The solution for the second stage model is the minimum fuel consumption and carbon emission for each scenario $s$ based on the given route which is obtained from the first stage model. After that, the expected value of the minimum fuel consumption for all scenarios will be implemented into the first stage model to obtain a better travel route which yields less fuel consumption and carbon emission.

\subsubsection{Carbon Emission Functions}

Fuel consumption and carbon emission for each vehicle depends on several factors: load, travel speed, travel distance. We assume the vehicle type is a diesel truck without catalysts and its workload is around 25 tons. Also, the temperature is assumed to be $25^{\circ} \mathrm{C}$. The carbon emission can be calculated as follows (Hickman et al., 1999):

$$
\begin{aligned}
& E_{i j}^{h o t}=765-7.04 \mathrm{v}_{i j}+0.000632 \mathrm{v}_{i j}^{3}+\frac{8334}{\mathrm{v}_{i j}} \\
& \varepsilon_{i j}=1.27-\frac{0.483}{\mathrm{v}_{i j}} \\
& E_{i j}^{\text {start }}=\omega_{i j} \times g_{i j}\left(\mathrm{~T}_{i j}\right) \times h_{i j}\left(\mathrm{~d}_{i j}\right)
\end{aligned}
$$

Where 


$$
\begin{aligned}
& \omega_{i j}=182.57 \\
& g_{i j}\left(\mathrm{~T}_{i j}\right)=-0.0458 \mathrm{~T}_{i j}+1.9163=-0.0458 * 25+1.9163=0.7713 \\
& h_{i j}\left(\mathrm{~d}_{i j}\right)=\frac{1-e^{-\frac{3.95 \mathrm{~d}_{i j}}{0.24 * \mathrm{v}_{i j}+0.09}}}{1-e^{-3.95}} \\
& f_{i j}=\left(E_{i j}^{\text {hot }} \varepsilon_{i j}+E_{i j}^{\text {start }}\right) * y_{i j} * d_{i j} \\
& =\left[\left(765-7.04 \mathrm{v}_{i j}+0.000632 \mathrm{v}_{i j}^{3}+\frac{8334}{\mathrm{v}_{i j}}\right)\left(1.27-\frac{0.483}{\mathrm{v}_{i j}}\right)+143.58\right. \\
& \left.*\left(1-e^{-\frac{3.95 \mathrm{~d}_{i j}}{0.24 * \mathrm{v}_{i j}+0.09}}\right)\right] * y_{i j} * d_{i j}
\end{aligned}
$$

\subsection{GVRP Models with Stochastic Speed Limit}

\subsubsection{Definitions and Notations}

Consider a vehicle routing problem defined over a network $G=(V, A)$ where $V=$ $\{0,1,2, \ldots, n\}$ is the set of nodes, 0 is the depot and $A=\{(i, j): i, j \in V, i \neq j\}$ is the set of arcs. We consider a set of vehicles, each with capacity limitations. Each customer has different demand and specified time window that need to be satisfied. If a vehicle does not arrive within the time window as a customer requested, a penalty cost is incurred.

The parameters of this stochastic model are similar as the deterministic VRPTW with fuel consumption model. The parameters and decision variables are summarized as below:

Parameters and Notations:

$d_{i j}$ is the distance from node $i$ to node $j$,

$V_{i j}^{*}$ is the posted maximum speed limit in the route from node $i$ to node $j$, 
$V_{i j}$ is the actual travel speed limit from node $i$ to node $j$ when we consider travel congestion, and $V_{i j}$ is a random value and $V_{i j} \leq V_{i j}^{*}$,

$q_{i}$ is the demand of node $i$,

$t s_{i}$ is the service time spent at node $i$,

$T_{i}$ is the due-date at node $i$, where the starting time at the depot is counted as 0 ,

$N$ is the number of vehicles (trucks),

$C_{0}$ is the weight of an empty vehicle,

$C$ is the weight capacity of a vehicle,

$f\left(d_{i j}, y_{i j}, v_{i j}\right)$ is the fuel consumption formula.

Decision variables for the first stage model:

$x_{i j}$ is a binary variable to indicate whether or not to choose the link from node $i$ to node $j$,

$y_{i j}$ is the total weight of a vehicle when it travels from node $i$ to node $j$,

$t_{i}$ is the arrival time at node $i$, where the starting time at the depot is counted as 0 .

Decision variables for the second stage model:

$S$ is a scenario of the actual speed limit with an instance of random variable $V_{i j}$,

$v_{i j}{ }^{s}$ is the travel speed from node $i$ to node $j$ for scenario $s$,

$t_{i}{ }^{s}$ is the arrival time at node $i$ for scenario $s$, where the starting time at the depot is counted as 0 .

\subsubsection{Models}

The two-stage stochastic model is shown below. The objective of model is to minimize the total fuel consumption and carbon emission.

The first stage: 
Min

$\sum_{i} \sum_{j} x_{i j} y_{i j} E_{s}\left[f\left(d_{i j}, v_{i j}{ }^{s}\right)\right]$

S.T.

$\sum_{j=0}^{n} x_{i j}=1, \forall i=1, \ldots, n$

$\sum_{j=1}^{n} x_{0 j} \leq N$

$\sum_{j=0, j \neq i}^{n} x_{i j}-\sum_{j=0, j \neq i}^{n} x_{j i}=0, \forall i=0, \ldots, n$

$\sum_{j=0, j \neq i}^{n} y_{j i}-\sum_{j=0, j \neq i}^{n} y_{i j}=q_{i}, \forall i=1, \ldots, n$

$y_{i j} \leq\left(C_{0}+C\right) x_{i j}, \forall i, j=0, \ldots, n,(i \neq j)$

$y_{i j} \geq C_{0} x_{i j}, \forall i, j=0, \ldots, n,(i \neq j)$

$t_{i}+t s_{i}+\frac{d_{i j}}{v_{i j}}-t_{j} \leq M\left(1-x_{i j}\right), \forall i, j=0, \ldots, n,(i \neq j)$

$t_{0}=0$

$0 \leq t_{i} \leq T_{i}, \forall i=1, \ldots, n$

$x_{i j} \in\{0,1\}, \forall i, j=0, \ldots, n$

where $M$ is a large constant.

The second stage:

Min

$$
\sum_{i} \sum_{j} f\left(d_{i j}, v_{i j}{ }^{s}\right) y_{i j}
$$

S.T.

$$
\begin{aligned}
& t_{i}^{s}+t s_{i}+\frac{d_{i j}}{v_{i j}{ }^{s}}-t_{j}{ }^{s} \leq M\left(1-x_{i j}\right), \forall i, j=0, \ldots, n,(i \neq j) \\
& t_{0}=0 \\
& 0 \leq t_{i}^{s} \leq T_{i}, \forall i=1, \ldots, n
\end{aligned}
$$


$0 \leq v_{i j}{ }^{s} \leq V_{i j}, \forall i, j=0, \ldots, n,(i \neq j)$

where $M$ is a large constant.

In the first stage model, the objective is to minimize the fuel consumption and carbon emission by optimization on the traveling route. Constraints (14)-(23) are the first stage constraints. Note that we force the travel speed $v_{i j}$ to be equal to the posted maximum speed limit in the first stage model. Constraints (14) ensure that for each node $i$ (except the depot node), the number of arcs from that node is equal to 1 . Constraint (15) is the total vehicle constraint. Constraints (16) guarantee the flow balance at each customer node, i.e. the incoming flow is equal to the outgoing flow. Constraints (17) are demand constraints. Constraints (18) and (19) are vehicle capacity constraints. Constraints (20) - (22) are time window constraints.

In the second stage model, the objective is to minimize the fuel consumption and carbon emission by optimizing the travel speed. Constraints (24) - (26) are time window constraints. Constraint (27) ensures the travel speed is less than the posted maximum speed limit. Note that, each random speed limit is considered as one specific scenario.

\subsection{Solution Approach}

\subsubsection{Two Stage Heuristic Algorithm}

In this section, we develop an algorithm to solve the stochastic green vehicle routing problem. The complicating factor in this problem is that travel speed limit is a random value. Because this stochastic VRPTW with fuel consumption problem is a nonlinear integer program, it cannot be solved by CPLEX directly. A two stage decomposition method is developed to solve this problem. We first use initial parameters in the first stage model to obtain a feasible solution. The first stage model is solved by 
CPLEX. Then we solve the second stage model to get a near-optimal solution and update the parameters in the first stage model. For the second stage model, with the given route that generated based on the first stage model, we use our proposed heuristic algorithm to obtain the proper travel speed for each random scenario. The process iterates until the optimal solution is reached.

The two stage heuristic method described below. The detailed steps of the algorithm are:

1. Set $U B=+\infty, k=0$. Initialize $v_{i j}=V_{i j}^{*}$ for all arc $i j$.

2. Solve the first stage problem. Let $x^{1}, y^{1}$ be the optimal solution, and $z^{1}$ be the optimal objective value. If $z^{1}>U B$, then terminate; otherwise, update $U B=z^{1}$, go to step 3.

3. Solve the second stage problem

3.1 For each scenario $s$, solve the problem $f\left(d_{i j}, v_{i j}{ }^{s}\right)$ with $x=x^{1}, y=y^{1}$ and $V=V^{s}$. Let $z_{i j}^{2 s}$ be the optimal value of $f\left(d_{i j}, v_{i j}{ }^{s}\right)$ for all $i j$.

3.2 Calculate the average $z_{i j}^{2}=\overline{z_{l j}^{2 s}}$ as the expectation of the optimal values of the second stage problem.

4. Update the first stage problem by $E_{s}\left[f\left(d_{i j}, v_{i j}{ }^{s}\right)\right]=z_{i j}^{2}$ and $v_{i j}=V_{i j}^{*}$ for all $i j$, and go to step 2 .

In the second phase, to improve the route, we have to check time window constraint first. However, the time window constraint is conducted based on travel speed. At that point, we have to assign a proper value to travel speed. However, heuristics that are used to solve the classical VRP cannot be directly applied for our problem. To solve this problem, we order the arc by the product of weight and distance. The reason is that carbon emission 
formulation depends largely on weight multiplied by distance. Then we choose a random travel speed limit based on a distribution function and treat this as one scenario. Based on the travel speed limit, we assign value to travel speed on the arc with largest product of weight and distance until the time window constraint is not satisfied. The algorithm for the second stage is shown as following. Figure 21 illustrates the procedure of the entire algorithm.

1. Initialize parameters, i.e., initial tour, initial travel speed limit $V_{i j}^{*}$, the maximum number of scenarios, the weight of empty vehicle and weight*distance list. The initial tour is generated based on the first stage model.

2. Calculate the weight of loaded vehicle for each arc on the initial route.

3. Sort arcs of the neighbor route in descending order of the product of weight and distance.

4. If the travel speed limit on arc with the largest product of weight and distance is equal to the initial travel speed limit, go to step 5. Otherwise, delete the arc from the weight*distance list and repeat step 4 until the weight*distance list is empty.

5. Generate travel speed limits randomly based on a truncated normal distribution starting from that arc. Choose the speed resulting in the smallest carbon emission. Assign the chosen speed to that arc.

6. If the time window constraint. is satisfied, repeat step 5 until the total running number is greater than the maximum number of scenarios. Calculate the average travel speed and average objective value for that arc. Delete the arc from the weight*distance list and go to step 4. 
7. If the time window constraint is not satisfied, set the travel speed of the latest chosen arc equal to travel speed limit, calculate the average travel speed and average objective value for that arc, then delete the arc from the weight*distance list and go to step 4. 


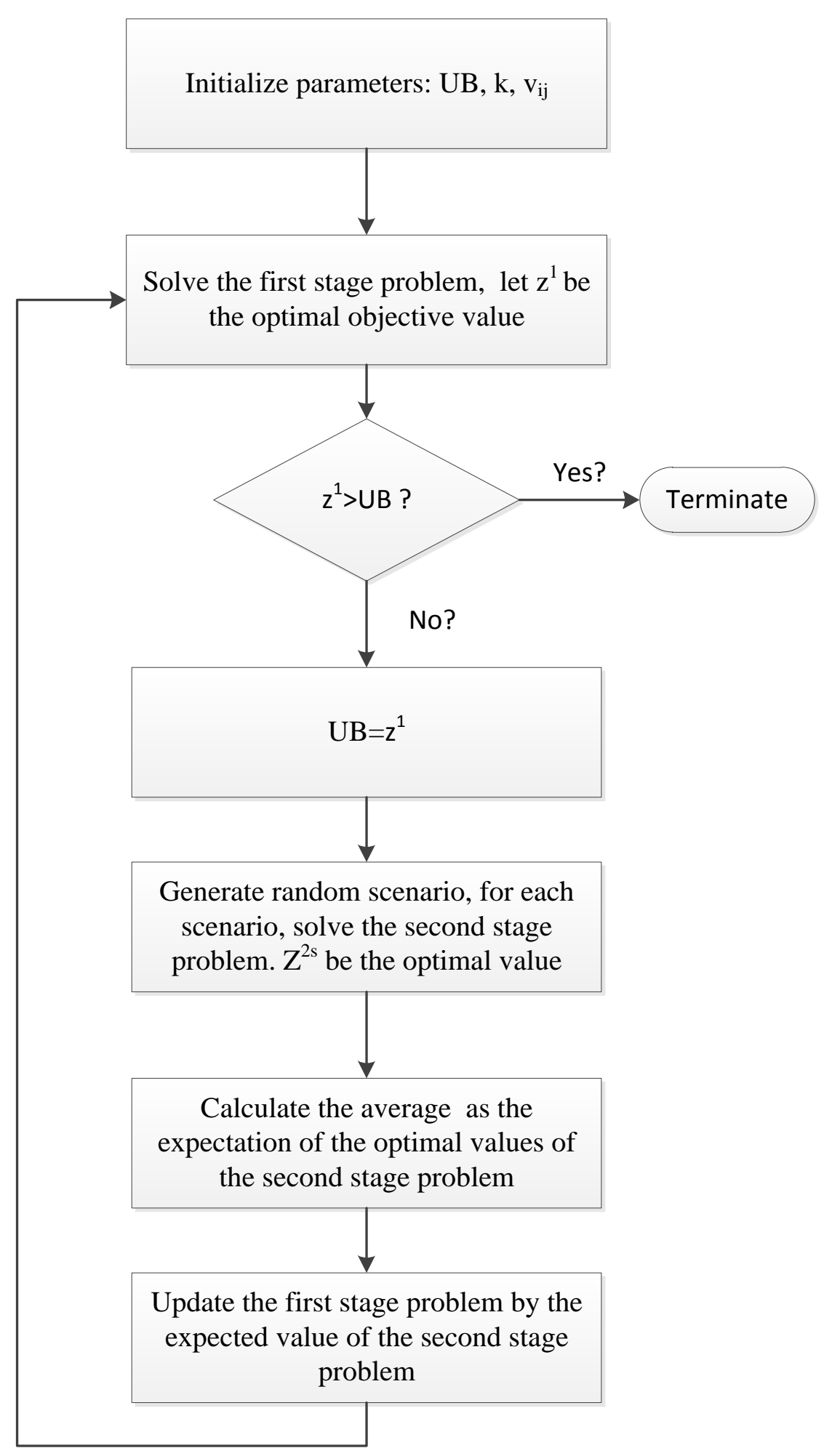

Figure 21. Algorithm for stochastic G-VRP 


\subsubsection{Sample Average Approximation}

The method proposed in section 5.1 aims to obtain a robust solution. In this section, we use sample average approximation (SAA) to solve the multiple scenarios of the stochastic problem to estimate the upper bound and lower bounds of the optimal objective values. Confidence intervals are then derived to evaluate the quality of the optimal solutions. Monte Carlo simulation can be used to approximate the optimal objective value for stochastic problems, especially when the random value is under continuous distribution. The procedure of the SAA algorithm (Santoso et al., 2005) for stochastic optimization is described below:

1. For $m=1, \ldots, M$, repeat the following steps:

(a) Generate random scenario samples $s_{1} \ldots \ldots s_{N}$.

(b) Solve the corresponding SAA problem. Let $\hat{\mathrm{x}}_{N}^{m}$ be the solution vector of a scenario, and $\mathrm{g}_{N}^{m}$ be the corresponding total fuel consumption and carbon emission.

2. Compute:

$$
\begin{gathered}
\bar{g}_{N, M}=\frac{1}{M} \sum_{m=1}^{M} \mathrm{~g}_{N}^{m} \\
\sigma_{\bar{g}_{N, M}}^{2}=\frac{1}{M(M-1)} \sum_{m=1}^{M}\left(\mathrm{~g}_{N}^{m}-\bar{g}_{N, M}\right)^{2}
\end{gathered}
$$

3. Choose the feasible solution $\tilde{x} \in X$ with the smallest objective value, $\hat{g}_{N^{\prime}}(\tilde{x})$.

4. Compute the estimators for the optimality gap and its estimated variance based on solutions from steps 2 and 3 , we get:

$$
\operatorname{gap}_{N, M, N^{\prime}}=\hat{g}_{N^{\prime}}(\tilde{x})-\bar{g}_{N, M}
$$




$$
\sigma_{g a p}^{2}=\sigma_{N^{\prime}}^{2}(\tilde{x})+\sigma_{\bar{g}_{N, M}}^{2}
$$

5. Compute the confidence interval for the optimality gap as:

$$
\left[\hat{g}_{N^{\prime}}(\tilde{x})-\bar{g}_{N, M}-z_{\alpha} \sigma_{g a p}, \hat{g}_{N^{\prime}}(\tilde{x})-\bar{g}_{N, M}+z_{\alpha} \sigma_{g a p}\right]
$$

Where $z_{\alpha}=\Phi^{-1}(1-\alpha)$, and $\Phi(\mathrm{z})$ is the cumulative distribution fuction of the standard normal distribution.

\subsection{Computational Study}

This section presents the results of numerical experiments to evaluate the performance the proposed heuristics for solving the green vehicle routing stochastic problem. We first describe the parameters that are used in the proposed methods and the generation of the test instances. Then, the computational results are presented to evaluate the solution quality against the problem size. We then demonstrate the quality of stochastic solution by comparing it to the solution obtained using the corresponding deterministic approach. At the end of this section, a real world case is introduced and sensitivity analysis of the impact of time window constraint and congestion on the optimal solution are conducted based on the real world case. All experiments are performed on a processor with 2.67 GHz speed and 4GB RAM. CPLEX 12.0 with default settings is used to solve the stage one models during the A two stage decomposition method. The optimality tolerances of two stage decomposition method are set to $0.001 \%$. All algorithms are coded in C\#.

\subsubsection{Parameter Setting}

For the experiments, test instances are generated based on the consideration of the impact of time window constraint and travel speed limit. We use small size problems instances with 7, 10, 15 nodes which are randomly selected depot and customers from US. The location information which includes longitude and latitude is randomly generated 
based on uniform distribution. The road distance is obtained based on the longitude and latitude of each node. The vehicle used in here is heavy-duty. The weight of the empty vehicle is set to $6,000 \mathrm{lb}$. The capacity of each vehicle is set to 4,259 lb. The service time at each node is set as 2 hours. The demand of each customer is randomly generated between 0 and 1,000 $\mathrm{lb}$ according uniform distribution. We consider three type of time window constraint in this experiment: no time window, loose time window and tight time window. Travel speed limit here is an uncertain parameter. According to actual speed distribution (Berry, D. S., and Belmont, D. M., 1951), we assume that the value of an uncertain parameter follows truncated normal distribution with uniformly distributed mean.

To explore the impact of congestion and time window constraint on the total carbon emission, we consider three type of congestion conditions and two type of time window limitation. We ran the algorithm 100 times with 1,000 iterations for each instance. The parameters that used in the experiments are given in Table 29.

\section{Table 29}

\section{$\underline{\text { Parameter setting }}$}

\begin{tabular}{ccc}
\hline & & Typical \\
Notation & Description & Values \\
\hline $\mathrm{Q}$ & Capacity Vehicle (ib) & 6,000 \\
$\mathrm{~m}$ & Vehicle Number & 5 \\
$\mathrm{Q}_{0}$ & Capacity of Empty Vehicle (ib) & 4,259 \\
& The reference excess emission (at $20^{\circ} \mathrm{C}$ and 12.43 & \\
$\omega$ & miles/hour) & 182.57 \\
$\mathrm{~T}$ & The temperature $\left({ }^{\circ} \mathrm{C}\right)$ & 25 \\
\hline
\end{tabular}

\subsubsection{Heuristic Performance}

\section{(1) Scalability of the Heuristic Algorithm}


To evaluate the scalability of the heuristic algorithm against the problem size, a set of computational experiments are conducted in Table 30. The column "Upper Bound" represents results when initial speed limit is 93.2 miles/hour (150 kilometers/hour), whereas "Lower Bound" represents results when initial speed limit is 42.25 miles/hour (68 kilometers/hour). The reason that we chose this two special case is 93.2 miles/hour can ensure the initial solution satisfy due time when there is time window limitation, and 42.25 miles/hour can provide the smallest carbon emission as shown in previous experiments in chapter 4 . Thus, when there is no time window constraint, we will use 42.25 miles/hour as the initial value. 93.2 miles/hour will only be used when there is time window constraint because 93.2 miles/hour could only provide an upper bound of the optimal solution. The average processing time for different scenarios over 100 iterations are shown in Table 31 respectively.

From Table 30, it can be seen that the average gaps between two cases for all scenarios remains small. They are all within a small range (less than 3\%) after approximately 30 seconds running time. For some problems, the optimality gap is very small, such as 7 nodes without time window constraint. Even for some problems where convergence is not achieved, the optimality gas remains small. Generally, the optimality gap for cases without time window limitation is less than cases with time window limitation. The impact of the problem size on optimality gap is not significant based on our observation. In Table 31, one can observe a dependency between problem size and the processing time. The second stage problem takes the majority of the time while the amount of time spent in solving the simplified first stage problem does not change too much with the number of iterations. 


\section{Table 30}

Optimality gap for different cases

\begin{tabular}{cccccc}
\hline $\begin{array}{c}\text { Problem } \\
\text { Set }\end{array}$ & Node & $\begin{array}{c}\text { Time } \\
\text { Window }\end{array}$ & $\begin{array}{c}\text { Upper Bound } \\
\text { (ton) }\end{array}$ & $\begin{array}{c}\text { Lower Bound } \\
\text { (ton) }\end{array}$ & $\begin{array}{c}\text { Gap } \\
(\%)\end{array}$ \\
\hline 1 & 7 & No TW & 13984.42 & 13982.06 & 0.02 \\
2 & 7 & With TW & 14173.73 & 14015.09 & 1.13 \\
3 & 10 & No TW & 18310.33 & 18238.11 & 0.4 \\
4 & 10 & With TW & 13150.12 & 12782.17 & 2.88 \\
5 & 15 & No TW & 17857.58 & 17855.18 & 0.01 \\
6 & 15 & With TW & 20241.18 & 20141.94 & 0.49 \\
\hline
\end{tabular}

\section{Table 31}

$\underline{\text { Average processing time in seconds over } 100 \text { iterations }}$

\begin{tabular}{rcccccccccccc}
\hline & \multicolumn{1}{c}{50} & \multicolumn{1}{c}{100} & \multicolumn{2}{c}{200} & \multicolumn{2}{c}{400} & \multicolumn{2}{c}{800} & \multicolumn{2}{c}{1000} \\
N & \multicolumn{2}{c}{ scenarios } & \multicolumn{2}{c}{ scenarios } & \multicolumn{2}{c}{ scenarios } & \multicolumn{2}{c}{ scenarios } & \multicolumn{2}{c}{ scenarios } & \multicolumn{2}{c}{ scenario } \\
\cline { 2 - 14 } & No & With & No & With & No & With & No & With & No & With & No & With \\
& TW & TW & TW & TW & TW & TW & TW & TW & TW & TW & TW & TW \\
\hline 7 & 5.95 & 5.55 & 5.96 & 5.77 & 5.78 & 5.6 & 6.04 & 5.84 & 6.35 & 5.8 & 6.42 & 5.94 \\
10 & 19.6 & 17.3 & 19.5 & 17.7 & 19.7 & 18 & 20.1 & 17.9 & 20.6 & 18 & 20.7 & 18.1 \\
15 & 77.1 & 58.2 & 69.2 & 60.8 & 69.8 & 57 & 69.9 & 67.4 & 70.7 & 69 & 71.7 & 58.8 \\
\hline
\end{tabular}

The computational performance of upper bound and lower bound using two stage heuristic algorithm are shown in Figures 22 and 23. Time window constraint is not considered in this two cases. The initial route is generated by a heuristic algorithm based on Tabu Seach which can be found in Chapter 4. We can see that the solution of upper bound decreases and the solution of lower bound increases with the number of iterations. But they will converge within an optimality gap of the optimal solution. The optimality gap will be evaluated in next section. If the optimality gap is very small, this means that the algorithm could obtain a good result that is very close to the optimal solution. Results shown in Figure 22 is the small-scale problem $($ Node $=7$ ) where both cases require 7 iterations to converge. Similarly, in Figure 23, the medium-size problem, the upper bound 
requires 14 iteration while lower bound require 24 iteration to reach the optimality gap. As the problem size increases, the number of iterations and computational time becomes larger.

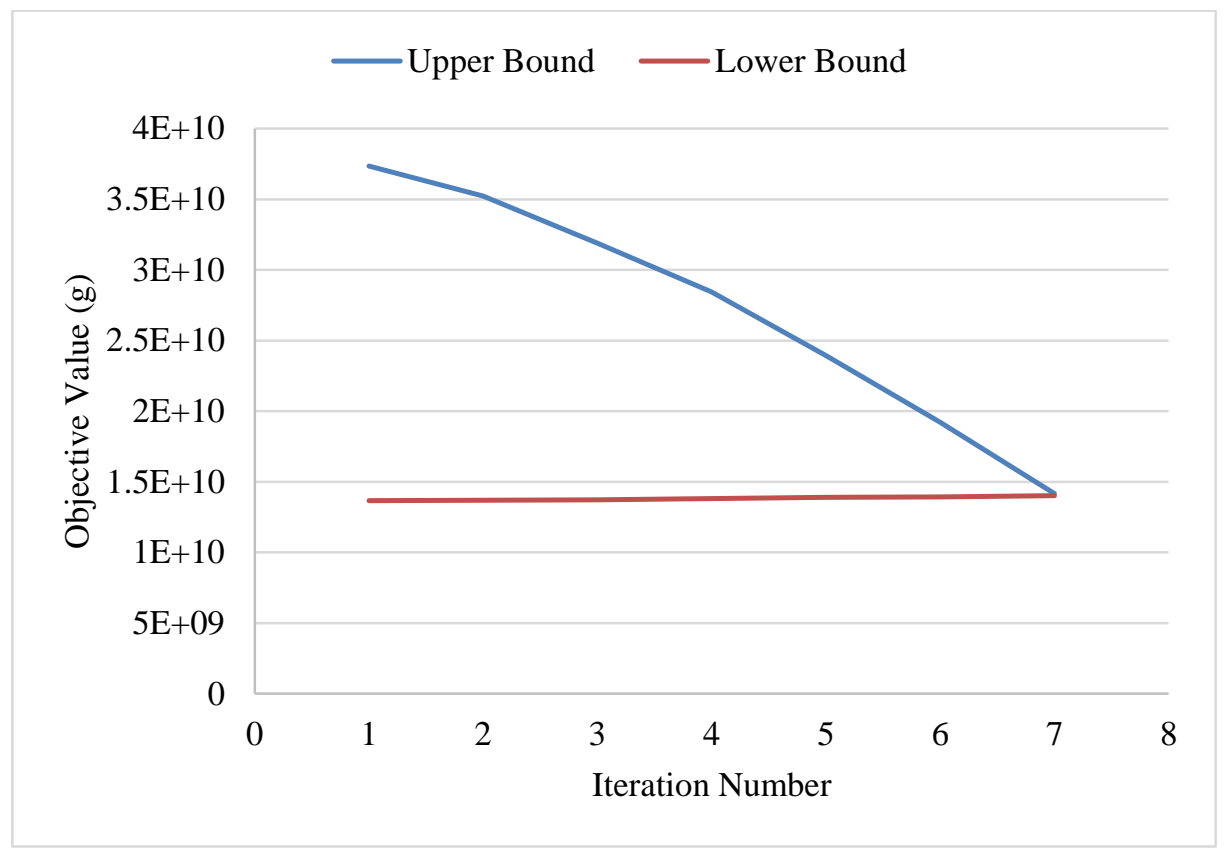

Figure 22. The convergence of the algorithm against iterations for 7 nodes

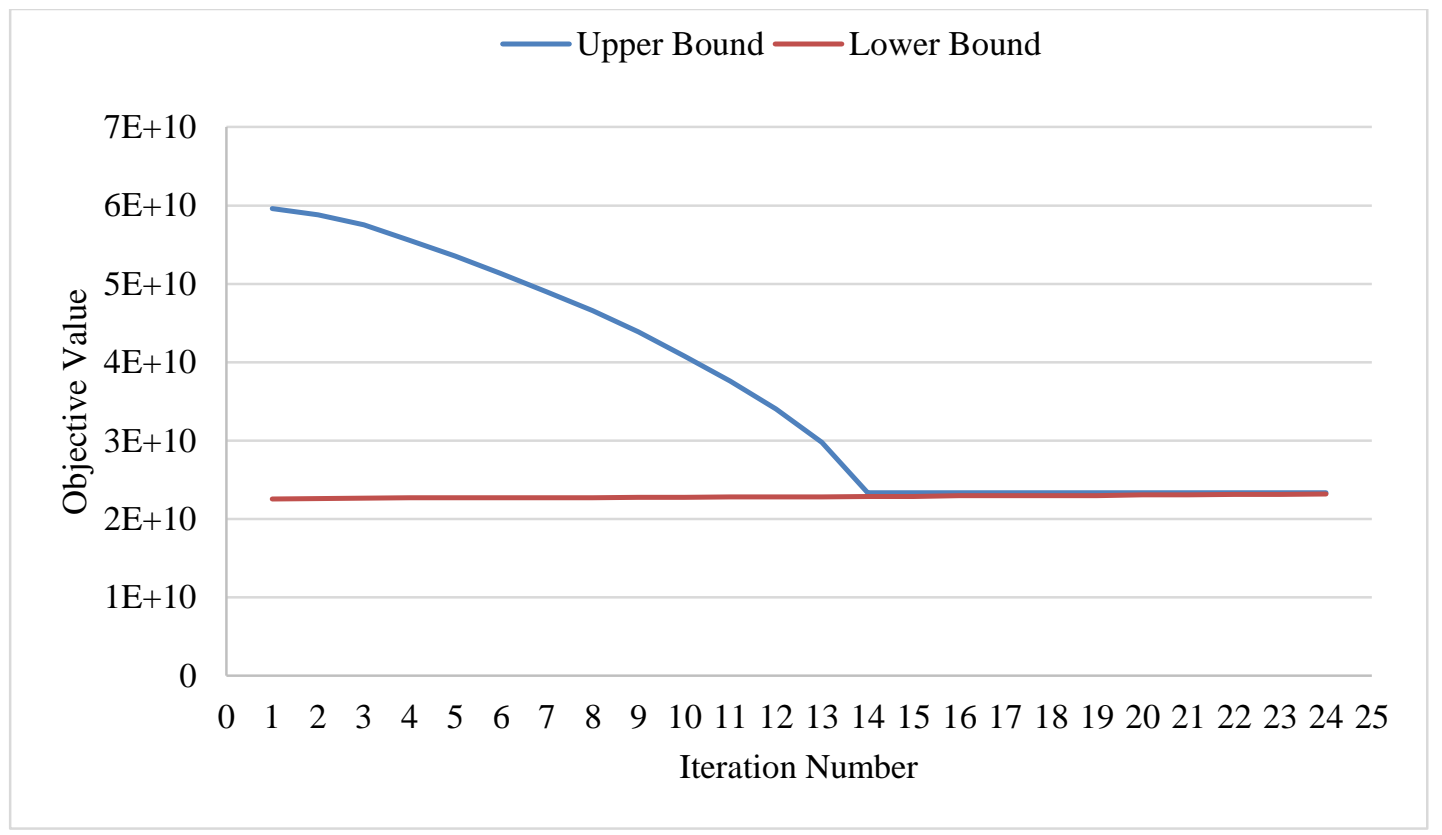

Figure 23. The convergence of the algorithm against iterations for 15 nodes 


\subsubsection{Quality of stochastic solutions}

In this section, the value of stochastic solution is used to measure the potential benefit of solving the stochastic problem over the corresponding deterministic problem. First, we use statistical mean to replace the random value (the travel speed limit) and solve the corresponding deterministic model. The deterministic problem is referred as meanvalue problem. The optimal solution denoted $\mathrm{H}$. Then, we compute the expected objective value over all scenarios which denoted $\mathrm{E}$. The uncertain parameter in each scenario is random generated based on a particular distribution. The difference between $\mathrm{H}$ and $\mathrm{E}$ is called the value of stochastic solution (VSS) (Birge, J. R., 1982).

To generate the random value for the uncertain parameter, some assumptions are made here:

1. The distribution of the uncertain parameter is assumed to be truncated normal distribution.

2. The mean of the truncated normal distribution is generated based on uniform distribution.

The experiment is conducted by solving $\mathrm{M}(=100)$ SAA problem instances with $\mathrm{N}$ (=1000). In order to study the impact of the variance of random value in quality of solutions, we consider two networks where each network has three different cases. The first case has

the highest variance. The variance of the second case is two-thirds the first case. In the third case, the variance is half of the first case. The result is shown in Table 32. 


\section{Table 32}

The sensitivity of VSS to variance

\begin{tabular}{|c|c|c|c|c|c|c|c|c|c|c|}
\hline \multirow{2}{*}{ Node } & \multirow{2}{*}{ Var. } & \multicolumn{4}{|c|}{$y$ (Kton) } & \multicolumn{4}{|c|}{$y_{m v p}$ (Kton) } & \multirow{2}{*}{$\begin{array}{l}\text { VSS } \\
(\%)\end{array}$} \\
\hline & & UB & LB & Mean & SD & JB & LB & Mean & SD & \\
\hline & 1 & 184.5 & & & 3 & 17.7 & 89.9 & & 0 & 9.2 \\
\hline & & 18 & 94.8 & & 10.5 & 109.4 & 94.5 & & 5. & 1.8 \\
\hline & & & 9 & & 6 & 9 & 90.8 & & & 2.4 \\
\hline & 10.8 & 9 & 103 & & 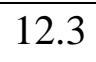 & 1 & 103.2 & & 4. & 10.0 \\
\hline & 8 & 156.4 & 97.6 & & 13.3 & 5 & 97.0 & & 0.9 & 5.6 \\
\hline & 5.4 & 145.4 & 98.4 & 113.9 & 8.8 & 120.6 & 97.9 & 111.0 & 7.1 & 2.6 \\
\hline
\end{tabular}

In Table 32, " $y$ " indicate the solution of each scenario among 100 SAA problem instances with $\mathrm{M}=100$. " $y_{m v p}$ " indicates the solution of the mean-value problem. "UB", "LB", "Mean", "SD" are the upper bound, lower bound, mean and standard deviation of the corresponding solution respectively. "VSS (\%)" is the percentage increase from average objective value to the solution of the mean-value problem. Table 32 indicates VSS is obvious for all nine cases which means that it is necessary to develop and solve stochastic green vehicle routing problem since the result of the mean-value problem cannot provide a robust solution when congestion is considered in the green vehicle routing problem. It is also noticed that VSS increases with variance for different problem size which means that stochastic green vehicle routing problem provides more benefits when uncertainty level of travel speed limit for each arc increases. For the base case with small variance, the relative increase is less than $3 \%$. However, VSS increases slightly with the increase of problem size. For example, even with the same variance, VSS for fifteen nodes problem is larger than seven nodes problem. The running time for stochastic problem and mean-value problem is almost the same, which means that stochastic green vehicle routing problem can provide more benefit without increasing computational effort. 
In Table 33, we estimate the optimality gap for different sample size $\mathrm{M}, \mathrm{N}$ and $\mathrm{N}^{\prime}$ by solving the SAA problem. The statistical upper bound and lower bounds of the 90 percent confidence interval are also presented for different set. The gap is calculated based on (X.X). "Max" and "Min" are the upper and lower limit for the confidence interval respectively. The percentage of the confidence interval is also provided here.

\section{Table 33}

Estimated optimality gap and confidence intervals

\begin{tabular}{|c|c|c|c|c|c|c|c|c|c|c|c|}
\hline \multirow[t]{2}{*}{$\mathrm{N}$} & \multirow[t]{2}{*}{ M } & \multirow[t]{2}{*}{$\mathrm{N}^{\prime}$} & \multicolumn{6}{|c|}{ Estimated optimality gap } & \multirow{2}{*}{$\begin{array}{c}\text { Gap } \\
\text { SD }\end{array}$} & \multicolumn{2}{|c|}{$\begin{array}{c}90 \% \\
\text { confidence } \\
\text { interval }\end{array}$} \\
\hline & & & Max & Var' & Min & Var & Gap & $\%$ & & Min & $\operatorname{Max}$ \\
\hline 1000 & 40 & 28000 & 99.0 & 2401.6 & 98.6 & 11.2 & 0.4 & 0.4 & 49.1 & -80.7 & 81.4 \\
\hline 500 & 20 & 10000 & 100.8 & 16.4 & 99.4 & 4.4 & 1.4 & 1.4 & 4.6 & -6.1 & 8.9 \\
\hline 100 & 10 & 1000 & 99.0 & 25.7 & 98.1 & 4.2 & 1.0 & 1.0 & 5.5 & -8.1 & 10.0 \\
\hline
\end{tabular}

As shown in Table 33, the optimality gap and the confidence interval decreases as the sample size increase in the SAA problem. The result indicate that we can get a better solution quality when we increase the number of scenarios. Moreover, the result of the optimality gap shows that our solution is applicable to provide good suggestion for a real world case. For example, when we use the sample size $N=500, M=20, N^{\prime}=10000$, it is 90 percent sure that the optimal solution is within range $(-6.12,8.93)$.

\subsection{Conclusions}

In this chapter, we consider a robust green vehicle problem, where speed limit on each arc is stochastic and expected fuel cost is minimized. This is to approach practice since conjunction generally exists in reality. Because the mathematical model cannot be solved directly by CPLEX, a two-stage heuristic with sample average approximation is 
developed and its advantage in solution quality is demonstrated through computational study. By comparing the solutions of robust with traditional green vehicle routing problems, it is found that our robust VRP solutions can reduces the expected fuel cost with small optimality gap. 


\section{CHAPTER VI}

\section{CONCLUSIONS AND FUTURE RESEARCH}

\subsection{Conclusions}

Motivated by the desire of designing an efficient and environmentally friendly logistics system to satisfy both government and carriers, we considered three problems in this dissertation: intermodal network design, the deterministic green vehicle routing problem and the stochastic green vehicle routing problem. These three problems were studied independently with detailed conclusions and discussion on future work in each underlying chapter. An overview of the contributions of this dissertation work and potential research directions are presented in this chapter.

The first problem is about intermodal network design. Based on the current transportation pattern choice and corresponding carbon emission data, we analyzed a real world intermodal network which covers fifteen states and the entire inland waterway system in US. Four boundary models were built to investigate the potential improvement

of the network in terms of economic cost and environmental cost. With the motivation of seeking a policy to maximize the usage of inland waterway without increasing economic cost, a multi-objective intermodal network model was built to minimize the environmental cost, economic cost and time penalty cost simultaneously. To simulate real choice in the network, a time penalty parameter was introduced in the multi-objective model. Based on the real world distance and carbon emission data, sensitivity 
analysis for carbon emission tax policy was conducted. The analytical results show that the breakeven point for carbon emission tax is $\$ 13 /$ ton, which can maximize the improvement of environment without increasing actual cost.

The second problem is an extended green vehicle routing problem which is formulated based on the pollution routing problem. With the consideration of various travel speeds, a mixed integer nonlinear programming model was formulated with the objective of minimizing the total carbon emission. The carbon emission function is a nonlinear function of travel speed, distance and load of vehicle. Because this problem is NP-Hard, a heuristic algorithm based on a savings heuristic and Tabu Search is developed to solve a large case for this problem. To assess the performance of the proposed heuristic algorithm, numerical experiments are conducted through comparison with solution obtained by BONMIN in GAMS on randomly generated problem instances. The results show that the improved Tabu Search performs better than BONMIN in all cases with the average carbon emission reduction of $7.76 \%$ and less running time. Sensitivity analysis is conducted to investigate the impact of a time window constraint, travel speed and travel speed limit. Total carbon emission increases significantly with the reduction of the range of time window limitation. The extensive experimental results indicate that improvement for environment is more apparent when the time window constraint is loose comparing with tight time window limitation. In addition, a real world case is conducted to further investigate the impact of time window limitation, travel speed and congestion. Under the no time window scenario, our proposed G-VRP with various travel speed could achieve $32.27 \%$ carbon emission reduction comparing with basic VRP with objective of minimizing travel distance, and $15.69 \%$ carbon emission reduction comparing with basic 
G-VRP with constant travel speed without increasing travel distance. Experiments on travel speed limit show that congestion has great influence on carbon emission.

To further investigate the impact of congestion on carbon emission in the real world, we study a stochastic green vehicle routing problem in Chapter 5. Actual travel speed limit on each arc is treated as a random value based on a truncated normal distribution. The objective of the stochastic green vehicle routing problem is to obtain a robust vehicle route with minimum expected total carbon emission. A two-stage heuristic algorithm is developed to solve this problem and sample average approximation is used to evaluate the quality of solutions through computational study. The value of the stochastic solution is used to compare the average objective value of stochastic problem with solutions of meanvalue problem. Numerical results show that VSS is obvious for all cases which indicate stochastic green vehicle routing problem can provide more benefit comparing with meanvalue problem, especially when uncertainty level of random value is high. In addition, it is noticed that our stochastic G-VRP solution can provide a robust solution with small optimality gap (less than $1.5 \%$ ) which means that our solution can provide applicable suggestion for the real world problem.

\subsection{Future work}

Based on the current research, possible future research directions and extensions for this work include:

1. Consider multiple types of cargos and larger network in the intermodal network design problem. In the current work, we analyzed the tax policy for a coal transportation network. It is necessary to extend this work to multiple types of cargo. In addition, we consider three transportation modes in this dissertation: 
railway, highway and inland waterway. Future studies could consider a network with airlines.

2. Improve the heuristic algorithm for the deterministic green vehicle routing problem. In this work, we use 2-Opt to generate neighbor routes in our heuristic algorithm. To improve the algorithm, different exchange rules could be used to generate neighbor routes, such as: K-Opt, Swap and Relocation.

3. Develop mix vehicle green vehicle routing model. We consider homogeneous vehicles in this work. To extend this work, future studies could include different types of vehicles in the deterministic and stochastic green vehicle routing model. Moreover, in the stochastic problem, we use a truncated normal distribution to generate the random values. Comparing other different distributions is another research direction for future work.

4. Use of real time models to assist dispatchers in making trade-offs between cost, time and carbon emissions. In our work, we have applied the aggregate problem to design the intermodal transportation network with the objective to minimize total cost and carbon emission for the entire supply chains. We could extend this work by considering a real time model for individual cases to help different decision makers balance the trade-offs between transportation cost and carbon emissions.

5. Implement of carbon emission tax in practice. In Chapter 3, we proposed a carbon emission tax policy for intermodal transportation. Because carbon emission tax could have a great impact on the economy. How to apply that policy in the real world is also a critical issue for future work. In general, there 
are two different ways to implement the carbon emission tax in the intermodal transportation. First, we could submit the proposal to the government agents. Because the revenue of the government depends largely on various tax. Based on our analysis, if we set the breakeven point for carbon emission tax to be $\$ 13 /$ ton, the total amount of revenue for the government will raise around $\$ 11.7$ million. The government can use the additional revenue to invest programs of improving environment, lower other taxes or as general salary income for government agents. Second, we could show the proposal to the some intermodal logistic companies, such as BNSF railway. Carbon emission tax would encourage companies to switch from expensive shipping method to a cheaper transportation method. Thus, the tax could boost the business of intermodal transportation. Based on our analysis, the percentage of intermodal transportation in the coal transportation system will increase $39.7 \%$ in an ideal situation. Thus, carbon emission tax policy could potentially increase the revenue of these logistic companies, which will encourage these companies to promote the implement of this policy. 


\section{REFERENCES}

Ando, N., \& Taniguchi, E. (2006). Travel time reliability in vehicle routing and scheduling with time windows. Networks and Spatial Economics, 6(3-4), 293-311.

Azi, N., Gendreau, M., \& Potvin, J. Y. (2007). An exact algorithm for a single-vehicle routing problem with time windows and multiple routes. European journal of operational research, 178(3), 755-766.

Azi, N., Gendreau, M., \& Potvin, J. Y. (2010). An exact algorithm for a vehicle routing problem with time windows and multiple use of vehicles. European Journal of Operational Research, 202(3), 756-763.

Beltran, B., Carresea, S., Cipriani, E., Petrellia, M. (2009). Transit network design with allocation of green vehicles: a genetic algorithm approach. Transportation Research Part C: Emerging Technologies 17, 475-483.

Bektas, T., \& Crainic, T. (2007). A brief overview of intermodal transportation. CIRRELT.

Berry, D. S., \& Belmont, D. M. (1951). Distribution of vehicle speeds and travel times. In Proceedings of the Second Berkeley Symposium on Mathematical Statistics and Probability. The Regents of the University of California, 589-602.

Bektaş, T., \& Laporte, G. (2011). The pollution-routing problem. Transportation Research Part B: Methodological, 45(8), 1232-1250. 
Benjaafar, S., Li, Y., \& Daskin, M. (2010). Carbon footprint and the management of supply chains: Insights from simple models. Working paper

Benjaafar, S., Li, Y., \& Daskin, M. (2013). Carbon footprint and the management of supply chains: Insights from simple models. Automation Science and Engineering, IEEE Transactions on, 10(1), 99-116.

Bentley, J. J. (1992). Fast algorithms for geometric traveling salesman problems. ORSA Journal on computing, 4(4), 387-411.

Birge, J. R. (1982). The value of the stochastic solution in stochastic linear programs with fixed recourse. Mathematical programming, 24(1), 314-325.

Blauwens, G., Vandaele, N., Van de Voorde, E., Vernimmen, B., \& Witlox, F. (2006). Towards a modal shift in freight transport? A business logistics analysis of some policy measures. Transport Reviews, 26(2), 239-251.

Bloemhof, J. M., Van der Laan, E. A., \& Beijer, C. (2011). Sustainable Inland Transportation. International Journal of Business Insights \& Transformation, 3. B. Murtagh and M. Saunders (1993). MINOS 5.4 user's guide, Report SOL 83-20R, Department of Operations Research, Stanford University.

Bräysy, O., \& Gendreau, M. (2005). Vehicle routing problem with time windows, Part II: Metaheuristics. Transportation science, 39(1), 119-139.

Bräysy, O., \& Gendreau, M. (2005). Vehicle routing problem with time windows, Part I: Route construction and local search algorithms. Transportation science, 39(1), 104-118.

Bräysy, O. (2003). Fast local searches for the vehicle routing problem with time windows. Inform.Systems Oper.Res. 41 179-194. 
Bonami, P., Kilinç, M., \& Linderoth, J. (2012). Algorithms and software for convex mixed integer nonlinear programs. Mixed integer nonlinear programming. Springer New York, 1-39.

Bostel, N., \& Dejax, P. (1998). Models and algorithms for container allocation problems on trains in a rapid transshipment shunting yard. Transportation science, 32(4), 370-379.

Bouthillier, A. L., \& Crainic, T. G. (2005). A cooperative parallel meta-heuristic for the vehicle routing problem with time windows. Computers \& Operations Research, 32(7), 1685-1708.

Chiang, W. C., \& Russell, R. A. (1996). Simulated annealing metaheuristics for the vehicle routing problem with time windows. Annals of Operations Research, 63(1), 3-27.

Clarke, G., Wright, J.W. (1964). Scheduling of vehicle from central depot to a number of delivery points. Operations Research $12,568-581$.

Cordeau, J. F., Desaulniers, G., Desrosiers, J., Solomon, M. M., \& Soumis, F. (2001). VRP with time windows. The vehicle routing problem, 9, 157-193.

Cordeau, J. F., Laporte, G., Ropke, S., \& Valentini, M. P. (2008). Modeling and solving a multimodal routing problem with timetables and time windows. CIRRELT.

Cordeau, J. F., \& Laporte, G. (2003). The dial-a-ride problem (DARP): Variants, modeling issues and algorithms. Quarterly Journal of the Belgian, French and Italian Operations Research Societies, 1(2), 89-101.

Cordeau, J.-F., Laporte, G., Savelsbergh, M.W.P., Vigo, D. (2007). Vehicle routing. In: Barnhart, C., Laporte, G. (Eds.), Transportation, Handbooks in Operations Research and Management Science, Amsterdam, The Netherlands, 14,367-428. 
Crainic, T. G., Florian, M., Guelat, J., \& Spiess, H. (1990). Strategic planning of freight transportation: STAN, an interactive-graphic system (No. 1283).

Dekker, R., Bloemhof, J., \& Mallidis, I. (2012). Operations Research for green logistics-An overview of aspects, issues, contributions and challenges. European Journal of Operational Research, 219(3), 671-679.

Desaulniers, G., Lavigne, J., \& Soumis, F. (1998). Multi-depot vehicle scheduling problems with time windows and waiting costs. European Journal of Operational Research, 111(3), 479-494.

Dumas, Y., Desrosiers, J., \& Soumis, F. (1991). The pickup and delivery problem with time windows. European Journal of Operational Research, 54(1), 7-22.

Desrochers, M., Desrosiers, J., \& Solomon, M. (1992). A new optimization algorithm for the vehicle routing problem with time windows. Operations research, 40(2), $342-354$

D’Agosto, M., \& Ribeiro, S. K. (2004). Eco-efficiency management program (EEMP) - a model for road fleet operation. Transportation Research Part D: Transport and Environment, 9(6), 497-511.

Eksioglu, B., Vural, A. V., \& Reisman, A. (2009). The vehicle routing problem: A taxonomic review. Computers \& Industrial Engineering, 57(4), 1472-1483.

Elhedhli, S., \& Merrick, R. (2012). Green supply chain network design to reduce carbon emissions. Transportation Research Part D: Transport and Environment, 17(5), $370-379$

El-Sherbeny, N. A. (2010). Vehicle routing with time windows: An overview of exact, heuristic and metaheuristic methods. Journal of King Saud UniversityScience, 22(3), 123-131. 
European Conference of Ministers of Transport (1993). Terminology on combined transport. Internet site <http://www.cordis.lu/transport $>$.

Fahimnia, B., Reisi, M., Paksoy, T., \& Özceylan, E. (2013). The implications of carbon pricing in Australia: An industrial logistics planning case study. Transportation Research Part D: Transport and Environment, 18, 78-85.

Feo, T. A., \& González-Velarde, J. L. (1995). The intermodal trailer assignment problem. Transportation Science, 29(4), 330-341.

Figliozzi, M. A. (2011). The impacts of congestion on time-definitive urban freight distribution networks CO 2 emission levels: Results from a case study in Portland, Oregon. Transportation Research Part C: Emerging Technologies, 19(5), 766-778.

Fisher, M., K. Joernsten, O. Madsen (1997). Vehicle routing with time windows: Two optimization algorithms. Operations research. 45(3) 488-492

Goel, A. (2010). The value of in-transit visibility for supply chains with multiple modes of transport. International Journal of Logistics: Research and Applications, 13(6), 475-492.

Golden, B.L., and Assad, A.A. (1988). Vehicle Routing: Methods and Studies, NorthHolland, Amsterdam.

Golden, B.L., Raghavan, S., Wasil, E.A. (2008). The Vehicle Routing Problem: Latest Advances and Recent Challenges. Operations Research Computer Science Interfaces. Springer, New York.

Hickman, J., Hassel, D., Joumard, R., Samaras, Z., \& Sorenson, S. (1999). Methodology for calculating transport emissions and energy consumption. 
Hoen, K. M. R., Tan, T., Fransoo, J. C., \& Van Houtum, G. J. (2010). Effect of carbon emission regulations on transport mode selection in supply chains. Eindhoven University of Technology.

Hua, G., Cheng, T. C. E., \& Wang, S. (2011). Managing carbon footprints in inventory management. International Journal of Production Economics, 132(2), 178-185.

I.H. Osman, Metastrategy (1993). simulated annealing and tabu search algorithms for the vehicle routing problems, Ann. Operations Research. 40, 421-452.

Iakovou, E., Karagiannidis, A., Vlachos, D., Toka, A., \& Malamakis, A. (2010). Waste biomass-to-energy supply chain management: a critical synthesis. Waste Management, 30(10), 1860-1870.

Janic, M. (2011). Assessing some social and environmental effects of transforming an airport into a real multimodal transport node. Transportation Research Part D: Transport and Environment, 16(2), 137-149.

J Bauer, T. B. S., \& Crainic, T. G. (2009). Minimizing greenhouse gas emissions in intermodal freight transport: an application to rail service design. Journal of the Operational Research Society, 61(3), 530-542.

J.R. Birge and F.V. Louveaux (1997). Introduction to Stochastic Programming. Springer, New York.

Jourquin, B., Beuthe, M., \& Demilie, C. L. (1999). Freight bundling network models: Methodology and application. Transportation Planning and Technology, 23(2), $157-177$

Kwon, Y. J., Choi, Y. J., \& Lee, D. H. (2013). Heterogeneous fixed fleet vehicle routing considering carbon emission. Transportation Research Part D: Transport and Environment, 23, 81-89. 
Kuo, Y. (2010). Using simulated annealing to minimize fuel consumption for the timedependent vehicle routing problem. Computers \& Industrial Engineering, 59(1), $157-165$.

Konings, R. (2007). Opportunities to improve container barge handling in the port of Rotterdam from a transport network perspective. Journal of Transport Geography, 15(6), 443-454.

Kara,_I., Kara, B., \& Yetis, M. (2007). Energy minimizing vehicle routing problem. Lecture notes in computer science, 4616, 62-71.

Kemper, P., Fischer, M. (2000). Modelling and analysis of a freight terminal with stochastic Petri nets. IFAC Control in Transportation Systems, Braunschweig, Germany, 267-272.

Koskosidis, Y. A., Powell, W. B., \& Solomon, M. M. (1992). An optimization-based heuristic for vehicle routing and scheduling with soft time window constraints. Transportation Science, 26(2), 69-85.

Laporte, G. (1992). The vehicle routing problem: An overview of exact and approximate algorithms. European Journal of Operational Research, 59(3), $345-358$

Leal Jr, I. C., \& D’Agosto, M. D. A. (2011). Modal choice evaluation of transport alternatives for exporting bio-ethanol from Brazil. Transportation Research Part D: Transport and Environment, 16(3), 201-207.

Lenstra, J. K., Desrochers, M., Savelbergh, M. W. P., \& Soumis, F. (1988).Vehicle routing with time windows: optimization and approximation. Elsevier Science Publishers, North-Holland, 65-83.

Lenstra, J. K., \& Kan, A. H. G. (1981). Complexity of vehicle routing and scheduling problems. Networks, 11(2), 221-227. 
Lin, C., Choy, K. L., Ho, G. T. S., Chung, S. H., \& Lam, H. Y. (2014). Survey of green vehicle routing problem: past and future trends. Expert Systems with Applications, 41(4), 1118-1138.

Loureiro, C.F.G. (1994). Modeling investment options for multimodal transportation networks. Dissertation at the University of Tennessee. UMI Dissertation Service, Ann Arbor, MI.

Maden, W., Eglese, R., \& Black, D. (2010). Vehicle routing and scheduling with timevarying data: A case study. Journal of the Operational Research Society, 61(3), $515-522$

Mallidis, I., Dekker, R., \& Vlachos, D. (2012). The impact of greening on supply chain design and cost: a case for a developing region. Journal of Transport Geography, 22, 118-128.

Macharis, C., \& Bontekoning, Y. M. (2004). Opportunities for OR in intermodal freight transport research: A review. European Journal of operational research, 153(2), 400-416.

N. Christofides and J. Beasley (1984). The period routing problem, Networks, 14 , $237-$ 246.

Ombuki, B., Ross, B. J., \& Hanshar, F. (2006). Multi-objective genetic algorithms for vehicle routing problem with time windows. Applied Intelligence, 24(1), 17-30.

Palmer, A. (2007). The development of an integrated routing and carbon dioxide emissions model for goods vehicles.

Pan, S., Ballot. E. \& Fontane, F. (2010). The reduction of greenhouse gas emissions from freight transport by pooling supply chains. International Journal of Production Economics, 143(1), 86-94. 
Potvin, J. Y., \& Rousseau, J. M. (1993). A parallel route building algorithm for the vehicle routing and scheduling problem with time windows. European Journal of Operational Research, 66(3), 331-340.

Powell, W. B., \& Carvalho, T. A. (1998). Real-time optimization of containers and flatcars for intermodal operations. Transportation Science, 32(2), 110-126.

Quariguasi Frota Neto, J., Walther, G., Bloemhof, J., Van Nunen, J. A. E. E., \& Spengler, T. (2009). A methodology for assessing eco-efficiency in logistics networks. European Journal of Operational Research, 193(3), 670-682.

Ren, Y., Dessouky, M., \& Ordóñez, F. (2010). The multi-shift vehicle routing problem with overtime. Computers \& Operations Research, 37(11), 1987-1998.

Rosenthal, R. E. (2004). GAMS--a user's guide.

Ross, M. (1997). Fuel efficiency and the physics of automobiles. Contemporary Physics, 38(6), 381-394.

Russell, R. A. (1995). Hybrid heuristics for the vehicle routing problem with time windows. Transportation Science, 29, 156-166.

Santoso, T., Ahmed, S., Goetschalckx, M., \& Shapiro, A. (2005). A stochastic programming approach for supply chain network design under uncertainty. European Journal of Operational Research, 167(1), 96-115.

Shenle, P. A. N., BALLOT, E., \& FONTANE, F. (2009). The reduction of greenhouse gas emissions from freight transport by merging supply chains.

Southworth, F., \& Peterson, B. E. (2000). Intermodal and international freight network modeling. Transportation Research Part C: Emerging Technologies, 8(1), 147166.

Srivastava, S. K. (2007). Green supply-chain management: a state-of-the-art literature review. International journal of management reviews, 9(1), 53-80. 
Sasikumar, P., Kannan, G., \& Haq, A. N. (2010). A multi-echelon reverse logistics network design for product recovery — a case of truck tire remanufacturing. The International Journal of Advanced Manufacturing Technology, 49(9-12), 12231234.

Sbihi, A., \& Eglese, R. W. (2007). The Relationship between Vehicle Routing \& Scheduling and Green Logistics-A Literature Survey.

Schneider, M., Stenger, A., \& Goeke D. (2012). The electric vehicle routing problem with time windows and recharging stations. Technical Report, University of Kaiserslautern, Kaiserslautern, Germany.

Short, J., \& Kopp, A. (2005). Transport infrastructure: investment and planning. Policy and research aspects. Transport Policy, 12(4), 360-367.

Solomon, M. M. (1987). Algorithms for the vehicle routing and scheduling problems with time window constraints. Operations research, 35(2), 254-265.

Spasovic, L. N., \& Morlok, E. K. (1993). Using marginal costs to evaluate drayage rates in rail-truck intermodal service. Transportation Research Record, 1383.

Taniguchi E, Thompson RG, Yamada T, van Duin R. (2001). City logistics—network modelling and intelligent transport systems. Pergamon, Oxford.

Taylor, G. D., Broadstreet, F., Meinert, T. S., \& Usher, J. S. (2002). An analysis of intermodal ramp selection methods. Transportation Research Part E: Logistics and Transportation Review, 38(2), 117-134.

Tsai, J. F. (1996). Models for optimal price and level of service positioning of intermodal service in competition with truck service. Transportation Research Part A, 1(30), 63.

Touati, N., \& Jost, V. (2012). On green routing and scheduling problem. arXiv preprint arXiv:1203.1604. 
Toth, P., \& Vigo, D. (2002). Models, relaxations and exact approaches for the capacitated vehicle routing problem. Discrete Applied Mathematics, 123(1), 487-512.

US DOT, Department of Transportation (2010). The Transportation's Role in Reducing US Greenhouse Gas Emissions.

U.S. Department of Transportation (USDOT), Bureau of Transportation Statistics (2002). Freight Shipments In America.

Vanek, F.M., Morlok, E.K. (2000). Improving the energy efficiency of freight in the United States through commodity-based analysis: justification and implementation. Transportation Research-D 5 (1), 11-29.

Van Duin, R., \& van Ham, H. (1998). A three-stage modeling approach for the design and organization of intermodal transportation services. In Systems, Man, and Cybernetics. 1998 IEEE International Conference, 4, 4051-4056.

Winston, C., \& Langer, A. (2006). The effect of government highway spending on road users' congestion costs. Journal of Urban Economics, 60(3), 463-483.

Xifeng, T., Ji, Z., \& Peng, X. (2013). A multi-objective optimization model for sustainable logistics facility location. Transportation Research Part D: Transport and Environment, 22, 45-48.

Xiao, Y., Zhao, Q., Kaku, I., \& Xu, Y. (2012). Development of a fuel consumption optimization model for the capacitated vehicle routing problem. Computers \& Operations Research, 39(7), 1419-1431.

X. Duan and S. Heragu (2015). Carbon Emission Tax Policy in an Intermodal Transportation Network. Proceedings of the 2015 Industrial and Systems Engineering Research Conference. 
Yan, S., Bernstein, D., \& Sheffi, Y. (1995). Intermodal pricing using network flow techniques. Transportation Research Part B: Methodological, 29(3), 171-180.

http://www.epa.gov/climatechange/ghgemissions/sources/transportation.html

http://en.wikipedia.org/wiki/Inland_waterways_of_the_United_States

http://www.mjc2.com/e-freight-logistics.htm Intermodal Optimization 


\section{APPENDIX}

Appendix I Result of Boundary Cases

\begin{tabular}{|c|c|c|c|c|c|c|c|}
\hline \multirow{2}{*}{} & \multicolumn{2}{|c|}{$\begin{array}{c}\text { Transportation } \\
\text { Path }\end{array}$} & $\begin{array}{c}\text { Transportation } \\
\text { Mode }\end{array}$ & $\begin{array}{c}\text { Original } \\
\text { Node }\end{array}$ & $\begin{array}{c}\text { Destination } \\
\text { Node }\end{array}$ & $\begin{array}{c}\text { Value } \\
\text { (kton) }\end{array}$ & $\begin{array}{c}\text { Reduced } \\
\text { Cost }\end{array}$ \\
\cline { 2 - 6 } & I & J & M & O & D & & \\
\hline $\mathrm{x}$ & 18 & 29 & R & 18 & 29 & 10.25 & 0 \\
\hline $\mathrm{x}$ & 29 & 44 & $\mathrm{R}$ & 29 & 44 & 2.15 & 0 \\
\hline $\mathrm{x}$ & 44 & 29 & $\mathrm{R}$ & 95 & 29 & 407.27 & 0 \\
\hline $\mathrm{x}$ & 61 & 44 & $\mathrm{R}$ & 95 & 29 & 407.27 & 0 \\
\hline $\mathrm{x}$ & 95 & 61 & $\mathrm{R}$ & 95 & 29 & 407.27 & 0 \\
\hline $\mathrm{x}$ & 36 & 40 & $\mathrm{R}$ & 95 & 40 & 2496.73 & 0 \\
\hline $\mathrm{x}$ & 44 & 36 & $\mathrm{R}$ & 95 & 40 & 2496.73 & 0 \\
\hline $\mathrm{x}$ & 61 & 44 & $\mathrm{R}$ & 95 & 40 & 2496.73 & 0 \\
\hline $\mathrm{x}$ & 95 & 61 & $\mathrm{R}$ & 95 & 40 & 2496.73 & 0 \\
\hline $\mathrm{x}$ & 95 & 60 & $\mathrm{R}$ & 95 & 60 & 9186.01 & 0 \\
\hline $\mathrm{x}$ & 95 & 115 & $\mathrm{R}$ & 95 & 113 & 1074.76 & 0 \\
\hline $\mathrm{x}$ & 115 & 116 & $\mathrm{R}$ & 95 & 113 & 1074.76 & 0 \\
\hline $\mathrm{x}$ & 116 & 113 & $\mathrm{H}$ & 95 & 113 & 1074.76 & 0 \\
\hline $\mathrm{x}$ & 95 & 247 & $\mathrm{R}$ & 95 & 122 & 7603.95 & 0 \\
\hline $\mathrm{x}$ & 127 & 122 & $\mathrm{R}$ & 95 & 122 & 7603.95 & 0 \\
\hline $\mathrm{x}$ & 247 & 127 & $\mathrm{R}$ & 95 & 122 & 7603.95 & 0 \\
\hline $\mathrm{x}$ & 95 & 247 & $\mathrm{R}$ & 95 & 161 & 6017.21 & 0 \\
\hline $\mathrm{x}$ & 127 & 145 & $\mathrm{R}$ & 95 & 161 & 6017.21 & 0 \\
\hline $\mathrm{x}$ & 145 & 161 & $\mathrm{R}$ & 95 & 161 & 6017.21 & 0 \\
\hline $\mathrm{x}$ & 247 & 127 & $\mathrm{R}$ & 95 & 161 & 6017.21 & 0 \\
\hline $\mathrm{x}$ & 95 & 247 & $\mathrm{R}$ & 95 & 163 & 4.47 & 0 \\
\hline $\mathrm{x}$ & 141 & 192 & $\mathrm{~W}$ & 95 & 163 & 4.47 & 0 \\
\hline $\mathrm{x}$ & 182 & 163 & $\mathrm{R}$ & 95 & 163 & 4.47 & 0 \\
\hline $\mathrm{x}$ & 192 & 195 & $\mathrm{R}$ & 95 & 163 & 4.47 & 0 \\
\hline $\mathrm{x}$ & 195 & 182 & $\mathrm{~W}$ & 95 & 163 & 4.47 & 0 \\
\hline $\mathrm{x}$ & 247 & 141 & $\mathrm{R}$ & 95 & 163 & 4.47 & 0 \\
\hline $\mathrm{x}$ & 95 & 247 & $\mathrm{R}$ & 95 & 183 & 820.03 & 0 \\
\hline $\mathrm{x}$ & 127 & 145 & $\mathrm{R}$ & 95 & 183 & 820.03 & 0 \\
\hline $\mathrm{x}$ & 145 & 175 & $\mathrm{R}$ & 95 & 183 & 820.03 & 0 \\
\hline $\mathrm{x}$ & 175 & 183 & $\mathrm{R}$ & 95 & 183 & 820.03 & 0 \\
\hline $\mathrm{x}$ & 247 & 127 & $\mathrm{R}$ & 95 & 183 & 820.03 & 0 \\
\hline $\mathrm{x}$ & 95 & 247 & $\mathrm{R}$ & 95 & 192 & 364.24 & 0 \\
\hline $\mathrm{x}$ & 141 & 192 & $\mathrm{~W}$ & 95 & 192 & 364.24 & 0 \\
\hline
\end{tabular}




\begin{tabular}{|c|c|c|c|c|c|c|c|}
\hline $\mathrm{x}$ & 247 & 141 & $\mathrm{R}$ & 95 & 192 & 364.24 & 0 \\
\hline $\mathrm{x}$ & 96 & 63 & $\mathrm{R}$ & 96 & 63 & 4155.23 & $\overline{0}$ \\
\hline $\mathrm{x}$ & 96 & 104 & $\mathrm{R}$ & 96 & 104 & 476.98 & 0 \\
\hline $\mathrm{x}$ & 96 & 121 & $\mathrm{~W}$ & 96 & 120 & 1979.69 & $\overline{0}$ \\
\hline $\mathrm{x}$ & 121 & 120 & $\mathrm{R}$ & 96 & 120 & \begin{tabular}{|c|}
1979.69 \\
\end{tabular} & 0 \\
\hline $\mathrm{x}$ & 96 & 104 & $\mathrm{R}$ & 96 & 183 & 8.85 & 0 \\
\hline $\mathrm{x}$ & 104 & 252 & $\mathrm{H}$ & 96 & 183 & 8.85 & 0 \\
\hline $\mathrm{x}$ & 122 & 139 & $\mathrm{R}$ & 96 & 183 & 8.85 & 0 \\
\hline $\mathrm{x}$ & 139 & 175 & $\mathrm{R}$ & 96 & 183 & 8.85 & 0 \\
\hline $\mathrm{x}$ & 175 & 183 & $\mathrm{R}$ & 96 & 183 & 8.85 & 0 \\
\hline $\mathrm{x}$ & 252 & 122 & $\mathrm{~W}$ & 96 & 183 & 8.85 & 0 \\
\hline $\mathrm{x}$ & 44 & 29 & $\mathrm{R}$ & 104 & 29 & 3.97 & 0 \\
\hline $\mathrm{X}$ & 60 & 44 & $\mathrm{R}$ & 104 & 29 & 3.97 & 0 \\
\hline $\mathrm{x}$ & 86 & 60 & $\mathrm{R}$ & 104 & 29 & 3.97 & 0 \\
\hline $\mathrm{x}$ & 97 & 86 & $\mathrm{R}$ & 104 & 29 & 3.97 & 0 \\
\hline $\mathrm{x}$ & 104 & 97 & $\mathrm{R}$ & 104 & 29 & 3.97 & 0 \\
\hline $\mathrm{x}$ & 86 & 60 & $\mathrm{R}$ & 104 & 60 & 11.68 & 0 \\
\hline $\mathrm{x}$ & 97 & 86 & $\mathrm{R}$ & 104 & 60 & 11.68 & 0 \\
\hline $\mathrm{x}$ & 104 & 97 & $\mathrm{R}$ & 104 & 60 & 11.68 & 0 \\
\hline $\mathrm{x}$ & 104 & 63 & $\mathrm{R}$ & 104 & 63 & 236.27 & 0 \\
\hline $\mathrm{x}$ & 104 & 96 & $\mathrm{R}$ & 104 & 96 & 188.32 & 0 \\
\hline $\mathrm{x}$ & 104 & 107 & $\mathrm{H}$ & 104 & 107 & 7.80 & 0 \\
\hline $\mathrm{x}$ & 104 & 120 & $\mathrm{R}$ & 104 & 120 & 5202.77 & 0 \\
\hline $\mathrm{x}$ & 104 & 252 & $\mathrm{H}$ & 104 & 122 & 895.51 & 0 \\
\hline $\mathrm{x}$ & 252 & 122 & $\mathrm{~W}$ & 104 & 122 & 895.51 & 0 \\
\hline $\mathrm{x}$ & 104 & 252 & $\mathrm{H}$ & 104 & 213 & 5.33 & 0 \\
\hline $\mathrm{x}$ & 122 & 145 & $\mathrm{R}$ & 104 & 213 & 5.33 & 0 \\
\hline $\mathrm{x}$ & 145 & 159 & $\mathrm{H}$ & 104 & 213 & 5.33 & 0 \\
\hline $\mathrm{x}$ & 159 & 170 & $\mathrm{R}$ & 104 & 213 & 5.33 & 0 \\
\hline $\mathrm{x}$ & 170 & 192 & $\mathrm{~W}$ & 104 & 213 & 5.33 & 0 \\
\hline $\mathrm{x}$ & 192 & 209 & $\mathrm{R}$ & 104 & 213 & 5.33 & 0 \\
\hline $\mathrm{x}$ & 209 & 213 & $\mathrm{R}$ & 104 & 213 & 5.33 & 0 \\
\hline $\mathrm{x}$ & 252 & 122 & $\mathrm{~W}$ & 104 & 213 & 5.33 & 0 \\
\hline $\mathrm{x}$ & 104 & 252 & $\mathrm{H}$ & 104 & 252 & 1992.58 & 0 \\
\hline $\mathrm{x}$ & 86 & 60 & $\mathrm{R}$ & 120 & 60 & 166.26 & 0 \\
\hline $\mathrm{x}$ & 97 & 86 & $\mathrm{R}$ & 120 & 60 & 166.26 & 0 \\
\hline $\mathrm{x}$ & 120 & 97 & $\mathrm{R}$ & 120 & 60 & 166.26 & 0 \\
\hline $\mathrm{x}$ & 104 & 63 & $\mathrm{R}$ & 120 & 63 & 3184.57 & 0 \\
\hline $\mathrm{x}$ & 120 & 104 & $\mathrm{R}$ & 120 & 63 & 3184.57 & 0 \\
\hline $\mathrm{x}$ & 120 & 121 & $\mathrm{R}$ & 120 & 96 & 9041.90 & 0 \\
\hline $\mathrm{x}$ & 121 & 96 & $\mathrm{~W}$ & 120 & 96 & 9041.90 & 0 \\
\hline $\mathrm{x}$ & 120 & 104 & $\mathrm{R}$ & 120 & 104 & 4442.94 & 0 \\
\hline $\mathrm{x}$ & 120 & 121 & $\mathrm{R}$ & 120 & 107 & 1051.32 & 0 \\
\hline $\mathrm{x}$ & 121 & 107 & $\mathrm{R}$ & 120 & 107 & 1051.32 & 0 \\
\hline $\mathrm{x}$ & 120 & 121 & $\mathrm{R}$ & 120 & 122 & 2589.98 & $\overline{0}$ \\
\hline
\end{tabular}




\begin{tabular}{|c|c|c|c|c|c|c|c|}
\hline $\mathrm{x}$ & 121 & 252 & W & 120 & 122 & 2589.98 & 0 \\
\hline $\mathrm{x}$ & 252 & 122 & $\mathrm{~W}$ & 120 & 122 & 2589.98 & 0 \\
\hline $\mathrm{x}$ & 120 & 121 & $\mathrm{R}$ & 120 & 161 & 817.38 & 0 \\
\hline $\mathrm{x}$ & 121 & 252 & $\mathrm{~W}$ & 120 & 161 & 817.38 & 0 \\
\hline $\mathrm{x}$ & 122 & 139 & $\mathrm{R}$ & 120 & 161 & 817.38 & 0 \\
\hline $\mathrm{x}$ & 139 & 161 & $\mathrm{R}$ & 120 & 161 & 817.38 & 0 \\
\hline $\mathrm{x}$ & 252 & 122 & $\mathrm{~W}$ & 120 & 161 & 817.38 & 0 \\
\hline $\mathrm{x}$ & 120 & 121 & $\mathrm{R}$ & 120 & 183 & 121.56 & 0 \\
\hline $\mathrm{x}$ & 121 & 252 & $\mathrm{~W}$ & 120 & 183 & 121.56 & 0 \\
\hline $\mathrm{x}$ & 122 & 139 & $\mathrm{R}$ & 120 & 183 & 121.56 & 0 \\
\hline $\mathrm{x}$ & 139 & 175 & $\mathrm{R}$ & 120 & 183 & 121.56 & 0 \\
\hline $\mathrm{x}$ & 175 & 183 & $\mathrm{R}$ & 120 & 183 & 121.56 & 0 \\
\hline $\mathrm{x}$ & 252 & 122 & $\mathrm{~W}$ & 120 & 183 & 121.56 & 0 \\
\hline $\mathrm{x}$ & 120 & 121 & $\mathrm{R}$ & 120 & 247 & 15.96 & 0 \\
\hline $\mathrm{x}$ & 121 & 252 & $\mathrm{~W}$ & 120 & 247 & 15.96 & 0 \\
\hline $\mathrm{x}$ & 122 & 127 & $\mathrm{R}$ & 120 & 247 & 15.96 & 0 \\
\hline $\mathrm{x}$ & 127 & 247 & $\mathrm{R}$ & 120 & 247 & 15.96 & 0 \\
\hline $\mathrm{x}$ & 252 & 122 & $\mathrm{~W}$ & 120 & 247 & 15.96 & 0 \\
\hline $\mathrm{x}$ & 120 & 121 & $\mathrm{R}$ & 120 & 252 & 2840.34 & 0 \\
\hline $\mathrm{x}$ & 121 & 252 & $\mathrm{~W}$ & 120 & 252 & 2840.34 & 0 \\
\hline $\mathrm{x}$ & 44 & 29 & $\mathrm{R}$ & 122 & 29 & 70.99 & 0 \\
\hline $\mathrm{x}$ & 60 & 44 & $\mathrm{R}$ & 122 & 29 & 70.99 & 0 \\
\hline $\mathrm{x}$ & 86 & 60 & $\mathrm{R}$ & 122 & 29 & 70.99 & 0 \\
\hline $\mathrm{x}$ & 107 & 86 & $\mathrm{R}$ & 122 & 29 & 70.99 & 0 \\
\hline $\mathrm{x}$ & 122 & 252 & $\mathrm{R}$ & 122 & 29 & 70.99 & 0 \\
\hline $\mathrm{x}$ & 252 & 107 & $\mathrm{H}$ & 122 & 29 & 70.99 & 0 \\
\hline $\mathrm{x}$ & 86 & 60 & $\mathrm{R}$ & 122 & 60 & 443.91 & 0 \\
\hline $\mathrm{x}$ & 107 & 86 & $\mathrm{R}$ & 122 & 60 & 443.91 & 0 \\
\hline $\mathrm{x}$ & 122 & 252 & $\mathrm{R}$ & 122 & 60 & 443.91 & 0 \\
\hline $\mathrm{x}$ & 252 & 107 & $\mathrm{H}$ & 122 & 60 & 443.91 & 0 \\
\hline $\mathrm{x}$ & 122 & 127 & $\mathrm{R}$ & 122 & 95 & 82.79 & 0 \\
\hline $\mathrm{x}$ & 127 & 247 & $\mathrm{R}$ & 122 & 95 & 82.79 & 0 \\
\hline $\mathrm{x}$ & 247 & 95 & $\mathrm{R}$ & 122 & 95 & 82.79 & 0 \\
\hline $\mathrm{x}$ & 122 & 252 & $\mathrm{R}$ & 122 & 104 & 2769.04 & 0 \\
\hline $\mathrm{x}$ & 252 & 104 & $\mathrm{H}$ & 122 & 104 & 2769.04 & 0 \\
\hline $\mathrm{x}$ & 116 & 113 & $\mathrm{H}$ & 122 & 113 & 4.62 & 0 \\
\hline $\mathrm{x}$ & 122 & 127 & $\mathrm{R}$ & 122 & 113 & 4.62 & 0 \\
\hline $\mathrm{x}$ & 127 & 116 & $\mathrm{R}$ & 122 & 113 & 4.62 & 0 \\
\hline $\mathrm{x}$ & 121 & 120 & $\mathrm{R}$ & 122 & 120 & 721.87 & 0 \\
\hline $\mathrm{x}$ & 122 & 252 & $\mathrm{R}$ & 122 & 120 & 721.87 & 0 \\
\hline $\mathrm{x}$ & 252 & 121 & $\mathrm{~W}$ & 122 & 120 & 721.87 & 0 \\
\hline $\mathrm{x}$ & 122 & 139 & $\mathrm{R}$ & 122 & 161 & 1977.10 & 0 \\
\hline $\mathrm{x}$ & 139 & 161 & $\mathrm{R}$ & 122 & 161 & 1977.10 & 0 \\
\hline $\mathrm{x}$ & 122 & 145 & $\mathrm{R}$ & 122 & 170 & 1.11 & 0 \\
\hline $\mathrm{x}$ & 145 & 159 & $\mathrm{H}$ & 122 & 170 & 1.11 & 0 \\
\hline
\end{tabular}




\begin{tabular}{|c|c|c|c|c|c|c|c|}
\hline $\mathrm{x}$ & 159 & 170 & $\mathrm{R}$ & 122 & 170 & 1.11 & 0 \\
\hline $\mathrm{x}$ & 122 & 139 & $\mathrm{R}$ & 122 & 183 & 5704.96 & 0 \\
\hline $\mathrm{x}$ & 139 & 175 & $\mathrm{R}$ & 122 & 183 & 5704.96 & 0 \\
\hline $\mathrm{x}$ & 175 & 183 & $\mathrm{R}$ & 122 & 183 & 5704.96 & 0 \\
\hline $\mathrm{x}$ & 122 & 145 & $\mathrm{R}$ & 122 & 213 & 168.46 & 0 \\
\hline $\mathrm{x}$ & 145 & 159 & $\mathrm{H}$ & 122 & 213 & 168.46 & 0 \\
\hline $\mathrm{x}$ & 159 & 170 & $\mathrm{R}$ & 122 & 213 & 168.46 & 0 \\
\hline $\mathrm{x}$ & 170 & 192 & $\mathrm{~W}$ & 122 & 213 & 168.46 & 0 \\
\hline $\mathrm{x}$ & 192 & 209 & $\mathrm{R}$ & 122 & 213 & 168.46 & 0 \\
\hline $\mathrm{x}$ & 209 & 213 & $\mathrm{R}$ & 122 & 213 & 168.46 & 0 \\
\hline $\mathrm{x}$ & 122 & 252 & $\mathrm{R}$ & 122 & 252 & 3075.13 & 0 \\
\hline $\mathrm{x}$ & 161 & 175 & $\mathrm{R}$ & 161 & 122 & 25.88 & 0 \\
\hline $\mathrm{x}$ & 175 & 122 & $\mathrm{~W}$ & 161 & 122 & 25.88 & 0 \\
\hline $\mathrm{x}$ & 86 & 60 & $\mathrm{R}$ & 183 & 60 & 558.29 & 0 \\
\hline $\mathrm{x}$ & 107 & 86 & $\mathrm{R}$ & 183 & 60 & 558.29 & 0 \\
\hline $\mathrm{x}$ & 122 & 252 & $\mathrm{R}$ & 183 & 60 & 558.29 & 0 \\
\hline $\mathrm{x}$ & 175 & 122 & $\mathrm{~W}$ & 183 & 60 & 558.29 & 0 \\
\hline $\mathrm{x}$ & 183 & 175 & $\mathrm{R}$ & 183 & 60 & 558.29 & 0 \\
\hline $\mathrm{x}$ & 252 & 107 & $\mathrm{H}$ & 183 & 60 & 558.29 & 0 \\
\hline $\mathrm{x}$ & 170 & 192 & $\mathrm{~W}$ & 183 & 163 & 5.99 & 0 \\
\hline $\mathrm{x}$ & 174 & 170 & $\mathrm{R}$ & 183 & 163 & 5.99 & 0 \\
\hline $\mathrm{x}$ & 182 & 163 & $\mathrm{R}$ & 183 & 163 & 5.99 & 0 \\
\hline $\mathrm{x}$ & 183 & 174 & $\mathrm{R}$ & 183 & 163 & 5.99 & 0 \\
\hline $\mathrm{x}$ & 192 & 195 & $\mathrm{R}$ & 183 & 163 & 5.99 & 0 \\
\hline $\mathrm{x}$ & 195 & 182 & $\mathrm{~W}$ & 183 & 163 & 5.99 & 0 \\
\hline $\mathrm{x}$ & 170 & 192 & $\mathrm{~W}$ & 183 & 205 & 476.74 & 0 \\
\hline $\mathrm{x}$ & 174 & 170 & $\mathrm{R}$ & 183 & 205 & 476.74 & 0 \\
\hline $\mathrm{x}$ & 183 & 174 & $\mathrm{R}$ & 183 & 205 & 476.74 & 0 \\
\hline $\mathrm{x}$ & 192 & 209 & $\mathrm{R}$ & 183 & 205 & 476.74 & 0 \\
\hline $\mathrm{x}$ & 209 & 205 & $\mathrm{R}$ & 183 & 205 & 476.74 & 0 \\
\hline $\mathrm{x}$ & 174 & 213 & $\mathrm{~W}$ & 183 & 213 & 6.83 & 0 \\
\hline $\mathrm{x}$ & 183 & 174 & $\mathrm{R}$ & 183 & 213 & 6.83 & 0 \\
\hline $\mathrm{x}$ & 170 & 174 & $\mathrm{R}$ & 192 & 183 & 7.58 & 0 \\
\hline $\mathrm{x}$ & 174 & 183 & $\mathrm{R}$ & 192 & 183 & 7.58 & 0 \\
\hline $\mathrm{x}$ & 192 & 170 & $\mathrm{~W}$ & 192 & 183 & 7.58 & 0 \\
\hline $\mathrm{x}$ & 213 & 215 & $\mathrm{R}$ & 213 & 215 & 52.78 & 0 \\
\hline $\mathrm{x}$ & 115 & 18 & $\mathrm{~W}$ & 247 & 18 & 3.53 & 0 \\
\hline $\mathrm{x}$ & 247 & 115 & $\mathrm{R}$ & 247 & 18 & 3.53 & 0 \\
\hline $\mathrm{x}$ & 44 & 29 & $\mathrm{R}$ & 247 & 29 & 28.22 & 0 \\
\hline $\mathrm{x}$ & 61 & 44 & $\mathrm{R}$ & 247 & 29 & 28.22 & 0 \\
\hline $\mathrm{x}$ & 95 & 61 & $\mathrm{R}$ & 247 & 29 & 28.22 & 0 \\
\hline $\mathrm{x}$ & 247 & 95 & $\mathrm{R}$ & 247 & 29 & 28.22 & 0 \\
\hline $\mathrm{x}$ & 36 & 40 & $\mathrm{R}$ & 247 & 40 & 3.61 & 0 \\
\hline $\mathrm{x}$ & 115 & 36 & $\mathrm{~W}$ & 247 & 40 & 3.61 & 0 \\
\hline $\mathrm{x}$ & 247 & 115 & $\mathrm{R}$ & 247 & 40 & 3.61 & 0 \\
\hline
\end{tabular}




\begin{tabular}{|c|c|c|c|c|c|c|c|}
$\mathrm{x}$ & 95 & 60 & $\mathrm{R}$ & 247 & 60 & 134.32 & 0 \\
\hline $\mathrm{x}$ & 247 & 95 & $\mathrm{R}$ & 247 & 60 & 134.32 & 0 \\
\hline $\mathrm{x}$ & 247 & 95 & $\mathrm{R}$ & 247 & 95 & 1037.57 & 0 \\
\hline $\mathrm{x}$ & 116 & 113 & $\mathrm{H}$ & 247 & 113 & 73.74 & 0 \\
\hline $\mathrm{x}$ & 247 & 116 & $\mathrm{R}$ & 247 & 113 & 73.74 & 0 \\
\hline $\mathrm{x}$ & 252 & 104 & $\mathrm{H}$ & 252 & 104 & 1.91 & 0 \\
\hline
\end{tabular}


Appendix II Carbon Emission Calculation

1. Road

$E_{H}=\left(E^{\text {hot }} \varepsilon+E^{\text {start }}+E^{\text {evaporative }}\right) N D$

Where

$E_{H}$ : Total emission in highway $(\mathrm{g})$

$\varepsilon$ : load correction factor function

$E^{\text {hot }}$ : The emission produced when the engine is hot $(\mathrm{g} / \mathrm{km})$

$E^{\text {start }}$ : The emission when the engine is cold $(\mathrm{g} / \mathrm{km})$

$E^{\text {evaporative }}$ : The emission by evaporation (only for VOC) $(\mathrm{g} / \mathrm{km})$

$N$ : The number of vehicles

$D$ : The average distance $(\mathrm{km})$

(1) $E^{\text {hot }}$

For gasoline light duty vehicles $<3.5 \mathrm{t}$,

$E^{\text {hot }}=0.0621 V^{2}-9.8381 V+601.2$

Where

$\mathrm{V}$ : The average speed travelled by the each vehicle $(\mathrm{km} / \mathrm{h})$

For diesel light duty vehicles $<3.5 \mathrm{t}$,

$E^{\text {hot }}=0.0617 V^{2}-7.8227 V+429.51$

For heavy goods vehicles with gross vehicle weights from 3.5 to 7.5 tonnes,

$E^{\text {hot }}=110+0.000375 V^{3}+\frac{8702}{V}$

For heavy goods vehicles with gross vehicle weights from 7.5 to 16 tonnes,

$E^{h o t}=871-16 V+0.143 V^{2}+\frac{32031}{V^{2}}$

For heavy goods vehicles with gross vehicle weights from 16 to 32 tonnes,

$E^{h o t}=765-7.04 V^{2}+0.000632 V^{3}+\frac{8334}{V}$

For heavy goods vehicles with gross vehicle weights from 32 to 40 tonnes, 
$E^{h o t}=1576-17.6 \mathrm{~V}+0.00117 V^{3}+\frac{36067}{V^{2}}$

For heavy goods vehicles with gross vehicle weights from 40 to 50 tonnes, $E^{\text {hot }}=1.17\left(1576-17.6 \mathrm{~V}+0.00117 V^{3}+\frac{36067}{V^{2}}\right)$

For heavy goods vehicles with gross vehicle weights from 50 to 60 tonnes, $E^{\text {hot }}=1.35\left(1576-17.6 \mathrm{~V}+0.00117 V^{3}+\frac{36067}{V^{2}}\right)$

(2) $\varepsilon$

For heavy goods vehicles with gross vehicle weights from 3.5 to 7.5 tonnes, $\varepsilon=1.27+0.0614 \gamma-0.0011 \gamma^{3}-0.00235 \mathrm{~V}-\frac{1.33}{\mathrm{~V}}$

Where $\gamma$ is road gradient, since we assume road gradient is 0 , we get,

$\varepsilon=1.27-0.00235 \mathrm{~V}-\frac{1.33}{\mathrm{~V}}$

For heavy goods vehicles with gross vehicle weights from 7.5 to 16 tonnes, $\varepsilon=1.26-2.03 * 10^{-7} V^{3}-\frac{1.14}{\mathrm{~V}}$

For heavy goods vehicles with gross vehicle weights from 16 to 32 tonnes, $\varepsilon=1.27-\frac{0.483}{\mathrm{~V}}$ For heavy goods vehicles with gross vehicle weights from 32 to 40 tonnes, $\varepsilon=1.43-\frac{0.916}{\mathrm{~V}}$

(3) $E^{\text {start }}$

$E^{\text {start }}=\omega \times(f(V)+g(T)-1) \times h(d)$

Where

$V:$ The average speed during the cold period $(\mathrm{km} / \mathrm{h})$;

$\omega$ : The reference excess emission (at $20{ }^{\circ} \mathrm{C}$ and $20 \mathrm{~km} / \mathrm{h}$ )

$T$ : The temperature $\left({ }^{\circ} \mathrm{C}\right)$ 
$d$ : The distance travelled $(\mathrm{km})$

$h(d)=\frac{1-e^{-\alpha \delta}}{1-e^{-\alpha}} ; \delta=\frac{d}{d_{c}}$

Where

$\delta:$ The ratio of the trip distance to the cold distance,

$\alpha$ : Constant

For gasoline,

$\omega=144.16$;

$f(V)=-0.0101 V+1.2024$

$g(T)=1$

$d_{c}=0.15 \mathrm{~V}+2.68$

$\alpha=2.85$

For diesel,

$\omega=182.57$

$f(V)=1$

$g(T)=-0.0458 T+1.9163$

$d_{c}=0.24 \mathrm{~V}+0.09$

$\alpha=3.95$

2. Rail

$$
E_{R}=0.0036 W S E C \times \frac{T k m}{T p t} \times B S E F \times D
$$

Where

$E_{R}$ : Total emission in railway $(\mathrm{g})$

WSEC: Weight specific energy consumption of train $i(\mathrm{kj} / \mathrm{ton}-\mathrm{km})$

$T \mathrm{~km}$ : The amount of freight transported train $i$

Tpt: The load factor of the train, (tonne-freight/total train tonne)

$B S E F$ : Brake specific emission factor of energy produced $(\mathrm{g} / \mathrm{kWh})$ 
(1) WSEC

For large freight train (600 ton empty mass),

$W S E C=0.019 \frac{V^{2}}{\ln (x)}+63$

Where

$x$ : Distance between two stops.

$V$ : Average speed for train $i$

For ICE train,

$W S E C=0.007 \frac{V^{2}}{\ln (x)}+74$

For TGV train,

$W S E C=0.0097 \frac{V^{2}}{\ln (x)}+70$

(2) $T p t$

$T p t=\frac{1}{1+\frac{W R}{(1-W R) x}}$

Where

WR: the ratio of tare weight with total weight, $\mathrm{WR}=0.27$

$x$ : The fraction of loading

3. Waterway

$$
E_{W}=S F \frac{D}{24 V}
$$

Where

$E_{W}$ : Total emission in waterway $(\mathrm{g})$

$S$ : Daily consumption of ship

$F:$ Average emission factor

$D$ : The average distance travelled by ship $(\mathrm{km})$

$t$ : The number of days in navigation 
$t=\frac{D}{24 V}$

(1) $S$

For solid bulk,

$S=0.8(9.8197+0.00143 G T)$

Where

GT: Gross tonnage of ship

For liquid bulk,

$S=0.8(14.685+.00079 * G T)$

For general cargo,

$S=0.8(9.8197+.00143 * G T)$

For container,

$S=0.8(8.0552+.00235 * G T)$

For inland cargo,

$S=0.8(9.8197+.00143 * G T)$

(2) $F$

The average emission factor is:

$F=3200 \mathrm{~kg} / \mathrm{ton}$ of fuel 


\section{CURRICULUM VITA}

NAME: $\quad$ Xiaoren Duan

ADDRESS: 805 Preakness Drive, Alpharetta, GA 30022

DOB: $\quad$ September 18, 1985

EDUCATION

\& TRAINING: $\quad$ B.S., Mechanical Engineering

Soochow University

2003-07

M.S., Mechatronics

Soochow University

2007-10

Ph.D., Industrial Engineering

University of Louisville

2012-16

AWARDS: Research and Fellowship Scholarship

University of Louisville

2012-2015

First-class People's Scholarship, The Zhu Jingwen Scholarship, The

Fairchild Semiconductor Scholarship, Excellent Student of Soochow

University, Outstanding Graduates Awards

Soochow University

2003-2007 


\section{PUBLICATIONS:}

X. Duan and S. Heragu (2015). Carbon Emission Tax Policy in an Intermodal Transportation Network. Proceedings of the 2015 Industrial and Systems Engineering Research Conference.

GONG Xiaoxin, RUI Yannian, QIAN Guofeng, DUAN Xiaoren (2010), CNC Machining Technology for the Sliding Block Parts with Special Shape in the Automobile Mold, Advanced Materials Research, Vol. 102-104, pp. 474-478.

ZHANG Jian, RUI Yannian, CHEN Jie, DUAN Xiaoren (2010), Research on the Fault Diagnosis of Trenchless Drilling Pneumatic Impact Device Based on Grey Relational Theory, Advanced Materials Research, Vol. 97-101, pp. 2672-2677.

DUAN Xiaoren, RUI Yannian, ZHU Xingman (2010), Synthetically evaluation of RMS based on extension theory, Machinery Design \& Manufacture, No. 01, pp. 125127.

DUAN Xiaoren, RUI Yannian, ZHU Xingman (2009), Reliability optimal design of mixing shaft in big power aeration machine based on artificial neural network, Microcomputer \& ITS Applications, Vol. 28, No. 07, pp. 70-72.

ZHU Xingman, RUI Yannian, DUAN Xiaoren (2009), Research on auto body design Schemes on the basis of extension and fuzzy theory, Machinery Design \& Manufacture, No. 11, pp. 224-226.

\section{NATIONAL MEETING PRESENTATIONS:}

Xiaoren Duan, Network Design for Intermodal Transportation with Inland Waterways, IIE Conference, Nashville, May 2015

Xiaoren Duan, Optimizing Vehicle Travel Speed in Green Vehicle Routing Problems, Informs, Philadelphia, November 2015 
Xiaoren Duan, Network Design for Intermodal Transportation with Inland Waterways, Barge and Rail Symposium sponsored by Transportation Research Board, Louisville KY, Aug 2013 